\title{
Interorgan short chain fatty acids exchange in humans : implications for clinical application in colorectal surgery
}

Citation for published version (APA):

Bloemen, J. G. (2012). Interorgan short chain fatty acids exchange in humans : implications for clinical application in colorectal surgery. [Doctoral Thesis, Maastricht University]. Universitaire Pers Maastricht. https://doi.org/10.26481/dis.20121123jb

Document status and date:

Published: 01/01/2012

DOI:

10.26481/dis.20121123jb

Document Version:

Publisher's PDF, also known as Version of record

Please check the document version of this publication:

- A submitted manuscript is the version of the article upon submission and before peer-review. There can be important differences between the submitted version and the official published version of record.

People interested in the research are advised to contact the author for the final version of the publication, or visit the DOI to the publisher's website.

- The final author version and the galley proof are versions of the publication after peer review.

- The final published version features the final layout of the paper including the volume, issue and page numbers.

Link to publication

\footnotetext{
General rights rights.

- You may freely distribute the URL identifying the publication in the public portal. please follow below link for the End User Agreement:

www.umlib.nl/taverne-license

Take down policy

If you believe that this document breaches copyright please contact us at:

repository@maastrichtuniversity.nl

providing details and we will investigate your claim.
}

Copyright and moral rights for the publications made accessible in the public portal are retained by the authors and/or other copyright owners and it is a condition of accessing publications that users recognise and abide by the legal requirements associated with these

- Users may download and print one copy of any publication from the public portal for the purpose of private study or research.

- You may not further distribute the material or use it for any profit-making activity or commercial gain

If the publication is distributed under the terms of Article $25 \mathrm{fa}$ of the Dutch Copyright Act, indicated by the "Taverne" license above, 


\section{INTERORGAN SHORT CHAIN FATTY ACIDS EXCHANGE IN HUMANS}

IMPLICATIONS FOR CLINICAL APPLICATION IN COLORECTAL SURGERY 
CC Johanne Gezina Bloemen, Maastricht 2012

ISBN: 9789461591791

Schilderij cover: Johanne Bloemen

Cover: Kim Rauwerdink

Lay out: Tiny Wouters

Production: Datawyse / Universitaire Pers Maastricht

Financial support for the publication of this thesis was kindly provided by TI Food and Nutrition and Nederlandse Vereniging voor Gastro-enterologie (NVGE). The studies presented in this thesis were performed at the Nutrition and Toxicology Research Institute Maastricht (NUTRIM). 


\title{
INTERORGAN SHORT CHAIN FATTY ACIDS EXCHANGE IN HUMANS
}

\author{
IMPLICATIONS FOR CLINICAL APPLICATION \\ IN COLORECTAL SURGERY
}

\author{
Proefschrift \\ ter verkrijging van de graad van doctor \\ aan de Universiteit Maastricht, \\ op gezag van de Rector Magnificus, Prof. dr. L.L.G. Soete, \\ volgens het besluit van het College van Decanen, \\ in het openbaar te verdedigen \\ op vrijdag 23 november 2012 om 10.00 uur \\ door \\ Johanne Gezina Bloemen
}

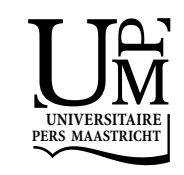


Promotor

Prof. dr. C.H.C. Dejong

Prof. dr. W.A. Buurman

Co-promotor

Dr. K. Venema (TNO Healthy Living, Zeist)

Beoordelingscommissie

Prof. dr. P.B. Soeters (voorzitter)

Prof. dr. W.A. Bemelman (Academisch Medisch Centrum, Amsterdam)

Prof. dr. M. Kleerebezem (WUR Wageningen)

Prof. dr. A.A.M. Masclee

Prof. dr. A.M.W.J. Schols 


\section{Contents}

$\begin{array}{lll}\text { Part I } & \text { Background \& methods } & 7\end{array}$

Chapter 1 General introduction 9

Chapter 2 Application of liquid chromatography mass spectrometry to 23 measure short chain fatty acids in blood

Part II Physiology \& pathophysiology of SCFA interorgan exchange 35

Chapter 3 Short chain fatty acids exchange across the gut and the liver in humans measured at surgery

Chapter 4 Short chain fatty acids exchange: is the cirrhotic, dysfunctional liver still able to clear them?

Chapter 5 Effects of liver resection on hepatic short chain fatty acid handling in humans

Chapter 6 Effects of a butyrate enema on systemic concentrations of short chain fatty acids

Part III Clinical application of short chain fatty acids

Chapter 7 Quality of life on the long-term in rectal cancer patients; association with severe postoperative complications and presence of a stoma

Chapter 8 Butyrate enemas to improve intestinal anastomotic strength in a rat model

Chapter 9 Discussion \& perspectives for the future

Publication list 

Part I

Background \& methods 



\section{Chapter 1}

Introduction 
Chapter 1 


\section{Introduction}

The human large intestine harbors more than 1000 bacterial species and consists of more than $10^{14}$ bacteria, which is 10 times more than the number of cells our body is built of. ${ }^{1}$ In the past, no significant role was assigned to the human microbiota, but the last decades more and more research has focused on the role of microbiota in human health. Colonic microbiota play a crucial role in maintenance of the intestinal barrier and enterohepatic cycle, colonization resistance, metabolism of indigestible carbohydrates and synthesis of vitamins. ${ }^{1,2}$ Furthermore, recent findings support the concept that intestinal bacteria together with the genetic constitution might contribute to obesity in humans. ${ }^{3}$ In mice, obesity is associated with substantial changes in microbiota composition and metabolic function, which results in a more efficient energy extraction in obese mice. ${ }^{4}$ Currently, there is growing interest in functional foods that affect the composition of gut microbiota; the so called probiotics, prebiotics and synbiotics. Probiotics are live bacterial strains that once ingested promote a healthy composition of the host microbiota. ${ }^{5}$ Prebiotics are indigestible carbohydrates that pass the upper gastro-intestinal tract relatively unaffected. They are a selective substrate for one or a limited number of potentially beneficial commensal bacteria (particularly bifidobacteria and lactobacilli) and able to alter the microbiota towards a potentially more healthy composition. ${ }^{6}$ Synbiotics are products combining pre- and probiotics. In this thesis the focus will be on prebiotics.

\section{Short chain fatty acids}

Prebiotics are thought to be beneficial for the gut through generation of short chain fatty acids (SCFA). SCFA are organic acids that are produced during colonic fermentation of indigestible carbohydrates (e.g. prebiotics). The main products of the colonic fermentation process, besides SCFA, are hydrogen gas, methane gas, additional biomass and heat. The most important short chain fatty acids, quantitatively as well as qualitatively, are acetate (C2), propionate (C3) and butyrate (C4). Besides these, also formate, valerate, caproate, 2-methyl-butyrate and isovalerate are produced, but in considerably smaller quantities. Furthermore, metabolic intermediates are formed during the fermentation reaction, such as ethanol, lactate and succinate, but these are metabolized almost directly to SCFA by other bacteria (cross-feeding). ${ }^{7}$

The total amount of SCFA released in the gut ranges from 60 to $800 \mathrm{mmol} / \mathrm{kg}$ colonic content (chyme) per day and is highly dependent on the diet, the composition of the gut microbiota and colonic transit time. ${ }^{8-10}$ For example, when colonic transit time exceeds 50 hours, almost no butyrate can be detected in the colonic content, probably because of uptake by colonic epithelial cells. ${ }^{11}$ Molar ratios range from 75:15:10, $60: 25: 15$ to 54:20:21 for acetate:propionate:butyrate, respectively, in different study populations. ${ }^{12,13}$ The production of SCFA decreases from the proximal 
colon to the distal colon, because indigestible carbohydrates are the preferred substrate for fermentation and most of them are fermented in the proximal colon. Once produced, SCFA are rapidly taken up across the apical membrane of the epithelial cells, because the SCFA are lipid and watersoluble. ${ }^{14}$ Different mechanisms for this absorption have been proposed, including diffusion across the membrane, SCFA $/ \mathrm{HCO}_{3}{ }^{-}$exchange and active transport by SCFA transporters (probably monocarboxylate transporter-1). ${ }^{15-20}$

Once absorbed by the colonic epithelium, there are three major sites where SCFA are metabolized. First, the colonic epithelium uses butyrate as the main energy source. Secondly, liver cells use propionate and butyrate in gluconeogenesis and cholesterol synthesis and last, muscle cells are able to generate energy from oxidation of acetate. ${ }^{11}$ Quantitatively, approximately $90 \%$ of the SCFA are transported across the epithelial cells, another $5 \%$ is excreted with the faeces and the remainder is thought to be released in the portal vein. ${ }^{21}$ It is proposed that roughly 70,50 and $10 \%$ of acetate, propionate and butyrate, respectively, reaches the liver. ${ }^{22}$ In the liver, acetate is partially retained and converted to acetoacetate, long chain fatty acids and glutamate. ${ }^{23}$ More specifically, acetate is metabolized to acetyl-coA which enters the tricarboxylic acid (TCA) cycle and subsequently generates ATP and NADH. Furthermore, in response to fasting, acetate can be used for ketogenesis and as a result ketone bodies are formed. ${ }^{24}$ Propionate has an odd number of carbon atoms (C3) and therefore the terminal oxidation product is propionyl-CoA, which is converted to succinyl-CoA and which eventually generates glucose. Butyrate is entering the TCA cycle, similarly to acetate.

\section{SCFA and gut health}

Research currently focuses mainly on local, intestinal effects of SCFA. Various studies report on effects of SCFA and prebiotics on intestinal integrity and gut health as reviewed by Hamer et al. and Preidis et al. ${ }^{25,26}$ Especially butyrate has drawn much attention, because it is the most important energy source for colonic epithelial cells, while it also influences different cellular processes affecting colonic function. ${ }^{18,27}$ Examples of these processes are inhibition of inflammatory responses through NFkB inhibition, migration of epithelial cells after wounding in vitro and inhibition of lymphocyte proliferation. ${ }^{13,28-34}$ There is also a growing body of evidence that SCFA improve intestinal wound healing, enhance epithelial proliferation and differentiation and improve absorptive function. ${ }^{18,21,35}$ Rectal and oral SCFA supplementation has been investigated in experimental models as well as in the clinical setting including ulcerative colitis, diversion colitis, radiation induced proctitis and short bowel syndrome. ${ }^{27,36-39}$ Welters et al. found that enteral prebiotic (i.g. inulin) administration leads to a reduction of inflammation of the colonic mucosa, a decrease in $\mathrm{pH}$ of faeces and a diminished concentration of secondary bile acids in patients with an ileo-anal pouch. ${ }^{36}$ In proctitis, a complication after radiation therapy, daily butyrate enemas 
lead to a significant decrease of clinical symptoms. ${ }^{39}$ Furthermore, there have been attempts to study the beneficial effects of SCFA in colonic anastomotic leakage in a rat model. $^{40-42}$

\section{Intestinal anastomotic leakage}

Intestinal anastomotic leakage is an important problem in daily surgical practice. Rates of this serious and feared complication range from $5 \%$ to as high as $15 \%$ in colorectal surgery, depending on the definition of anastomotic leakage. ${ }^{43,44}$ It leads to high morbidity and mortality postoperatively and even contributes to impaired oncological outcome. ${ }^{45,46}$ Many risk factors for the development of anastomotic leakage have been indentified in mostly retrospective studies, but the conclusions are not equivocal. ${ }^{43,47-49}$ Experimental studies aimed to clarify the underlying mechanism of anastomotic healing and dehiscence. These experimental studies have mainly focussed on the administration of growth factors and the prevention of ischemia and hypoperfusion of the anastomotic site during and after the operation. ${ }^{50-54}$ Supplementation of specific nutritional components constitutes a different approach to improve anastomotic strength. Anastomotic healing is comparable to healing of the skin, which is a well studied subject. ${ }^{55}$ Wound healing can be roughly divided in three stages; inflammation, proliferation and maturation. The inflammatory phase starts directly after injury. This phase is characterized by increased vascular permeability, recruitment of proinflammatory cells from the circulation, local release of cytokines and growth factors and activation of cell migration. Granulocytes are the predominant infiltrating cells in the first 24 hours. Thereafter fibroblasts and smooth muscle cells are recruited and produce matrix proteins, such as collagen type I, III and V, proteoglycans and glycoproteins. ${ }^{31}$ This phase of proliferation of cellular elements is called the proliferation phase and is the second step in wound healing. In the final stage, the remodelling phase, young collagen fibers become interconnected by means of crosslinking, which gives strength to the anastomosis. ${ }^{56,57}$

In the first 24-48 hours degradation of the extracellular matrix enables removal of damaged tissue and necrosis and allows vessel ingrowth. This degradation results in a decline in anastomotic strength in the early postoperative days because of loss of mature collagen fibers. Factors responsible for the degradation of the extracellular matrix are amongst others matrix metalloproteinases (MMPs). These are endopeptidases that have in common the presence of zinc in their active site. MMPs are synthesized in an enzymatically inactive form (pro-MMP) by subepithelial myofibroblasts in response to pro-inflammatory cytokines. To allow MMPs to become biologically active several steps and mechanisms are required. ${ }^{58-60}$ These MMPs are involved in normal healing, but some studies report on their role in anastomotic dehiscence and mucosal destruction in inflammatory bowel disease. ${ }^{61-63}$ Furthermore, experimental studies using MMP inhibitors resulted in positive effects on bursting strength of colonic anastomoses. ${ }^{64}$ Recently, Kawamura et al. reported inhibition of 
cytokine induced MMP secretion in human colonic subepithelial myofibroblasts in vitro after stimulation with SCFA. ${ }^{65}$ Kerem et al. reported increased bursting strength and lower MMP-2 levels after oral fiber supplementation and transrectal butyrate administration. ${ }^{41}$ Although the exact mechanism of action is not clear, this is an interesting finding in the context of the potential beneficial effects of butyrate in colonic anastomosis healing. This may provide opportunities to influence gut health in humans by administration of SCFA into the lumen of the gut, e.g. by SCFA enemas. However, not much is known whether this can be safely done because little is known about basic physiology of gut handling of SCFA in vivo in humans.

\section{Interorgan exchange}

Although the intestinal effects of prebiotic and SCFA administration have been investigated extensively, the knowledge on the role of the gut, liver and splanchnic area and their interorgan interaction is minimal, particular in humans. This is important information, because high systemic concentrations of butyrate and propionate are considered toxic. ${ }^{66,67}$ If, for example, the liver would not be able to clear excess butyrate and propionate that is generated by fermentation, it might be harmful to the patient to supplement diets with prebiotics. This may constitute an even greater risk in patients with impaired liver function.

Intestinal production and rate of absorption of SCFA have been investigated in animal models, such as the rat, pig and ruminants. These experimental studies in animals add valuable information to the physiology of SCFA metabolism, but there are some important differences in digestion aspects between animals and humans. For example, rats are coprophagous, and ruminants are predominantly forestomach fermenters. ${ }^{22}$ These varieties of the digestion system result in large differences in the quantity of fermentation products produced and their subsequent metabolism by epithelial cells, liver and splanchnic area.

The role of the liver has also been studied in experimental animal models. In sheep, it is clear that $80-100 \%$ of both propionate and butyrate are metabolized by the liver, whereas only small amounts of acetate are metabolized by the liver. ${ }^{68}$ Most of the acetate produced by the gut escapes the splanchnic bed and reaches the peripheral circulation. Acetate is a preferred energy substrate for almost all types of cells and its oxidation contributes substantially to whole body energy expenditure in animals and in humans. ${ }^{48,69,70}$ Furthermore, acetate is produced and utilized by different parts of the body. Especially the liver has the capability of producing acetate. Consequently, there is an endogenous acetate pool (i.e. acetate produced by the liver) and an exogenous acetate pool (i.e. gut supply of acetate). ${ }^{71,72}$ However, the majority of acetate is formed by fermentation of dietary fibers and the arterial concentration is the major factor determining acetate use by peripheral tissue. ${ }^{73-75}$

The available knowledge on SCFA interorgan exchange in humans is limited to data gathered from sudden death individuals, healthy individuals and patients undergoing 
gallbladder surgery. Two decades ago, Cummings et al. demonstrated that portal venous SCFA concentrations exceeded arterial concentrations and hepatic venous concentrations were slightly higher than arterial concentrations. ${ }^{76}$ Furthermore, Dankert et al. measured portal venous SCFA concentrations in patients undergoing gall bladder surgery and concluded that the liver metabolizes SCFA, because the portal venous concentrations exceeded the venous concentrations in an arm vein. ${ }^{77}$ Furthermore, in the early eighties several studies have been done on acetate kinetics, also in humans, because acetate was considered to contribute for a substantial part to whole body energy expenditure. ${ }^{69,78-80}$ These studies gave valuable information and insight in venous and arterial concentrations of SCFA, but this is only indirect information about interorgan exchange and it is not possible to extrapolate data of sudden death individuals directly to healthy individuals because of the lack of blood flow. In short, knowledge on the role of the gut and liver in particular as well as quantification of net exchange across these organs is missing.

\section{Methods}

To study interorgan metabolism of SCFA in vivo, a model was developed in Maastricht to sample blood across splanchnic organs in humans during upper abdominal surgery. Patients were operated for liver or pancreatic pathology and this specific patient population was chosen because of the accessibility of the portal and hepatic vein during the surgical procedure (Figure 1.1). Blood sampling from these veins and the radial artery is required to calculate fluxes across the gut, liver and splanchnic area. Fluxes are a quantitative measure of substance exchange (i.e. release or uptake) across an organ. In this thesis acetate, propionate and butyrate exchange across the gut, the liver and the splanchnic area were calculated specifically. Fluxes can be calculated when arterial and venous concentrations and plasma flow are known.

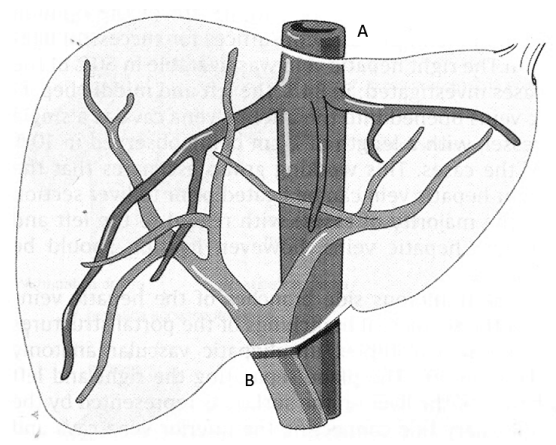

Figure 1.1 Schematic representation of hepatic venous (A) and portal venous (B) architecture. Adapted from: Liver surgery operative techniques and avoidance of complications. Auteurs: F. Kockerling, S.I. Schwart, 2001. 
Mathematically, the flux is the arteriovenous concentration difference times plasma flow [ $\Delta \mathrm{VA} *$ plasma flow]. Plasma flows were measured in the portal vein and hepatic artery as described before by our group. ${ }^{81}$ In short, organ blood flow was measured by means of colour Doppler ultrasound. Time-averaged mean velocities of the blood stream and cross-sectional area of the portal vein and hepatic artery were measured. Blood flow was calculated by multiplying the cross-sectional area of the vessel with the velocity of the blood stream. Plasma flow was calculated by correcting blood flow for hematocrit.

The gut flux can be calculated by calculating the difference between the arterial and portal venous concentrations and by subsequently multiplying this by portal plasma flow. The splanchnic flux, comprising the gut, liver, pancreas and spleen, can be calculated by subtracting the arterial concentration from the hepatic venous concentrations and multiplying this by liver plasma flow. Subsequently, the liver flux can be calculated as the splanchnic flux minus the gut flux. This model has been used extensively in previous studies on amino acids metabolism and ammonia metabolism and trafficking in humans. ${ }^{81-85}$

To study the effect of impaired liver function on the interorgan exchange of SCFA, patients with a transjugular intrahepatic portosystemic shunt were included. Our group described the patients and methods earlier. ${ }^{86-89}$ For the treatment of portal hypertension as a result of cirrhosis, a shunt was placed between the portal vein and one of the hepatic veins (Figure 1.2). As a consequence, part of the blood is shunted and bypasses the liver. The fluxes need to be corrected for the shunting fraction; the fraction of the blood that bypasses the liver. In this thesis we used two scenarios to express the effect of shunting, i.e. 70 and $90 \%$ shunting, based on experience of our group in earlier studies. ${ }^{87}$

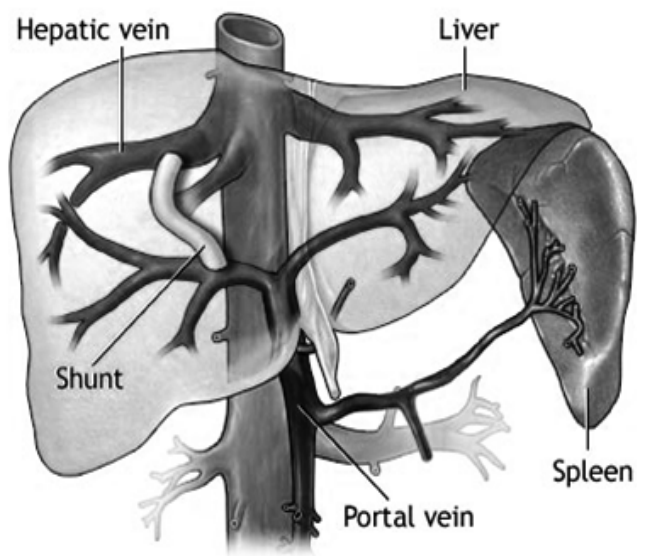

Figure 1.2 Schematic representation of a transjugular intrahepatic portosystemic shunt. Adapted from: http://cdn.nursingcrib.com. 


\section{Aim and outline of the thesis}

The main goal of the current project was to elucidate the role of the gut and liver in interorgan short chain fatty acid trafficking. A human model during upper abdominal surgery was developed to study this topic. Subsequently, a possible clinical application of butyrate was investigated in a rat model.

This thesis is divided in three parts. In part I (chapters 1 and 2) a general introduction to short chain fatty acids is given, with emphasis on the current knowledge on physiology of SCFA metabolism. In chapter 2 the method of measuring SCFA with a liquid chromatography combined with mass spectrometry system is presented.

In part II (chapters 3-6) the physiology of interorgan SCFA trafficking is studied. First, the role of the liver and the gut was studied in a model of upper abdominal surgery in otherwise healthy patients (chapter 3). To further elucidate the role of the liver, patients with chronic liver failure based on underlying liver disease were studied (chapter 4) and subsequently patients were studied before and after partial liver resection of otherwise healthy liver, mimicking a controlled loss of liver function (chapter 5). Last, the farmacokinetics of rectal butyrate supplementation with respect to liver and splanchnic interorgan trafficking were studied to try and clarify the safety of such rectal SCFA administration with respect to liver clearance. (chapter 6)

Part III (chapter 7-9) describes the impact on quality of life of an important clinical problem in surgical practice; anastomotic leakage after colorectal cancer surgery. In chapter 8 the results of an experimental study on SCFA administration to improve colonic anastomotic healing in a rat model is described. In chapter 9 the major findings of all studies are reviewed and discussed, as well as the potential implications for future research. 


\section{References}

1. O'Keefe SJ. Nutrition and colonic health: the critical role of the microbiota. Curr Opin Gastroenterol 2008;24:51-8.

2. Watzl B, Girrbach S, Roller M. Inulin, oligofructose and immunomodulation. Br J Nutr 2005;93(Suppl 1):S49-55.

3. Bajzer M, Seeley RJ. Physiology: obesity and gut flora. Nature 2006;444:1009-10.

4. Tilg H, Moschen AR, Kaser A. Obesity and the microbiota. Gastroenterology 2009;136:1476-83.

5. Goossens D, Jonkers D, Stobberingh E, van den Bogaard A, Russel M, Stockbrügger R. Probiotics in gastroenterology: indications and future perspectives. Scand J Gastroenterol Suppl 2003;(239):15-23.

6. Roberfroid MB, Van Loo JA, Gibson GR. The bifidogenic nature of chicory inulin and its hydrolysis products. J Nutr 1998;128:11-9.

7. Macfarlane S, Macfarlane GT. Regulation of short-chain fatty acid production. Proc Nutr Soc, 2003; 62:67-72.

8. Fredstrom SB, Lampe JW, Jung HJ, Slavin JL. Apparent fiber digestibility and fecal short-chain fatty acid concentrations with ingestion of two types of dietary fiber. JPEN J Parenter Enteral Nutr 1994;18:14-9.

9. Beauvieux MC, Tissier $\mathrm{P}$, Gin H, Canioni $\mathrm{P}$, Gallis JL. Butyrate impairs energy metabolism in isolated perfused liver of fed rats. J Nutr 2001;131:1986-92.

10. Fitch MD, Fleming SE. Metabolism of short-chain fatty acids by rat colonic mucosa in vivo. Am J Physiol 1999;277:G31-40.

11. Wong JM, de Souza R, Kendall CW, Emam A, Jenkins DJ. Colonic health: fermentation and short chain fatty acids. J Clin Gastroenterol 2006;40:235-43.

12. Wong CS, Sengupta S, Tjandra JJ, Gibson PR. The influence of specific luminal factors on the colonic epithelium: high-dose butyrate and physical changes suppress early carcinogenic events in rats. Dis Colon Rectum 2005;48:549-59.

13. Cook SI, Sellin JH. Review article: short chain fatty acids in health and disease. Aliment Pharmacol Ther 1998;12:499-507.

14. Sellin JH. SCFAs: The enigma of weak electrolyte transport in the colon. News Physiol Sci 1999;14: 58-64.

15. Hadjiagapiou C, Schmidt L, Dudeja PK, Layden TJ, Ramaswamy K. Mechanism(s) of butyrate transport in Caco-2 cells: role of monocarboxylate transporter 1. Am J Physiol Gastrointest Liver Physiol 2000; 279:G775-80.

16. Charney AN, Micic L, Egnor RW. Nonionic diffusion of short-chain fatty acids across rat colon. Am J Physiol 1998;274:G518-24.

17. Velazquez OC, Lederer HM, Rombeau JL. Butyrate and the colonocyte. Production, absorption, metabolism, and therapeutic implications. Adv Exp Med Biol 1997;427:123-34.

18. Wachtershauser A, Stein J. Rationale for the luminal provision of butyrate in intestinal diseases. Eur J Nutr 2000;39:164-71.

19. Kawamata K, Hayashi H, Suzuki Y. Propionate absorption associated with bicarbonate secretion in vitro in the mouse cecum. Pflugers Arch 2007;454:253-62.

20. Sellin JH, DeSoignie R. Short-chain fatty acid absorption in rabbit colon in vitro. Gastroenterology 1990;99:676-83.

21. Topping DL, Clifton PM. Short-chain fatty acids and human colonic function: roles of resistant starch and nonstarch polysaccharides. Physiol Rev 2001;81:1031-64.

22. Bergman EN. Energy contributions of volatile fatty acids from the gastrointestinal tract in various species. Physiol Rev 1990;70:567-90.

23. Knudsen CT, Quistorff B, Grunnet N. Ethanol inhibits acetate metabolism in rat hepatocytes. Pharmacol Toxicol 1995;76:133-5.

24. Crawford PA, Crowley JR, Sambandam N, Muegge BD, Costello EK, Hamady M, Knight R, Gordon JI. Regulation of myocardial ketone body metabolism by the gut microbiota during nutrient deprivation. Proc Natl Acad Sci U S A 2009;106:11276-81. 
25. Hamer HM, Jonkers D, Venema K, Vanhoutvin S, Troost FJ, Brummer RJ. Review article: the role of butyrate on colonic function. Aliment Pharmacol Ther 2008;27:104-19.

26. Preidis GA, Versalovic J. Targeting the human microbiome with antibiotics, probiotics, and prebiotics: gastroenterology enters the metagenomics era. Gastroenterology 2009;136:2015-31.

27. Tedelind S, Westberg F, Kjerrulf M, Vidal A. Anti-inflammatory properties of the short-chain fatty acids acetate and propionate: a study with relevance to inflammatory bowel disease. World J Gastroenterol 2007;13:2826-32.

28. Dzierzewicz Z, Orchel A, Weglarz L, Latocha M, Wilczok T. Changes in the cellular behaviour of human colonic cell line Caco-2 in response to butyrate treatment. Acta Biochim Pol 2002;49:211-20.

29. Segain JP, Raingeard de la Blétière D, Bourreille A, Leray V, Gervois N, Rosales C, Ferrier L, Bonnet C, Blottière HM, Galmiche JP. Butyrate inhibits inflammatory responses through NFkappaB inhibition: implications for Crohn's disease. Gut 2000;47:397-403.

30. Wilson AJ, Gibson PR. Short-chain fatty acids promote the migration of colonic epithelial cells in vitro. Gastroenterology 1997;113:487-96.

31. De Hingh I. Anastomotic healing in the intestine. Pre-clinical studies with the emphasis on the role of gelatinases and the effect of peritonitis2005, Nijmegen: PrintPartners, Ipskamp.

32. Cavaglieri CR, Nishiyama A, Fernandes LC, Curi R, Miles EA, Calder PC. Differential effects of shortchain fatty acids on proliferation and production of pro- and anti-inflammatory cytokines by cultured lymphocytes. Life Sci 2003;73:1683-90.

33. Steinhart $A H$, Hemphill D, Greenberg GR. Sulfasalazine and mesalazine for the maintenance therapy of Crohn's disease: a meta-analysis. Am J Gastroenterol 1994;89:2116-24.

34. Andoh A, Fujiyama Y, Hata K, Araki Y, Takaya H, Shimada M, Bamba T. Counter-regulatory effect of sodium butyrate on tumour necrosis factor-alpha (TNF-alpha)-induced complement C3 and factor B biosynthesis in human intestinal epithelial cells. Clin Exp Immunol 1999;118:23-9.

35. Kristensen NB, Harmon DL. Effect of increasing ruminal butyrate absorption on splanchnic metabolism of volatile fatty acids absorbed from the washed reticulorumen of steers. J Anim Sci 2004;82:3549-59.

36. Welters CF, Heineman E, Thunnissen FB, van den Bogaard AE, Soeters PB, Baeten CG. Effect of dietary inulin supplementation on inflammation of pouch mucosa in patients with an ileal pouch-anal anastomosis. Dis Colon Rectum 2002;45:621-7.

37. Lührs H, Gerke T, Müller JG, Melcher R, Schauber J, Boxberge F, Scheppach W, Menzel T. Butyrate inhibits NF-kappaB activation in lamina propria macrophages of patients with ulcerative colitis. Scand J Gastroenterol 2002;37:458-66.

38. Senagore AJ, MacKeigan JM, Scheider M, Ebrom JS. Short-chain fatty acid enemas: a cost-effective alternative in the treatment of nonspecific proctosigmoiditis. Dis Colon Rectum 1992;35:923-7.

39. Hille A, Herrmann MK, Kertesz T, Christiansen H, Hermann RM, Pradier O, Schmidberger H, Hess CF. Sodium butyrate enemas in the treatment of acute radiation-induced proctitis in patients with prostate cancer and the impact on late proctitis. A prospective evaluation. Strahlenther Onkol 2008; 184:686-92.

40. Terzi C, Sevinç Al, Koçdor H, Oktay G, Alanyali H, Küpelioğlu A, Ergör G, Füzün M. Improvement of colonic healing by preoperative rectal irrigation with short-chain fatty acids in rats given radiotherapy. Dis Colon Rectum 2004;47:2184-94.

41. Kerem M, Bedirli A, Karahacioglu E, Pasaoglu H, Sahin O, Bayraktar N, Yilmaz TU, Sakrak O, Goksel F, Oguz M. Effects of soluble fiber on matrix metalloproteinase-2 activity and healing of colon anastomosis in rats given radiotherapy. Clin Nutr 2006;25:661-70.

42. Topçu O, Karaday K, Kuzu MA, Ulukent S, Erkek B, Alaçayir I. Enteral and intraluminal short-chain fatty acids improves ischemic left colonic anastomotic healing in the rat. Int J Colorectal Dis 2002;17:171-6.

43. Peeters KC, Tollenaar RA, Marijnen CA, Klein Kranenbarg E, Steup WH, Wiggers T, Rutten HJ, van de Velde CJ; Dutch Colorectal Cancer Group. Risk factors for anastomotic failure after total mesorectal excision of rectal cancer. Br J Surg 2005;92:211-6.

44. Bruce J, Krukowski ZH, Al-Khairy G, Russell EM, Park KG. Systematic review of the definition and measurement of anastomotic leak after gastrointestinal surgery. Br J Surg 2001;88:1157-68. 
45. Ptok H, Marusch F, Meyer F, Schubert D, Gastinger I, Lippert H; Study Group Colon/Rectum Carcinoma (Primary Tumour). Impact of anastomotic leakage on oncological outcome after rectal cancer resection. Br J Surg 2007;94:1548-54.

46. Bell SW, Walker KG, Rickard MJ, Sinclair G, Dent OF, Chapuis PH, Bokey EL. Anastomotic leakage after curative anterior resection results in a higher prevalence of local recurrence. Br J Surg 2003;90: 1261-6.

47. Rullier E, Laurent C, Garrelon JL, Michel P, Saric J, Parneix M. Risk factors for anastomotic leakage after resection of rectal cancer. Br J Surg 1998;85:355-8.

48. Bergman EN, Reid RS, Murray MG, Brockway JM, Whitelaw FG.Interconversions and production of volatile fatty acids in the sheep rumen. Biochem J 1965;97:53-8.

49. Alves A, Panis Y, Trancart D, Regimbeau JM, Pocard M, Valleur P.Factors associated with clinically significant anastomotic leakage after large bowel resection: multivariate analysis of 707 patients. World J Surg 2002;26:499-502.

50. Mantzoros I, Kanellos I, Demetriades H, Christoforidis E, Kanellos D, Pramateftakis MG, Zaraboukas T, Betsis D. Effects of steroid on the healing of colonic anastomoses in the rat. Tech Coloproctol 2004;8 (Suppl 1):s180-3.

51. Kanellos I, Mantzoros I, Demetriades H, Kalfadis S, Kelpis T, Sakkas L, Betsis D. Healing of colon anastomoses covered with fibrin glue after immediate postoperative intraperitoneal administration of 5-fluorouracil. Dis Colon Rectum 2004;47:510-5.

52. Attard JA, Raval MJ, Martin GR, Kolb J, Afrouzian M, Buie WD, Sigalet DL. The effects of systemic hypoxia on colon anastomotic healing: an animal model. Dis Colon Rectum 2005;48:1460-70.

53. liczek A, Zeebregts CJ, Benaron DA, Coppes RP, Wiggers T, van Dam GM. Preoperative irradiation with $5 \times 5 \mathrm{~Gy}$ in a murine isolated colon loop model does not cause anastomotic weakening after colon resection. Int J Colorectal Dis 2008;23:1115-24.

54. Inglin RA, Baumann G, Wagner OJ, Candinas D, Egger B. Insulin-like growth factor I improves aspects of mycophenolate mofetil-impaired anastomotic healing in an experimental model. Br J Surg 2008;95: 793-8.

55. Thornton FJ, Barbul A. Healing in the gastrointestinal tract. Surg Clin North Am 1997;77:549-73.

56. Hendriks T, MastboomWJ. Healing of experimental intestinal anastomoses. Parameters for repair. Dis Colon Rectum 1990;33:891-901.

57. Witte MB, Barbul A. Repair of full-thickness bowel injury. Crit Care Med 2003;31(8 Suppl):S538-46.

58. Ferrans, V.J., New insights into the world of matrix metalloproteinases. Circulation, 2002;105: 405-7.

59. Okuno T, Andoh A, Bamba S, Araki Y, Fujiyama Y, Fujiyama M, Bamba T. Interleukin-1beta and tumor necrosis factor-alpha induce chemokine and matrix metalloproteinase gene expression in human colonic subepithelial myofibroblasts. Scand J Gastroenterol 2002;37:317-24.

60. Bamba S, Andoh A, Yasui H, Araki Y, Bamba T, Fujiyama Y. Matrix metalloproteinase-3 secretion from human colonic subepithelial myofibroblasts: role of interleukin-17. J Gastroenterol 2003;38:548-54.

61. Stumpf M, Klinge U, Wilms A, Zabrocki R, Rosch R, Junge K, Krones C, Schumpelick V.Changes of the extracellular matrix as a risk factor for anastomotic leakage after large bowel surgery. Surgery 2005; 137:229-34.

62. Syk I, Agren MS, Adawi D, Jeppsson B. Inhibition of matrix metalloproteinases enhances breaking strength of colonic anastomoses in an experimental model. Br J Surg 2001;88:228-34.

63. Louis E, Ribbens C, Godon A, Franchimont D, De Groote D, Hardy N, Boniver J, Belaiche J, Malaise M. Increased production of matrix metalloproteinase- 3 and tissue inhibitor of metalloproteinase- 1 by inflamed mucosa in inflammatory bowel disease. Clin Exp Immunol 2000;120:241-6.

64. de Hingh IH, Siemonsma MA, de Man BM, Lomme RM, Hendriks T. The matrix metalloproteinase inhibitor BB-94 improves the strength of intestinal anastomoses in the rat. Int J Colorectal Dis 2002; 17:348-54.

65. Kawamura T, Andoh A, Nishida A, Shioya M, Yagi Y, Nishimura T, Hashimoto T, Tsujikawa T, Yasui H, Fujiyama Y. Inhibitory Effects of Short-Chain Fatty Acids on Matrix Metalloproteinase Secretion from Human Colonic Subepithelial Myofibroblasts. Dig Dis Sci 2009;54:238-45.

66. Manns, JG, Boda JM. Insulin release by acetate, propionate, butyrate, and glucose in lambs and adult sheep. Am J Physiol 1967;212:747-55. 
67. Feliz B, Witt DR, Harris BT. Propionic acidemia: a neuropathology case report and review of prior cases. Arch Pathol Lab Med 2003;127:e325-8.

68. Bergman EN, Wolff JE. Metabolism of volatile fatty acids by liver and portal-drained viscera in sheep. Am J Physiol 1971;221:586-92.

69. Pouteau E, Piloquet $H$, Maugeais $P$, Champ $M$, Dumon $H$, Nguyen $P$, Krempf $M$. Kinetic aspects of acetate metabolism in healthy humans using [1-13C] acetate. Am J Physiol 1996;271:E58-64.

70. Cook RM, Miller LD. Utilization of volatile fatty acids in ruminants. I. Removal of them from portal blood by the liver. J Dairy Sci 1965;48:1339-45.

71. Knowles SE, Jarrett IG, Filsell $\mathrm{OH}$, Ballard FJ. Production and utilization of acetate in mammals. Biochem J 1974;142:401-11.

72. Ballard FJ. Supply and utilization of acetate in mammals. Am J Clin Nutr 1972;25:773-9.

73. Pethick DW, Lindsay DB, Barker PJ, Northrop AJ. Acetate supply and utilization by the tissues of sheep in vivo. Br J Nutr 1981;46:97-110.

74. Pethick DW, Lindsay DB. Acetate metabolism in lactating sheep. Br J Nutr 1982;48:319-28.

75. Pouteau E, Vahedi K, Messing B, Flourié B, Nguyen P, Darmaun D, Krempf M. Production rate of acetate during colonic fermentation of lactulose: a stable-isotope study in humans. Am J Clin Nutr, 1998;68:1276-83.

76. Cummings JH, Pomare EW, Branch WJ, Naylor CP, Macfarlane GT. Short chain fatty acids in human large intestine, portal, hepatic and venous blood. Gut 1987;28:1221-7.

77. Dankert J, Zijlstra JB, Wolthers BG. Volatile fatty acids in human peripheral and portal blood: quantitative determination vacuum distillation and gas chromatography. Clin Chim Acta 1981;110: 301-7.

78. Mittendorfer B, Sidossis LS, Walser E, Chinkes DL, Wolfe RR. Regional acetate kinetics and oxidation in human volunteers. Am J Physiol 1998;274:E978-83.

79. Skutches CL, Holroyde CP, Myers RN, Paul P, Reichard GA. Plasma acetate turnover and oxidation. J Clin Invest 1979;64:708-13.

80. van Hall G, Sacchetti M, Radegran G. Whole body and leg acetate kinetics at rest, during exercise and recovery in humans. J Physiol 2002;542:263-72.

81. van de Poll MC, Ligthart-Melis GC, Olde Damink SW, van Leeuwen PA, Beets-Tan RG, Deutz NE, Wigmore SJ, Soeters PB, Dejong $\mathrm{CH}$. The gut does not contribute to systemic ammonia release in humans without portosystemic shunting. Am J Physiol Gastrointest Liver Physiol 2008;295:G760-5.

82. van de Poll MC, Soeters PB, Deutz NE, Fearon KC, Dejong CH. Renal metabolism of amino acids: its role in interorgan amino acid exchange. Am J Clin Nutr 2004;79:185-97.

83. Ligthart-Melis GC, van de Poll MC, Vermeulen MA, Boelens PG, van den Tol MP, van Schaik C, De Bandt JP, Deutz NE, Dejong CH, van Leeuwen PA. Enteral administration of alanyl-[2-(15)N]glutamine contributes more to the de novo synthesis of arginine than does intravenous infusion of the dipeptide in humans. Am J Clin Nutr 2009;90:95-105.

84. van de Poll MC, Wigmore SJ, Redhead DN, Beets-Tan RG, Garden OJ, Greve JW, Soeters PB, Deutz NE, Fearon KC, Dejong CH.Effect of major liver resection on hepatic ureagenesis in humans. Am J Physiol Gastrointest Liver Physiol 2007;293:G956-62.

85. Ligthart-Melis GC, van de Poll MC, Dejong CH, Boelens PG, Deutz NE, van Leeuwen PA. The route of administration (enteral or parenteral) affects the conversion of isotopically labeled L-[2$15 N$ ]glutamine into citrulline and arginine in humans. JPEN J Parenter Enteral Nutr 2007;31:343-48; discussion 349-50.

86. Olde Damink SW, Jalan R, Deutz NE, Dejong CH, Redhead DN, Hynd P, Hayes PC, Soeters PB. Isoleucine infusion during "simulated" upper gastrointestinal bleeding improves liver and muscle protein synthesis in cirrhotic patients. Hepatology 2007;45:560-8.

87. Olde Damink SW, Jalan R, Redhead DN, Hayes PC, Deutz NEP, Soeters PB. Interorgan ammonia and amino acid metabolism in metabolically stable patients with cirrhosis and a TIPSS. Hepatology 2002; 36:1163-71.

88. Olde Damink SW, Dejong CH, Deutz NE, Redhead DN, Hayes PC, Soeters PB, Jalan R. Kidney plays a major role in ammonia homeostasis after portasystemic shunting in patients with cirrhosis. Am J Physiol Gastrointest Liver Physiol 2006;291:G189-94. 
Chapter 1

89. Olde Damink SW, Deutz NE, Dejong CH, Soeters PB, Jalan R. Interorgan ammonia metabolism in liver failure. Neurochem Int 2002;41:177-88. 


\section{Chapter 2}

Application of liquid chromatography mass spectrometry to measure short chain fatty acids in blood

HM van Eijk, JG Bloemen, CHC Dejong J Chromatogr B Analyt Techn Biomed Life Science 2009;877:719-724 


\section{Abstract}

A new liquid chromatography mass spectrometry method is described to determine concentrations of the short chain fatty acids acetic acid, propionic acid and butyric acid (SCFA) in human plasma. The method is based on reversed phase chromatography followed by postcolumn neutralization of the mobile phase with ammonia and a consecutive measurement of the SCFA ammonia adducts using negative electro spray ionization. Sample preparation involved simple organic acid deproteinization, resulting in 100\% recovery. SCFA eluted baseline separated within a $25 \mathrm{~min}$ run cycle. A linear response was obtained in the range between 0 and $250 \mu \mathrm{mol} / \mathrm{l}$ ( $R^{2}$ ranged from 0.997 to 0.9999 ). The limit of detection ranged from $0.05 \mu \mathrm{mol} / \mathrm{l}$ for propionic and butyric acid to $0.1 \mu \mathrm{mol} / \mathrm{l}$ for acetic acid. The method was tested by analyzing plasma of arterial, portal venous and hepatic venous blood from patients undergoing a pylorus-preserving pancreaticoduodenectomy. As expected, the highest SCFA concentrations were found in portal plasma, hepatic vein levels were in between, while arterial concentrations were lowest. This newly developed method is suitable to determine SCFA concentrations in human plasma samples. 


\section{Introduction}

Bacterial fermentation in the colon of complex carbohydrates that escape digestion in the small intestine results in production of acetic acid, propionic acid and butyric acid, also known as short chain fatty acids (SCFA). ${ }^{1}$ SCFA in general exert a variety of effects important for intestinal health and function and in particular butyric acid serves as principal metabolic fuel for colonic epithelial cells. ${ }^{1,2}$ Under normal conditions the liver takes up most of the surplus of intestinal butyric and propionic acid, resulting in low systemic propionic and butyric acid concentrations. Levels of acetic acid, which escapes liver metabolism, are usually much higher. ${ }^{3}$

Presently, numerous studies are undertaken in an effort to increase intestinal SCFA concentrations by providing human subjects with prebiotics. However, it is still unclear to what extent the liver is capable of metabolizing an increased SCFA inflow, both under normal and pathological conditions. This is important in preventing too high systemic concentrations, because such elevated levels are considered toxic. ${ }^{4,5}$ To expand our knowledge about interorgan exchange of SCFA in humans and especially the role of gut and liver in SCFA metabolism in vivo, we aimed to measure SCFA concentrations in portal venous, hepatic venous and arterial blood, collected during upper abdominal surgery.

Several methods have been reported to measure SCFA in blood. ${ }^{6,7}$ Most of these methods however, require laborious sample preparation and apply acid deproteinization. Recently, we reported a liquid chromatography mass spectrometry method to measure SCFA concentrations in blood $^{8}$, in which we also showed acid deproteinization does not provide a $100 \%$ recovery for SCFA. We now aim at developing a new method with reduced run times, enhanced sensitivity and a reduced need of analytical column and MS-system regeneration to allow analyses of large numbers of samples collected in patient studies.

Therefore, a new approach was developed in which plasma samples were deproteinized with organic acid and the supernatant was separated on a reversed phase column with hydrochloric acid acidified water and an ethanol gradient. Next, the column effluent was mixed with ammonia, thus increasing the $\mathrm{pH}$ to allow SCFA measurement through negative ionisation electrospray MS.

\section{Materials and Methods}

\section{Chemicals}

All chemicals used were of analytical grade, and unless specified otherwise, purchased from Sigma Aldrich (Zwijndrecht, the Netherlands). Ultra pure water was generated through a Super-Q water purification system (Millipore, Amsterdam, the Netherlands). 


\section{Liquid chromatography -Mass spectrometry}

The chromatographic separation was performed using two Model PU-1580 HPLC pumps (Jasco Benelux, Maarsen, the Netherlands). Samples were injected using a Model 233XL sample processor (Gilson, The Hague, the Netherlands) with peltier chilled sample storage compartments $\left(10^{\circ} \mathrm{C}\right)$ and equipped with a $20 \mu \mathrm{l}$ sample loop. The analytical column was an Altima ODS $5 \mu \mathrm{M}$ reversed phase column $(250 \mathrm{~mm} x$ $2.1 \mathrm{~mm}$, I.D. Grace-Alltech, Breda, the Netherlands), mounted in a Mistral column oven (Separations, H.I.Ambacht, the Netherlands), set to $35^{\circ} \mathrm{C}$ (Figure 2.1). The following gradient was applied: from $t=0$ min to $t=3 \min 100 \%$ solvent $A$ (an aqueous solution of $1.5 \mathrm{mmol} / \mathrm{I}$ hydrochloric acid) was pumped at $0.35 \mathrm{ml} / \mathrm{min}$. From t=3 $\mathrm{min}$ to $t=12 \mathrm{~min}$ a linear gradient to $35 \%$ solvent $\mathrm{B}$ (ethanol/water $(95 / 5: \mathrm{v} / \mathrm{v}$ )containing $0.75 \mathrm{mmol} / \mathrm{l}$ hydrochloric acid) was applied. From $\mathrm{t}=12 \mathrm{~min}$ to $\mathrm{t}=15 \mathrm{~min}$ the gradient was increased to $100 \%$ solvent $B$, maintained at $100 \%$ solvent $B$ for 5 min and then returned to $100 \%$ solvent $A$ in $1 \mathrm{~min}$. After a 10 min equilibration the following sample was injected. Before entering the MS system, the column effluent was mixed with $0.15 \mathrm{~mol} / \mathrm{I}$ ammonia in ethanol, delivered from an additional pump (Model PU 980) to increase the $\mathrm{pH}$ to about 9-10, which supported negative ionization of SCFA. The mass spectrometer (MS) was a Model LCQ Advantage (Thermo Electron, Breda, the Netherlands), equipped with an orthogonal electrospray (ESI) probe. The MS was operated in negative mode. Measurements were done in selected ion monitoring mode (SIM), set to a range of $\mathrm{m} / \mathrm{z} 54-90$, thus including the ions of acetic acid, $m / z=59(-)$, propionic acid $m / z=73(-)$ and butyric acid $m / z=87(-)$. In this way any potential shifts in retention time were anticipated, while this scan mode cleans out unwanted ions from the ion-trap which otherwise would be included in the ion trap in full scan mode. Maximum sensitivity of the LC-MS system was obtained at the following settings: ion-time $750 \mathrm{msec}, 2$ micro scans, heated capillary temperature $125^{\circ} \mathrm{C}$. To avoid rapid blocking of the heated capillary by ammonium chloride, the MS probe was flushed between each analysis cycle with methanol/water (50/50 v/v) supplied by a Model PU980 pump at $0.5 \mathrm{ml} / \mathrm{min}$ in between runs, in practice after elution of butyric acid until the start of a new run. The solvent was switched automatically using the MS divert valve, programmed through the Xcalibur software (Thermo Electron).

\section{Human experiments}

Six patients were studied during pylorus-preserving pancreaticoduodenectomy at Maastricht University Medical Centre. The Medical Ethical Committee approved the study and all patients gave written informed consent. Exclusion criteria were parenchymal liver disease, inborn errors of metabolism, diabetes mellitus type I, use of antibiotics prior to the operation and cancer cachexia. The patients were on a stable, western diet. They were fasted from midnight before surgery. Prior to surgery all patients received a single intravenous dose of $2200 \mathrm{mg}$ amoxicillin/clavulanic acid as an antibiotic prophylaxis. 
Anaesthetic management was according to institutional routines and has been described previously. ${ }^{9,10}$ The procedure included placement of two peripheral venous catheters, an epidural catheter for per- and postoperative analgesia, an arterial line, and a central venous line. Anaesthesia was maintained using isoflurane and propofol. When exposure of portal and hepatic veins was adequate, blood was drawn from the portal vein and the middle hepatic vein by direct puncture, simultaneously with arterial blood sampling, as described before by our group. ${ }^{9}$ Blood was collected in prechilled heparinized vacuum tubes (BD Vacutainer, Franklin Lakes, NJ) and placed on ice.

Blood samples were immediately centrifuged at 8.500xg in a Model Biofuge Stratos (Hereaus, Dijkstra Vereenigde, Lelystad, the Netherlands) for $10 \mathrm{~min}$ at $4^{\circ} \mathrm{C}$. Plasma was separated and transferred into $2 \mathrm{ml}$ Eppendorf safe lock micro tubes (VWR, Amsterdam, the Netherlands) and stored at $-80^{\circ} \mathrm{C}$ until analysis. Before analysis, $50 \mu \mathrm{l}$ plasma aliquots were deproteinized by addition of $100 \mu \mathrm{l}$ methanol, vortex-mixed vigorously and centrifuged at $50.000 \mathrm{~g}$ for $10 \mathrm{~min}$ at $4^{\circ} \mathrm{C}$. A $125 \mu \mathrm{l}$ aliquot of the clear plasma supernatant was transferred into a $300 \mu$ glass micro-insert ( $40 \times 6 \mathrm{~mm})$, spring adjusted into a $4 \mathrm{ml}$ WISP-style vial (Waters, Etten-Leur, the Netherlands) and sealed with a PTFE self-sealing seal and injected into the LC-MS system.

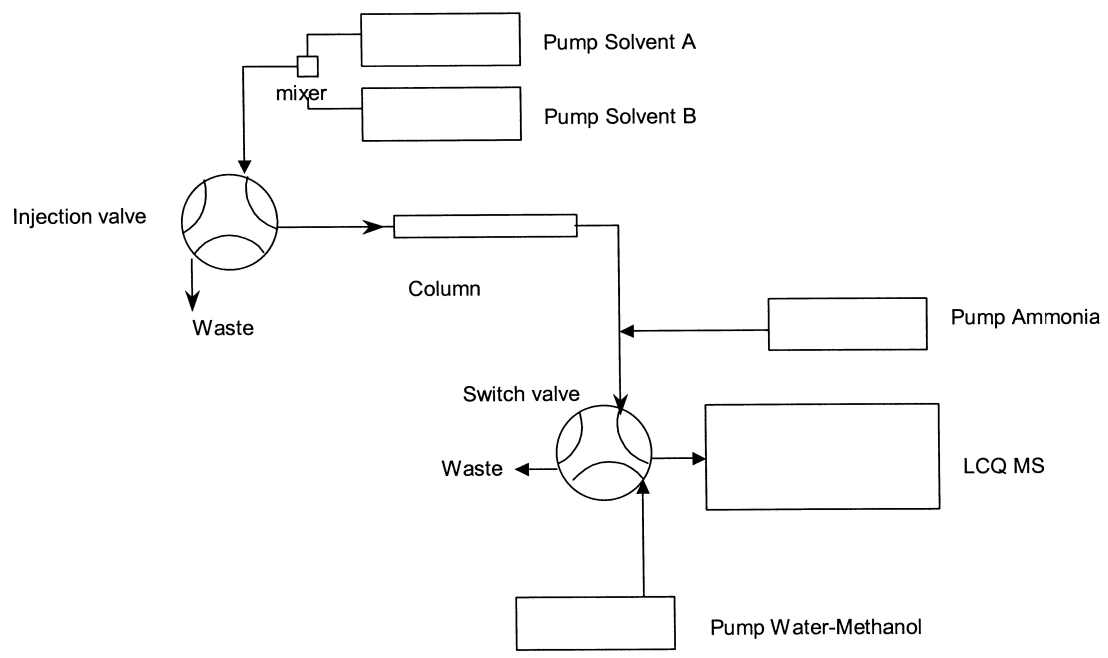

Figure 2.1 Schematically setup of the LC-MS system for SCFA determination.

\section{Results}

\section{System optimization and validation}

Solvent A was a $1.5 \mathrm{mmol} / \mathrm{l}$ solution of hydrochloric acid in water resulting in a $\mathrm{pH}$ of about 2.8. Using this solvent, a maximum of $20 \mu \mathrm{l}$ sample could be injected. Injection 
of a higher amount affected peak symmetry and retention time of especially the first eluting peak, acetic acid. Increasing the hydrochloric acid concentration by a factor of 2 or more allowed us to inject more sample before retention times shifted and peak symmetry was affected. However, it also increased the amount of ammonium chloride formed in the electrospray process, resulting in a twice as fast blocking of the heated capillary of our MS. Therefore, we considered the application of $20 \mu \mathrm{l}$ samples and $1.5 \mathrm{mmol} / \mathrm{l}$ hydrochloric acid in our solvent optimal as this combination allowed us to analyze batches of 30 samples, before we had to clean the system.

The present method allows the baseline separation and detection of acetic acid (3.3 $\mathrm{min})$, propionic acid (5.5 min), butyric acid (7.9 $\mathrm{min}$ ) and valeric acid (10.7 $\mathrm{min}$ ) (Figure 2.2) in a 25 min run cycle. Ten point calibration curves for these components were constructed using aqueous standards in the following concentrations $0,0.5,1.0$, $2.5,5,10,25,50,75,125,250 \mu \mathrm{mol} / \mathrm{l}$. A linear response for all SCFA was obtained. The equations of the lines were $Y=195498( \pm 536) X+134133( \pm 49998)$ (valeric acid, $\left.R^{2}=1.000\right), \quad Y=163701( \pm 843) X+25493( \pm 78625)$ (butyric acid, $\left.R^{2}=1.000\right)$, $Y=107918( \pm 876) X+138282( \pm 81688)$ (propionic acid, $\left.R^{2}=0.999\right)$ and $Y=34852( \pm 605) X$ $+103467( \pm 56439)$ (acetic acid, $\left.R^{2}=0.997\right)$.
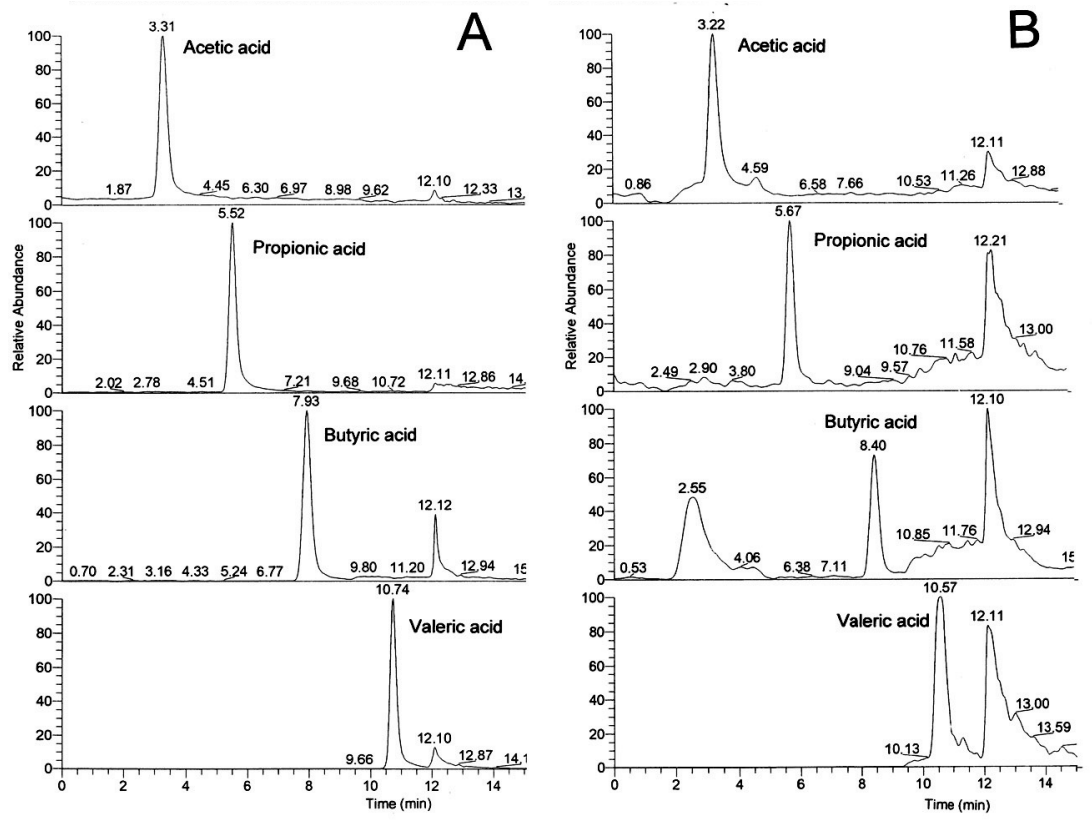

Figure 2.2 Separation and detection of SCFA. Panel A: $100 \mu \mathrm{M}$ aqueous standard. Panel B: Portal plasma sample (acetate $156 \mu \mathrm{M}$; propionate $35 \mu \mathrm{M}$, butyrate $24 \mu \mathrm{M}$, valerate $0.7 \mu \mathrm{M})$. 
The intra-day precision, determined for a $250 \mu \mathrm{M}$ standard $(\mathrm{N}=10)$ of acetic acid, propionic acid and butyric acid in water, was $2.8 \%$ for acetic acid, $2.1 \%$ for propionic acid and $1.9 \%$ for butyric acid. The inter day precision determined for the same standard on 6 different days was $4.0 \%$ for acetic acid, $3.4 \%$ for propionic acid and $3.3 \%$ for butyric acid.

\section{Influence of deproteinization agent}

Venous plasma from 3 normal human volunteers was pooled to prepare a representative plasma sample. This pooled plasma was methanol deproteinized and analyzed in six fold using the present method. As can be seen from Table 2.1 the method can easily be used to determine SCFA concentrations at the low $\mu$ mol level. Next, the recovery of the deproteinization step was determined by first spiking the pooled plasma sample with $75 \mu \mathrm{mol} / \mathrm{l}$, conduct a methanol deproteinization and measure the concentrations of acetic acid, propionic acid and butyric acid again in six fold (Table 2.1). The recovery was determined by subtracting these 2 sets of data.

Table 2.1 Recovery of a $75 \mu$ M SCFA spike to a venous plasma sample ( $n=6)$.

\begin{tabular}{|c|c|c|c|c|c|c|c|c|c|}
\hline \multirow[t]{3}{*}{ Component } & \multicolumn{3}{|c|}{ Venous Plasma } & \multicolumn{3}{|c|}{ Spiked $(75 \mu \mathrm{M})$ Plasma } & \multicolumn{3}{|c|}{ Spike Recovery (\%) } \\
\hline & Mean & SD & CV & Mean & SD & CV & Mean & SD & CV \\
\hline & $\mu \mathrm{mol} / \mathrm{l}$ & $\mu \mathrm{mol} / \mathrm{l}$ & $\%$ & $\mu \mathrm{mol} / \mathrm{l}$ & $\mu \mathrm{mol} / \mathrm{l}$ & $\%$ & $\%$ & $\%$ & $\%$ \\
\hline Acetic acid & 55.4 & 2.3 & 4.2 & 135.0 & 4.8 & 3.6 & 106.8 & 2.9 & 2.8 \\
\hline Propionic acid & 1.0 & 0.1 & 9.8 & 75.8 & 3.1 & 4.1 & 99.8 & 3.1 & 3.1 \\
\hline Butyric acid & 0.4 & 0.0 & 5.1 & 74.9 & 1.8 & 2.4 & 99.3 & 2.0 & 2.0 \\
\hline
\end{tabular}

Mean recovery ( \pm coefficient of variation (\%)) derived from these measurements was $106.8 \%( \pm 2.8 \%)$ for acetic acid, $99.8 \%( \pm 3.1 \%)$ for propionic acid and $99.3 \%( \pm 2.0 \%)$ for butyric acid (Table 2.1). Thus, methanol deproteinization provides recoveries, which are comparable to zinc-sulphate deproteinization. ${ }^{8}$

To determine if the presented method is capable of measuring different levels of SCFA in patient blood samples, we analyzed arterial, portal vein and hepatic vein blood samples of 6 patients. To eliminate possible effects of the method of deproteinization on SCFA concentrations, all samples were treated both with zinc-sulphate and methanol. Only marginal differences were found between both methods (Table 2.2). As expected, highest SCFA concentrations were measured in portal plasma samples, while hepatic vein plasma showed a slightly lower acetic acid concentration, and considerably lower propionic and butyric acid concentrations. In arterial samples all SCFA were substantially lower. 
Table 2.2 Short chain fatty acids concentrations in human plasma samples deprotenized with zinc sulphate $(\mathrm{z})$ and methanol $(\mathrm{m})$.

\begin{tabular}{|c|c|c|c|c|c|c|c|c|c|c|c|c|c|c|}
\hline \multirow[t]{3}{*}{$\mathrm{Pt}$} & \multirow[t]{3}{*}{ Sex } & \multirow[t]{3}{*}{ Age } & \multicolumn{6}{|c|}{ Acetic acid } & \multicolumn{6}{|c|}{ Propionic acid } \\
\hline & & & \multicolumn{2}{|c|}{ Art } & \multicolumn{2}{|l|}{ PV } & \multirow{2}{*}{$\begin{array}{l}\mathrm{HV} \\
\mathrm{M}\end{array}$} & \multicolumn{3}{|c|}{ Art } & \multirow{2}{*}{$\begin{array}{l}\text { PV } \\
M\end{array}$} & \multicolumn{3}{|c|}{ HV } \\
\hline & & & $\mathrm{M}$ & $\mathrm{Z}$ & $\mathrm{M}$ & $\mathrm{Z}$ & & $\mathrm{Z}$ & $\mathrm{M}$ & Z & & Z & $\mathrm{M}$ & $\mathrm{Z}$ \\
\hline 1 & $M$ & 74 & 121.3 & 130.9 & 398.8 & 382.7 & 225.5 & 212.4 & 3.9 & 3.8 & 38.3 & 32.8 & 1.6 & 0.9 \\
\hline 2 & $M$ & 60 & 246.0 & 240.3 & 312.7 & 320.6 & 251.8 & 252.8 & 6.1 & 4.9 & 34.0 & 35.5 & 9.5 & 3.5 \\
\hline 3 & $M$ & 42 & 155.8 & 146.4 & 170.5 & 178.3 & 127.5 & 125.7 & 4.5 & 3.2 & 35.2 & 37.4 & 6.4 & 2.2 \\
\hline 4 & $\mathrm{~F}$ & 43 & 181.0 & 209.0 & 188.5 & 181.1 & 207.1 & 187.6 & 1.5 & 1.3 & 9.2 & 10.8 & 0.7 & 0.7 \\
\hline 5 & $M$ & 66 & 111.2 & 96.9 & 173.0 & 160.2 & 102.1 & 94.6 & 1.4 & 0.7 & 24.8 & 15.7 & 0.6 & 0.6 \\
\hline 6 & $M$ & 49 & 84.8 & 95.4 & 108.6 & 114.7 & & 98.4 & 4.6 & 3.3 & 19.8 & 16.5 & & 1.4 \\
\hline Mean & & 55.7 & 150.0 & 153.1 & 225.3 & 222.9 & 182.8 & 161.9 & 3.7 & 2.9 & 26.9 & 24.8 & 3.8 & 1.6 \\
\hline SEM & & 5.3 & 23.67 & 24.34 & 44.15 & 42.59 & 26.42 & 26.67 & 0.76 & 0.64 & 4.53 & 4.78 & 1.64 & 0.46 \\
\hline$P$-value & & & & ns & & ns & & ns & & 0.031 & & ns & & ns \\
\hline \multirow[t]{3}{*}{$\mathrm{Pt}$} & \multirow[t]{3}{*}{ Sex } & \multirow[t]{3}{*}{ Age } & \multicolumn{2}{|c|}{ Butyric acid } & \multicolumn{10}{|c|}{ Valeric acid } \\
\hline & & & Art & & PV & & $\mathrm{HV}$ & & Art & & PV & & $\mathrm{HV}$ & \\
\hline & & & $M$ & Z & $\mathrm{M}$ & $\mathrm{Z}$ & $\mathrm{M}$ & $\mathrm{Z}$ & $\mathrm{M}$ & Z & $\mathrm{M}$ & Z & $M$ & Z \\
\hline 1 & $M$ & 74 & 3.5 & 2.7 & 46.2 & 34.2 & 5.8 & 5.5 & 0.5 & 0.4 & 10.5 & 5.4 & 0.4 & 0.3 \\
\hline 2 & $M$ & 60 & 8.3 & 6.1 & 48.6 & 40.9 & 6.1 & 3.6 & 0.7 & 0.3 & 3.5 & 1.9 & 0.5 & 0.2 \\
\hline 3 & $M$ & 42 & 3.8 & 2.9 & 24.3 & 21.5 & 3.3 & 2.3 & 0.8 & 0.3 & 0.7 & 0.5 & 0.8 & 0.5 \\
\hline 4 & $\mathrm{~F}$ & 43 & 6.8 & 4.7 & 9.6 & 4.9 & 0.9 & 0.9 & 1.5 & 0.8 & 1.1 & 2.0 & 1.3 & 0.2 \\
\hline 5 & $M$ & 66 & 1.8 & 1.5 & 23.3 & 20.4 & 0.6 & 0.7 & 0.8 & 0.3 & 14.9 & 7.6 & 0.3 & 0.1 \\
\hline 6 & $M$ & 49 & 4.3 & 2.0 & 25.8 & 22.3 & & 2.1 & 1.0 & 0.4 & 7.3 & 5.1 & & 0.5 \\
\hline Mean & & 55.7 & 4.7 & 3.3 & 29.6 & 24.0 & 3.3 & 2.5 & 0.8 & 0.4 & 6.3 & 3.8 & 0.7 & 0.3 \\
\hline SEM & & 5.3 & 0.97 & 0.72 & 6.11 & 5.09 & 1.06 & 0.74 & 0.14 & 0.07 & 2.31 & 1.10 & 0.16 & 0.07 \\
\hline$P$-value & & & & 0.031 & & 0.031 & & ns & & 0.031 & & ns & & ns \\
\hline
\end{tabular}

\section{Mass filter application}

In plasma samples a large unknown component with $\mathrm{m} / \mathrm{z} 60$ eluted just after the acetic acid peak. As in the standard SIM mode of our MS system a resolution of 1 AMU is applied, this large peak partially overlapped the acetic acid peak, overestimating the acetic acid concentration (Figure 2.3, panel A). Applying a $0.2 \mathrm{AMU}$ mass filter instead of the default 1.0 AMU for the acetic acid peak eliminated this problem (panel $\mathrm{B}$ ). As a consequence however, the total ion current (TIC) of acetic acid was lower, resulting in a limit of detection (LOD, calculated as the concentration with a signal to noise ratio of $3: 1)$ of $0.1 \mu \mathrm{mol} / \mathrm{l}$ for acetic acid, while propionic, butyric and valeric acid could be detected already at $0.05 \mu \mathrm{mol} / \mathrm{l}$. 


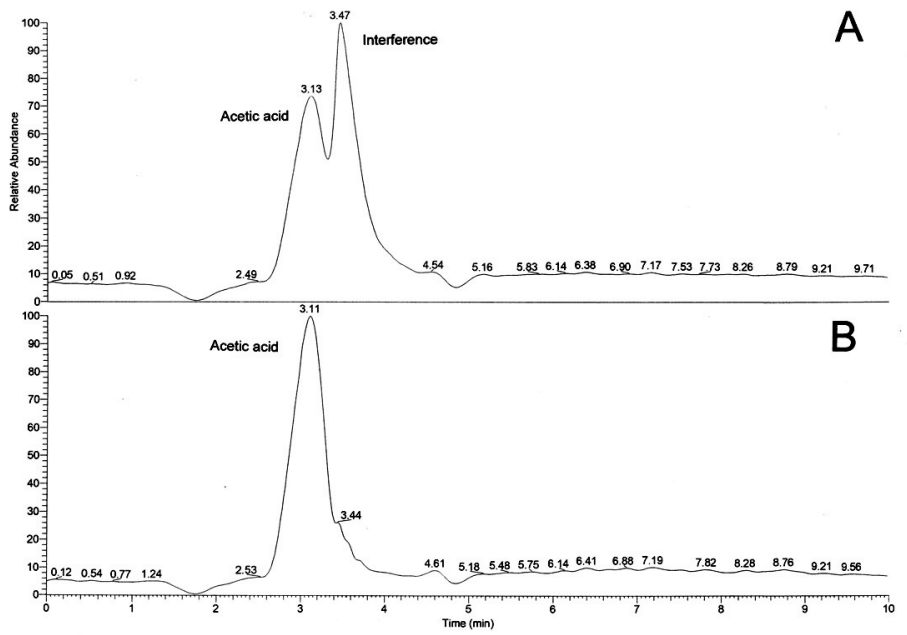

Figure 2.3 Effect of limited mass filter application on acetic acid determination in plasma Panel A: normal mass filter (width $1.0 \mathrm{AMU}$ ), panel B: small mass filter (width $0.2 \mathrm{AMU}$.

\section{Discussion}

Considering the volatile character of SCFA most published methods use gas chromatography to determine their concentrations. ${ }^{6,7,11}$ However, these methods are laborious, while the required complex sample preparations can potentially influence the analytical recovery. For instance, Pouteau et al. ${ }^{6}$ and Moreau et al. ${ }^{7}$ applied sulfosalicylic acid plasma deproteinization, which as we proved influences SCFA recovery. ${ }^{8}$ Morrison et al. ${ }^{11}$ like Remesy et al. ${ }^{3}$ applied ultra filtration to deproteinize their samples. However, giving the long time samples have to be centrifuged, there is more time to allow the volatile SCFA to evaporate from the samples. To exclude these variables we recently presented an alternative approach using LC-MS. ${ }^{8}$ In contrast to gas-chromatography, both sample preparation and the analytical procedure itself are simple and result in $100 \%$ recovery. However, with a limit of detection of $7.5 \mu \mathrm{mol} / \mathrm{l}$, sensitivity was not good enough to determine especially propionic and butyric acid in human (arterial) plasma being one of the targets in our present study. Furthermore, the analysis was based on an isocratic separation, but each series of about 20 samples required a thorough column regeneration requiring several days of work.

To enable the interaction of SCFA with a reversed phase packing material, SCFA must be entirely in their neutral form, as their ionized forms are too polar to be retained. In consequence, the solvent pH must be preferably 2 units below the SCFA pKs (which are all between 4.6-4.8), thus below pH 3. However, all volatile (and thus MS 
compatible) acids, suitable to set this $\mathrm{pH}$ (like tri-fluoroacetic acid, tri-chloroacetic acid) degrade the MS signal of target SCFA completely, possibly due to the $\mathrm{mmol} / \mathrm{I}$ solvent (acid) ions, leaving little trapping capacity for the ion-trap of our system for the $\mu \mathrm{mol} / \mathrm{l}$ quantities of target SCFA analytes. This is probably because injected sample salts temporarily increase the solvent $\mathrm{pH}$, interfering with the acid-base balance of the acetic acid peak.

Instead we used hydrochloric acid in a $1.5 \mathrm{mmol} / \mathrm{l}$ concentration to acidify the solvent to a $\mathrm{pH}$ of 2.8, low enough to prohibit SCFA ionization, but high enough to prohibit column deterioration. The harmful effect of hydrochloric acid to the MS system was neutralized by mixing the column effluent with a 100 times higher concentrated ammonia solution, increasing the $\mathrm{pH}$ to about 8.5 , ionizing all SCFA completely and converting all chloride ions to ammonium chloride which, due to the electrospray process and the orthogonal setup of the ionization probe, precipitated mostly on the spray shield of the MS-probe. Because we also used the MS bypass valve to switch from the analytical solvent to a mixture of methanol-water (50/50; v/v) after elution of the last SCFA of interest, we could avoid blocking of the heated capillary as a consequence of which the signal was stable for at least 30 runs. Hereafter, a simple wet tissue wiping of the probe was sufficient to allow another 30 samples to be run without losing signal intensity. Even so, we avoided possible dirt accumulation in the MS system itself, by cleaning also the MS skimmer and first lens each 90 runs, after which the vacuum was restored (within hours) and the cycle was repeated.

To obtain correct SCFA-concentrations a correct sample preparation is of utmost importance. We demonstrated previously ${ }^{8}$ that acid deproteinization results in too low recoveries, whereas zinc-sulphate provided $100 \%$ recoveries. However, we observed that zinc-sulphate deproteinization often resulted in still cloudy supernatants, possibly due to micelle formation of plasma lipids. In addition, Remesy ${ }^{3}$ described that a significant part of plasma SCFA are protein bound as a result of which they escape the analysis if samples were deproteinized using the in these days commonly applied ultra filtration techniques. He suggested only organic solvent deproteinization would liberate protein bound SCFA. However, where only $10 \mu \mathrm{l}$ of zinc-sulphate was sufficient to deproteinize $100 \mu \mathrm{l}$ of plasma, organic solvent deproteinization required double the amount of solvent $(200 \mu \mathrm{l})$, thus resulting in a three-fold dilution and decreased sensitivity. In contrast, methanol deproteinization always produced clear supernatants preventing injection problems and making it an attractive alternative to zinc-sulphate. In addition, we also obtained a nearly $100 \%$ spike recovery (Table 2.1 ) which is comparable to the zinc-sulphate deproteinization we applied before. ${ }^{8}$

Remesy ${ }^{3}$ also indicated that the amount of SCFA protein binding differed between species and sampling site of the blood samples. To exclude possible effects in humans we analyzed samples obtained from portal vein derived plasma, hepatic vein derived plasma and arterial plasma samples obtained through a pilot patient study from a group of 6 patients undergoing pylorus-preserving pancreaticoduodenectomy. For these samples we also compared zinc-sulphate and methanol deproteinization 
(Table 2.2). As a higher number of SCFA carbon atoms is supposed to increase the percentage of protein binding, we also included measurement of valeric acid in this study.

As expected, highest SCFA concentrations were measured in portal plasma samples, while hepatic vein plasma showed a slightly lower acetic acid concentration, and considerably lower propionic and butyric acid concentrations. In arterial samples all SCFA were substantially lower. However, although the methanol deproteinization method overall seemed to result in a slightly higher concentrations, this usually did not reach statistical significance.

We thus cannot confirm the findings of Remesy. A possible explanation might be a difference in species (Remesy studied rats and sheep, this study is in humans), but we also suggest the lower SCFA concentrations found through ultra filtration might be explained by a higher percentage of evaporation due to the time consuming ultra filtration process, which is excluded when organic solvent deproteinization is applied.

\section{Conclusion}

The newly developed method is suitable for the analysis of SCFA concentrations in large patient plasma sample series. 


\section{References}

1. Bergman EN. Energy contributions of volatile fatty acids from the gastrointestinal tract in various species. Physiol Rev 1990;70:567-90.

2. Chadwick VS, Anderson RP. The role of intestinal bacteria in etiology and maintenance of inflammatory bowel disease, in Human colonic bacteria: role in nutrition, physiology and pathology, G.R. Gibson and G.T. Macfarlane, Editors. CRC press: Boca Raton. 1995:227-256.

3. Remesy C, Demigne C. Determination of volatile fatty acids in plasma after ethanolic extraction. Biochem J 1974;141:85-91.

4. Manns JG, Boda JM. Insulin release by acetate, propionate, butyrate, and glucose in lambs and adult sheep. Am J Physiol 1967;212:747-55.

5. Feliz B, Witt DR, Harris BT. Propionic acidemia: a neuropathology case report and review of prior cases. Arch Pathol Lab Med 2003;127:325-8.

6. Pouteau E, Meirim I, Métairon S, Fay LB. Acetate, propionate and butyrate in plasma: determination of the concentration and isotopic enrichment by gas chromatography/mass spectrometry with positive chemical ionization. J Mass Spectrom 2001;36:798-805.

7. Moreau NM, Goupry SM, Antignac JP, Monteau FJ, Le Bizec BJ, Champ MM, Martin LJ, Dumon HJ. Simultaneous measurement of plasma concentrations and 13C-enrichment of short-chain fatty acids, lactic acid and ketone bodies by gas chromatography coupled to mass spectrometry. J Chromatogr B Analyt Technol Biomed Life Sci 2003;784:395-403.

8. Meesters RJ, van Eijk HM, ten Have GA, de Graaf AA, Venema K, van Rossum BE, Deutz NE. Application of liquid chromatography-mass spectrometry to measure the concentrations and study the synthesis of short chain fatty acids following stable isotope infusions. J Chromatogr B Analyt Technol Biomed Life Sci 2007;854:57-62.

9. van de Poll MC, Siroen MP, van Leeuwen PA, Soeters PB, Melis GC, Boelens PG, Deutz NE, Dejong CH. Interorgan amino acid exchange in humans: consequences for arginine and citrulline metabolism. Am J Clin Nutr 2007;85:167-72.

10. van de Poll MC, Ligthart-Melis GC, Boelens PG, Deutz NE, van Leeuwen PA, Dejong CH. Intestinal and hepatic metabolism of glutamine and citrulline in humans. J Physiol 2007;581:819-27.

11. Morrison DJ, Cooper K, Waldron S, Slater C, Weaver LT, Preston T. A streamlined approach to the analysis of volatile fatty acids and its application to the measurement of whole-body flux. Rapid Commun Mass Spectrom 2004;18:2593-600. 
Part II

Physiology \& pathophysiology of SCFA interorgan exchange 



\section{Chapter 3}

Short chain fatty acids exchange across the gut and liver in humans measured at surgery

JG Bloemen, K Venema, MCG van de Poll, SWM Olde Damink, WA Buurman, CHC Dejong

Clin Nutr 2009;28:657-61 


\section{Abstract}

\section{Background and aim}

Short chain fatty acids (SCFA; acetate, propionate and butyrate) are important energy sources for colonocytes and are assumed to play a key role in gut health. Local effects of SCFA have been investigated, but less is known about whole body metabolism of these SCFA. The aim of the present study was to quantify the role of the gut and liver in interorgan exchange of SCFA in humans in vivo.

\section{Methods}

Twenty-two patients undergoing major upper abdominal surgery were studied. Blood was sampled from a radial artery, the portal and a hepatic vein. Portal, splanchnic and arterial blood flow was measured using intra-operative Duplex ultrasonography. SCFA were measured on a liquid chromatography system combined with mass spectometry.

\section{Results}

SCFA were released by the gut, 34.9 (9.1) $\mu \mathrm{mol} \cdot \mathrm{kg}$ bodyweight ${ }^{-1} \cdot \mathrm{h}^{-1}$. SCFA uptake by the liver was significant for propionate and butyrate; $-5.6(1.3)$ and $-3.8(1.6) \mu \mathrm{mol} \cdot \mathrm{kg}$ bodyweight ${ }^{-1} \cdot \mathrm{h}^{-1}$ $(P=0.0002$ and $P=0.03)$ respectively and counterbalanced gut release. Liver uptake of acetate was not significant, $-5.2(6.6) \mu \mathrm{mol} \cdot \mathrm{kg}$ bodyweight ${ }^{-1} \cdot \mathrm{h}^{-1}(P=0.434)$. Splanchnic (i.e., gut + liver) SCFA release was significant for acetate and propionate, $17.3(7.3)$ and $1.2(0.4) \mu \mathrm{mol} \cdot \mathrm{kg}$ bodyweight ${ }^{-1} \cdot h^{-1}(P=0.027$ and $P=0.0038)$, respectively. Splanchnic release of butyrate was not significantly different from zero (1.9 (1.2) $\mu \mathrm{mol} \cdot \mathrm{kg}$ bodyweight $\left.{ }^{-1} \cdot \mathrm{h}^{-1}, P=0.129\right)$. BMI and previous colonic resection did not affect gut release of SCFA.

\section{Conclusion}

This is the first in vivo study on the role of the gut and liver in SCFA exchange in humans. It is shown that intestinal SCFA release by the gut is equalled by hepatic uptake. 


\section{Introduction}

Short chain fatty acids (SCFA) have recently attracted considerable interest, because of their importance for host health. SCFA are produced during the fermentation process of fibres, resistant starch and undigestible carbohydrates (prebiotics) in the human colon. ${ }^{1}$ Principal products of this process are SCFA, carbon dioxide, methane, hydrogen gas, heat and additional biomass. The main SCFA produced are acetate, propionate and butyrate, in the respective proportion of $60 \%, 20 \%$ and $20 \% .{ }^{2,3}$ SCFA are rapidly absorbed by the colon in a concentration-dependent manner. Once absorbed by the colonocytes, SCFA are locally used as the dominant nutrient for mucosal epithelial cells, with butyrate as the preferred SCFA. ${ }^{4}$ There is a growing body of evidence that SCFA improve intestinal wound healing, enhance epithelial proliferation and differentiation and improve absorptive function. ${ }^{2,5,6}$ SCFA supplementation has been investigated in the clinical setting including ulcerative colitis, diversion colitis and short bowel syndrome. ${ }^{7-10}$ Since propionate and butyrate are toxic in high systemic concentrations ${ }^{11,12}$, knowledge about the physiological metabolism of SCFA in humans is necessary to administer prebiotics safely for therapeutic purposes. ${ }^{13}$ Such knowledge is currently lacking to some extent, and particularly, the interaction between gut and liver in vivo in humans is unclear.

In vivo studies of SCFA uptake and release by the gut and liver require blood sampling from the hepatic and portal vein, but these are difficult to access in humans. Portal and peripheral SCFA concentrations have been determined by others in subjects undergoing surgery and in sudden death patients. ${ }^{14,15}$ However, such data do not allow assessment of SCFA handling of individual organs and the role of the liver has hitherto remained unexplored. This information can be obtained by measuring net exchange of metabolites across organs, also called organ flux. The aim of the present study was to quantify for the first time in vivo in humans the exchange of SCFA between gut and liver.

\section{Methods}

\section{Patients}

Twenty-two patients were studied during major upper abdominal surgery at Maastricht University Medical Centre, 17 patients underwent a partial liver resection, four patients a pylorus-preserving pancreaticoduodenectomy and one patient a duodenectomy (Table 3.1). On the day of admission (one day pre-operatively) routine blood tests were performed. Patients with known parenchymal liver disease, inborn errors of metabolism, diabetes mellitus type I, use of antibiotics prior to the operation or cancer cachexia were excluded from the study. The patients were on a stable, Western diet and did not take antibiotics in the period before surgery. Oral intake except for water was ceased at 8:00 PM on the day of admission and all patients were 
transported to the operation theatre at approximately 7:30 AM the next day. All patient received a single intravenous dose of $2200 \mathrm{mg}$ amoxicillin/clavulanic acid as antibiotic prophylaxis, immediately preoperatively. The study was approved by the Medical Ethical Committee of the University Hospital Maastricht and all patients gave written informed consent.

Table 3.1 Baseline characteristics.

\begin{tabular}{ll}
\hline Male/Female & $11 / 11$ \\
Adenoca liver/adenoca pancreas/benign disease of the liver & $17 / 4 / 1$ \\
Age (years) & $59(30-78)$ \\
Weight $(\mathrm{kg})$ & $72(55-134)$ \\
$\mathrm{BMI}\left(\mathrm{kg} / \mathrm{m}^{2}\right)$ & $25(19.3-42.9)$ \\
\hline
\end{tabular}

\section{Study protocol}

Anesthetic management was according to institutional routines and has been described previously. ${ }^{16}$ The procedure included placement of two peripheral venous catheters, an epidural catheter for per- and postoperative analgesia, an arterial line, and a central venous line. Anesthesia was maintained using sevoflurane and propofol. When exposure of portal and hepatic veins was adequate $(<1$ hour following laparotomy and before organ transection), blood was drawn from the portal vein and the middle hepatic vein by direct puncture, simultaneously with arterial blood sampling, as described before by our group. ${ }^{16}$ Blood was collected in pre-chilled EDTA vacuum tubes (BD Vacutainer, Franklin Lakes, NJ) and placed on ice. Before centrifugation, hematocrit of each blood sample was determined using a micro capillary centrifuge.

\section{Duplex flow measurement}

Hepatic and intestinal blood flow was measured by means of colour Doppler ultrasound (Aloka Prosound SSD 5000, Aloka Co., Ltd, Tokyo, Japan) as described before. ${ }^{17}$ Briefly, time-averaged mean velocities of the blood stream and cross sectional area of the portal vein and hepatic artery were measured before their hilar bifurcations. Blood flow was calculated by multiplying the cross-sectional area of the vessel with the velocity of the blood stream. Plasma flow (PF) was calculated by correcting blood flow (BF) for hematocrit $(\mathrm{Ht})(\mathrm{PF}=\mathrm{BF} \times(1-\mathrm{Ht}))$. Hepatic (and splanchnic) plasma flow was calculated by adding up plasma flows in the portal vein and hepatic artery. Mean blood flows were used to calculate organ fluxes.

\section{Sample preparation and liquid chromatography-mass spectrometry (LC-MS)}

Deproteinization and further preparation of the plasma samples for analysis of SCFA was done as recently reported. ${ }^{18}$ The plasma samples were deproteinized using methanol, after which the samples were centrifuged at $50.000 \mathrm{~g}$ for 10 minutes. The 
clear supernatant was transferred in a $300 \mu$ l glass micro-insert into a WISP-style vial. Analysis was performed using a liquid chromatography system combined with mass spectrometry. SCFA concentrations were determined using the external standard method by calibration curves of SCFA. The detection limits for acetate, propionate and butyrate of this method were $0.1,0.05$ and $0.05 \mu \mathrm{mol} / \mathrm{I}$ respectively. The coefficients of variance were $4.2 \%, 9.8 \%$ and $5.1 \%$ for acetate, propionate and butyrate in human venous plasma, respectively.

\section{Calculations and statistics}

Arteriovenous differences $(\triangle \mathrm{AV})$ and net organ fluxes (flow $\times \Delta \mathrm{AV}$ ) were calculated across the liver, portal drained viscera (PDV) and the splanchnic area. The corresponding AV differences were calculated as follows: $\triangle A V_{P D V}=[P V]-[A]$ and $\Delta \mathrm{AV}_{\text {splanchnic area }}=[\mathrm{HV}]-[\mathrm{A}]$. Fluxes were calculated as $\mathrm{F}_{\mathrm{PDV}}=$ portal plasma flow $*[\mathrm{PV}-\mathrm{A}]$, $F_{\text {splanchnic }}=$ splanchnic plasma flow $*[H V]-[A], F_{\text {liver }}=F_{\text {splanchnic }}-F_{\text {PDV }}$. Splanchnic plasma flow was calculated as portal flow plus hepatic artery flow. ${ }^{16}$ In these equations [PV], [A] and [HV] indicate portal venous, radial artery and hepatic venous concentrations respectively, whilst $F_{\text {splanchnic, }} F_{\text {liver, }} F_{\text {PDV }}$ denote splanchnic flux, liver flux and PDV flux, respectively. Positive fluxes indicate release, whilst negative fluxes indicate uptake. Fluxes were tested vs. zero using a one-sample t-test with a theoretical mean of zero.

A subgroup analysis was conducted to look at any potential effect of body weight. In addition, since most patients undergoing a liver resection had undergone prior large bowel resection for colon carcinoma, we investigated the effect of prior large bowel surgery. Sub-group analyses were done by using one-way ANOVA. A $P$-value of $<0.05$ was regarded to indicate statistical significance. Statistical calculations were made using Prism 4.0 for Windows (GraphPad Software Inc. San Diego, CA). Data are presented as mean (SEM).

\section{Results}

\section{General}

Twenty-two patients were included in the study. All patients but one were operated upon for malignant disease (Table 3.1). Sampling was performed in all patients according to the protocol. At the time of baseline blood sampling $(<1$ hour following laparotomy), total intraoperative blood loss was negligible. Plasma flows in the portal vein and hepatic artery were $320(42) \mathrm{ml} / \mathrm{min}$ and $110(23) \mathrm{ml} / \mathrm{min}$, respectively. Splanchnic plasma flow was calculated to be 430 (47) $\mathrm{ml} / \mathrm{min}$.

\section{Gut SCFA exchange}

Portal concentrations of acetate, propionate and butyrate were 262.8 (31.2), 30.3 (5.6) and 30.1 (4.8) $\mu \mathrm{mol} / \mathrm{l}$, respectively (Figure 3.1A and 3.1B). Arterial acetate, 
propionate and butyrate concentrations were 172.9 (19.1), 3.6 (0.4) and 7.5 (1.2) $\mu \mathrm{mol} / \mathrm{l}$, respectively. Consequently, the portal drained viscera fluxes of acetate, propionate and butyrate, which reflect gut metabolism, were 22.5 (7.2), 6.7 (1.3) and $5.7(1.0) \mu \mathrm{mol} \cdot \mathrm{kg}$ bodyweight ${ }^{-1} \cdot \mathrm{h}^{-1}$, indicating net intestinal release of these SCFA into the portal vein $(P<0.0051$, Table 3.2$)$.
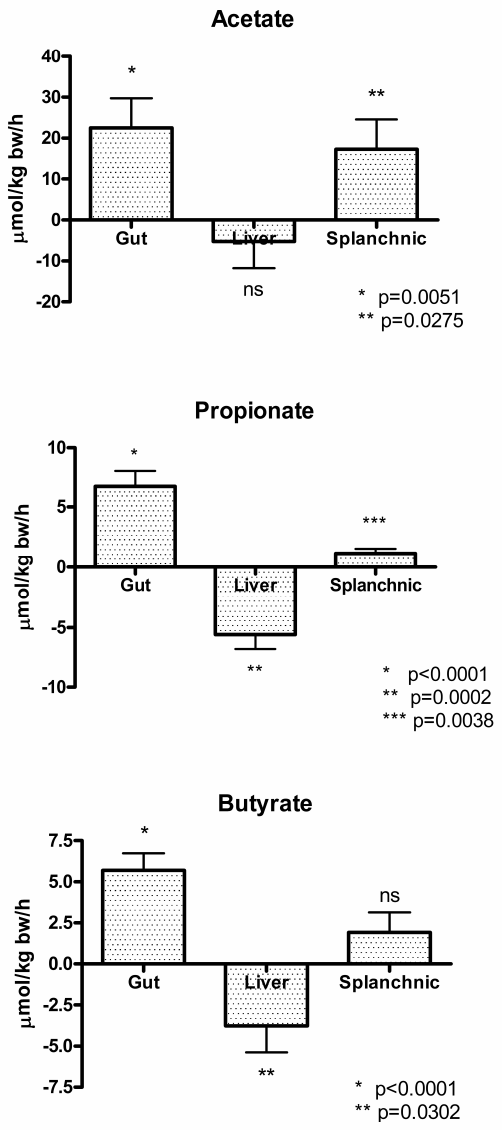

Figure 3.1 Gut, liver and splanchnic fluxes in surgical patients with normal liver function $(n=22)$. A positive flux indicates release across an organ, whereas a negative flux indicates uptake of a substrate across an organ.

\section{Hepatic SCFA exchange}

Hepatic venous concentrations of acetate, propionate and butyrate were 219.5 (22.8), 6.9 (1.2) and $12.0(2.6) \mu \mathrm{mol} / \mathrm{l}$, respectively. There was a significant uptake of propionate and butyrate by the liver: $-5.6(1.2)$ and $-3.8(1.6) \mu \mathrm{mol} \cdot \mathrm{kg}$ bodyweight ${ }^{-1} \cdot \mathrm{h}^{-1}(P=0.0002$ and $P=0.0302)$, 
respectively. Acetate was not significantly taken up by the liver; $-5.2(6.5) \mu \mathrm{mol} \cdot \mathrm{kg}$ bodyweigh $\mathrm{t}^{-1} \cdot \mathrm{h}^{-1} .(P=0.434)$. The portal acetate to propionate to butyrate ratio was 9:1:1.

Table 3.2 Arterial, portal venous and hepatic venous concentrations $(n=22)$.

\begin{tabular}{llll}
\hline & Arterial & Portal venous & Hepatic venous \\
\hline Acetate & $172.9(19.1)$ & $262.8(31.2)$ & $219.5(22.8)$ \\
Proprionate & $3.6(0.4)$ & $30.3(5.6)$ & $6.9(1.2)$ \\
Butyrate & $7.5(1.2)$ & $30.1(4.8)$ & $12.0(2.6)$ \\
\hline
\end{tabular}

Concentrations in $\mu \mathrm{mol} / \mathrm{l}$.

\section{Splanchnic SCFA exchange}

The splanchnic release of butyrate was negligible, $1.9(1.2) \mu \mathrm{mol} \cdot \mathrm{kg}$ bodyweight ${ }^{-1} \cdot \mathrm{h}^{-1}$ $(P=0.129)$. Acetate was released from the splanhnic area in significant amounts, 17.3 (7.2) $\mu \mathrm{mol} \cdot \mathrm{kg}$ bodyweight ${ }^{-1} \cdot \mathrm{h}^{-1}(P=0.027)$. Furthermore, propionate was released in a significant, but very small amount, $1.2(0.3) \mu \mathrm{mol} \cdot \mathrm{kg}$ bodyweight ${ }^{-1} \cdot \mathrm{h}^{-1}(P=0.0003)$. Thus, the liver scavenged virtually all potentially harmfull SCFA (i.e. propionate and butyrate) released by the gut, and consequently the contribution of the splanchnic area to systemic ambient propionate and butyrate concentrations was negligible.

\section{Effects of BMI and colonic resection on SCFA fluxes}

A subgroup analysis of patients with a $B M I \geq 25(n=11)$ compared with patients with a $B M I<25(n=11)$ revealed no significant differences between gut production of acetate, propionate and butyrate (Table 3.3).

Furthermore, patients with a normal colon $(n=9)$ were compared with patients with a part of their colon resected because of large bowel cancer in the past $(n=13)$. There were also no significant differences found (Table 3.3).

Table 3.3 Effects of BMI and partial colon resection on gut SCFA production

\begin{tabular}{lcccccc}
\hline & $\begin{array}{c}\mathrm{BMI}<25 \\
(\mathrm{n}=11)\end{array}$ & $\begin{array}{c}\mathrm{BMI} \geq 25 \\
(\mathrm{n}=11)\end{array}$ & $P$ & $\begin{array}{c}\text { No colon } \\
\text { resection } \\
(\mathrm{n}=9)\end{array}$ & $\begin{array}{c}\text { Partial colon } \\
\text { resection } \\
(\mathrm{n}=13)\end{array}$ & $P$ \\
\hline Acetate & $15.8(5.5)$ & $29.1(13.3)$ & 0.371 & $22.9(8.5)$ & $22.2(10.9)$ & 0.962 \\
Propionate & $5.9(1.5)$ & $7.4(2.2)$ & 0.679 & $6.0(1.7)$ & $7.2(1.9)$ & 0.675 \\
Butyrate & $4.6(0.9)$ & $6.7(1.8)$ & 0.338 & $4.4(1.1)$ & $6.5(1.5)$ & 0.334 \\
\hline
\end{tabular}

Gut fluxes are expressed as $\mu \mathrm{mol} \cdot \mathrm{kg}$ bodyweight $\mathrm{h}^{-1} \cdot \mathrm{h}^{-1}$

\section{Discussion}

The present study was undertaken to expand our knowledge on the physiology of SCFA metabolism in the splanchnic area in humans. To the best of our knowledge it is 
the first in vivo study on interorgan SCFA metabolism in humans. Short chain fatty acids (SCFA) are supposed to be beneficial for humans, especially in intestinal diseases. ${ }^{6,7,19-21}$ Traditionally, most studies have focused on the effects of SCFA on the intestinal mucosa while limited information is available on physiological systemic concentrations in humans and the interaction between splanchnic organs in SCFA metabolism. ${ }^{6,22-25}$

The present study showed that the gut is the main SCFA releasing organ and the liver is subsequently able to take up virtually all butyrate and propionate in patients with normal liver function. The model used provides insight in the physiological portal, hepatic venous and arterial concentrations in humans in vivo and combining this with blood flow measurements allows a quantitative measure of net exchange to be calculated. The present data obtained in vivo in humans extend our knowledge derived from previous human studies by others.

These studies have already yielded valuable information on SCFA metabolism. Two decades ago Cummings et al. reported interesting results from their study in sudden death individuals. ${ }^{14}$ They demonstrated that portal SCFA concentrations in these patients exceeded arterial concentrations and hepatic venous concentrations were slightly higher than arterial concentrations. The portal and hepatic venous concentrations of acetate, propionate as well as butyrate reported were higher than the concentrations found in the present study. The differences in concentrations found might be explained by the lack of blood flow in sudden death subjects compared with heart-beating subjects, which can lead to accumulation of SCFA in the portal vein in sudden death individuals. The current results corroborate in the in vivo situation the historical data of Cummings et al in deceased individuals.

Dankert et al. measured SCFA concentrations in an arm vein in healthy volunteers and compared these venous SCFA concentrations with portal SCFA concentrations in patients undergoing surgery. ${ }^{15}$ Portal concentrations of acetate and propionate in surgical patients were 114.0 (34.2) and 32.0 (21.4) $\mu \mathrm{mol} / \mathrm{l}$ respectively, which are comparable with our data. Based on their data, Dankert et al. suggested SCFA metabolism in the liver, since portal concentrations were higher than venous concentrations. However, they did not measure hepatic venous concentrations and plasma flows were not available in Dankert's or Cummings' studies. In the present study we were able to confirm the suggestion that the liver is in fact involved in SCFA metabolism, and we also were able to quantify the role of the gut and liver by measuring organ fluxes, a measure of net exchange.

Ratios of faecal acetate to propionate to butyrate concentrations in man varied between 48:29:23 and 70:15:15. ${ }^{25}$ Cummings et al. reported the portal acetate to propionate to butyrate ratio to be 58:26:16, whereas Peters et al. reported a ratio of 78:15:7. ${ }^{13,14}$ These figures are not directly comparable with our findings, because in the present study the propionate and butyrate proportion were relatively low.

The influence of fasting on SCFA production and portal release is not entirely clear. In a catheterized sheep model Bergman et al. found that acetate concentrations were significantly lower in the fasted state than in the fed state. ${ }^{26}$ This information can not 
be extrapolated entirely to our model, since the sheep were fasted for three days, whereas our patients had just an overnight fast, so the influence of fasting on SCFA concentrations in our model may be limited.

After release into the portal vein, propionate and butyrate are metabolized by the liver and used for gluconeogenesis, whereas acetate is a substrate for lipogenesis, cholesterol synthesis and is taken up by adipose and muscle tissue. ${ }^{26,27}$ There are large individual differences in intestinal SCFA fluxes, which might indicate differences in generation or utilization of SCFA by the colon. In a subgroup analysis, the influence of a partial colon resection was excluded. Patients were operated on for colorectal liver metastases and had a resection of a part of their colon for the primary tumor in the past. However, this had no effect on the portal release of SCFA.

An important consideration is the possible difference in intestinal microbiota between the patients, because microbiota and diet are determinants of SCFA generation in the colon. Peters et al. showed a rapid increase in SCFA concentrations in portal and peripheral blood within 15-45 minutes after instillation of lactulose, which indicates that the dietary content of carbohydrates, starches and fibres influence SCFA concentrations. ${ }^{13}$ Several other studies in rats and humans have shown alterations in bacterial composition after administration of fibres, yogurt, inulin and oligofructans, indicating an equilibrium between dietary intake and microbiotic composition. ${ }^{23,28}$ Since our patients were on a stable western diet, did not take prebiotics or probiotics as dietary supplements and did not receive oral antibiotics prior to surgery (except for a single dose of antibiotics intravenously at the start of surgery), they can be regarded as representative of the average population. The patients in the present study had a relatively high BMI. Although this can influence the microbiota, a high BMI does not seem to result in altered SCFA production in the intestine. ${ }^{29,30}$ In the present study, this statement was also confirmed.

\section{Conclusion}

This is the first in vivo study on interorgan short chain fatty acids exchange assessed by measuring organ fluxes across the gut and liver in humans. The gut is the main net SCFA releasing organ but no intestinal produced butyrate and propionate escapes the splanchnic area because of highly efficient hepatic uptake. Since the liver appears to prohibit escape of gut-derived butyrate and propionate into the systemic circulation, this may indicate that SCFA or prebiotics can be safely delivered into the gut on a therapeutic basis. In the future, additional information about the SCFA exchange in non-physiological situations (e.g. liver failure) and the influence of prebiotic supplementation on systemic SCFA concentrations is required to further improve our understanding of the interorgan exchange of SCFA. 


\section{References}

1. Macfarlane S, Macfarlane GT, Cummings JH. Review article: prebiotics in the gastrointestinal tract. Aliment Pharmacol Ther 2006;24:701-14.

2. Topping DL, Clifton PM. Short-chain fatty acids and human colonic function: roles of resistant starch and nonstarch polysaccharides. Physiol Rev 2001;81:1031-64.

3. Knudsen, K.E.B., Effect of dietary non-digestible carbohydrates on the rate of SCFA delivery to peripheral tissues. Foods Food Ingredients Journal of Japan 2005;210:1008-17.

4. Cook SI, Sellin JH. Review article: short chain fatty acids in health and disease. Aliment Pharmacol Ther 1998;12:499-507.

5. Kristensen NB, Harmon DL. Effect of increasing ruminal butyrate absorption on splanchnic metabolism of volatile fatty acids absorbed from the washed reticulorumen of steers. J Anim Sci, 2004;82:3549-59.

6. Wachtershauser A, Stein J. Rationale for the luminal provision of butyrate in intestinal diseases. Eur J Nutr 2000;39:164-71.

7. Welters CF, Heineman E, Thunnissen FB, van den Bogaard AE, Soeters PB, Baeten CG. Effect of dietary inulin supplementation on inflammation of pouch mucosa in patients with an ileal pouch-anal anastomosis. Dis Colon Rectum 2002;45:621-7.

8. Welters $\mathrm{CF}$, Deutz NE, Dejong $\mathrm{CH}$, Soeters PB, Heineman E. Supplementation of enteral nutrition with butyrate leads to increased portal efflux of amino acids in growing pigs with short bowel syndrome. J Pediatr Surg 1996;31:526-9.

9. Finney M, Smullen J, Foster HA, Brokx S, Storey DM. Effects of low doses of lactitol on faecal microflora, pH, short chain fatty acids and gastrointestinal symptomology. Eur J Nutr 2007;46:307-14.

10. Tedelind S, Westberg F, Kjerrulf M, Vidal A. Anti-inflammatory properties of the short-chain fatty acids acetate and propionate: a study with relevance to inflammatory bowel disease. World J Gastroenterol 2007;13:2826-32.

11. Manns JG, Boda JM. Insulin release by acetate, propionate, butyrate, and glucose in lambs and adult sheep. Am J Physiol 1967;212:747-55.

12. Feliz B, Witt DR, Harris BT. Propionic acidemia: a neuropathology case report and review of prior cases. Arch Pathol Lab Med 2003;127:e325-8.

13. Peters SG, Pomare EW, Fisher CA. Portal and peripheral blood short chain fatty acid concentrations after caecal lactulose instillation at surgery. Gut 1992;33:1249-52.

14. Cummings JH, Pomare EW, Branch WJ, Naylor CP, Macfarlane GT. Short chain fatty acids in human large intestine, portal, hepatic and venous blood. Gut 1987;28:1221-7.

15. Dankert J, Zijlstra JB, Wolthers BG. Volatile fatty acids in human peripheral and portal blood: quantitative determination vacuum distillation and gas chromatography. Clin Chim Acta 1981;110: 301-7.

16. van de Poll MC, Siroen MP, van Leeuwen PA, Soeters PB, Melis GC, Boelens PG, Deutz NE, Dejong CH. Interorgan amino acid exchange in humans: consequences for arginine and citrulline metabolism. Am J Clin Nutr 2007;85:167-72.

17. Siroen MP, van der Sijp JR, Teerlink T, van Schaik C, Nijveldt RJ, van Leeuwen PA. The human liver clears both asymmetric and symmetric dimethylarginine. Hepatology 2005;41:559-65.

18. van Eijk HM, Bloemen JG, Dejong $\mathrm{CH}$. Application of liquid chromatography-mass spectrometry to measure short chain fatty acids in blood. J Chromatogr B Analyt Technol Biomed Life Sci 2009;877: 719-24.

19. Cummings JH, Macfarlane GT, Englyst HN. Prebiotic digestion and fermentation. Am J Clin Nutr 2001; 73(2 Suppl):415S-20S

20. Scheppach W, Christl SU, Bartram HP, Richter F, Kasper H. Effects of short-chain fatty acids on the inflamed colonic mucosa. Scand J Gastroenterol Suppl 1997;222:53-7.

21. Kiely EM, Ajayi NA, Wheeler RA, Malone M. Diversion procto-colitis: response to treatment with short-chain fatty acids. J Pediatr Surg 2001;36:1514-7. 
22. Kles KA, Chang EB. Short-chain fatty acids impact on intestinal adaptation, inflammation, carcinoma, and failure. Gastroenterology 2006;130(2 Suppl 1):S100-5.

23. Kleessen B, Hartmann L, Blaut M. Oligofructose and long-chain inulin: influence on the gut microbial ecology of rats associated with a human faecal flora. Br J Nutr 2001;86:291-300.

24. Fitch MD, Fleming SE. Metabolism of short-chain fatty acids by rat colonic mucosa in vivo. Am J Physiol 1999;277(1 Pt 1):G31-40.

25. Hamer HM, Jonkers D, Venema K, Vanhoutvin S, Troost FJ, Brummer RJ. Review article: the role of butyrate on colonic function. Aliment Pharmacol Ther 2008;27:104-19.

26. Bergman EN, Wolff JE. Metabolism of volatile fatty acids by liver and portal-drained viscera in sheep. Am J Physiol 1971;221:586-92.

27. Wong JM, de Souza R, Kendall CW, Emam A, Jenkins DJ. Colonic health: fermentation and short chain fatty acids. J Clin Gastroenterol 2006; 40:235-43.

28. Alvaro E, Andrieux C, Rochet V, Rigottier-Gois L, Lepercq P, Sutren M, Galan P, Duval Y, Juste C, Doré J. Composition and metabolism of the intestinal microbiota in consumers and non-consumers of yogurt. Br J Nutr 2007;97:126-33.

29. Wolever TM, Josse RG, Leiter LA, Chiasson JL. Time of day and glucose tolerance status affect serum short-chain fatty acid concentrations in humans. Metabolism 1997;46:805-11.

30. O'Keefe SJ. Nutrition and colonic health: the critical role of the microbiota. Curr Opin Gastroenterol, 2008;24:51-58. 



\section{Chapter 4}

Short chain fatty acid exchange: is the cirrhotic, dysfunctional liver still able to clear them?

JG Bloemen, SWM Olde Damink, K Venema, WA Buurman, R Jalan, CHC Dejong Clin Nutr 2010;29:365-69 


\section{Abstract}

\section{Background and aim}

Prebiotics are increasingly used to improve gut integrity. A presumed mechanism of their beneficial action is the synthesis of short chain fatty acids (SCFA: acetate, propionate and butyrate). High systemic concentrations of propionate and butyrate are toxic and can adversely affect the patient. In physiological situations the liver uses propionate and butyrate for energy metabolism. The aim of the present study was to investigate to which extent patients with liver cirrhosis are still able to metabolize portal derived SCFA in the liver.

\section{Methods}

Twelve patients with liver cirrhosis and intrahepatic portosystemic shunt (TIPSS) were studied. Blood was sampled from the femoral artery, portal and hepatic vein. Organ plasma flow was measured. Net release or uptake was calculated by multiplying the arteriovenous differences by plasma flow. SCFA plasma concentrations were measured using LC-MS.

\section{Results}

Arterial concentrations were $124 \pm 12,8 \pm 1$ and $10 \pm 1 \mu \mathrm{mol} / \mathrm{l}$ for acetate, propionate and butyrate, respectively. The gut produced $542 \pm 235,80 \pm 22$ and $102 \pm 36 \mu \mathrm{mol} \cdot \mathrm{kg} \mathrm{bw}^{-1} \cdot \mathrm{min}^{-1}$ of acetate, propionate and butyrate, respectively. Assuming $70 \%$ portosystemic shunting, hepatic uptake of propionate and butyrate was $52 \pm 10$ and $87 \pm 22 \mu \mathrm{mol} \cdot \mathrm{kg} \mathrm{bw}^{-1} \cdot \mathrm{min}^{-1}$. Hepatic uptake of acetate was non-significant $\left(202 \pm 168 \mu \mathrm{mol} \cdot \mathrm{kg} \mathrm{bw}^{-1} \cdot \mathrm{min}^{-1}\right)$. As a consequence of shunting, part of total acetate escaped from the splanchnic bed, which equalled $581 \pm 221 \mu \mathrm{mol} \cdot \mathrm{kg} \mathrm{bw}^{-1} \cdot \mathrm{min}^{-1}$.

\section{Conclusion}

The liver of patients with stable cirrhosis is able to take up butyrate and propionate, most likely preventing increased systemic concentrations. This suggests that prebiotics can be administered safely, but monitoring butyrate levels may be advisable in patients with diminished liver function. 


\section{Introduction}

Prebiotics, such as plant cell wall material, constitute an important source for substrates that alter gut microbiota and microbial metabolism. Humans lack enzymes to break down undigestible carbohydrates and therefore prebiotics pass the upper gastro-intestinal tract relatively unaffected. ${ }^{1,2}$ Colonic bacteria ferment these products to short chain fatty acids (SCFA, notably acetate, propionate and butyrate). ${ }^{3-5}$ Supplementing diets with prebiotics (e.g. inulin) to improve intestinal health has become increasingly popular since these products are commercially available without a prescription. Although several beneficial effects of prebiotics are proven, the exact mechanisms of action remain largely unknown. ${ }^{6,7}$

Following their production, SCFA are absorbed by colonic epithelium and are metabolized at three major sites: the colonic epithelium, the liver and peripheral muscle tissue. ${ }^{8}$ SCFA are oxidized and used as an energy source by colonic epithelial cells, with butyrate as preferred substrate. Acetate, propionate and the remainder of butyrate are transported to the liver. Here, propionate serves as a substrate for gluconeogenesis and may inhibit cholesterol synthesis, whereas acetate is utilized as a substrate for the synthesis of long chain fatty acids, glutamine, glutamate and betahydroxybutyrate. ${ }^{9}$ Butyrate is oxidized directly by the hepatocytes preventing high, toxic systemic concentrations. ${ }^{10,11}$

Our group recently showed that the liver of patients undergoing major upper abdominal surgery and having normal liver function, is capable of scavenging all SCFA released by the gut. ${ }^{12}$ The aim of the present study was to investigate to which extent patients with cirrhosis of the liver are still able to metabolize portal derived short chain fatty acids by the liver.

\section{Methods}

\section{Patients}

The study was performed in the Royal Infirmary of Edinburgh (UK). Metabolically stable patients with biopsy proven cirrhosis of the liver, who had previously received a transjugular intrahepatic portosystemic shunt (TIPSS) for the treatment of complications of liver cirrhosis and who subsequently underwent routine portography to check TIPSS patency were studied (Table 4.1). Exclusion criteria were severe ascites, pitting peripheral oedema, hepatic encephalopathy, recent upper gastro-intestinal bleeding ( $<14$ days), diabetes, portocaval pressure gradient $>12 \mathrm{mmHg}$, clinically evident cardiovascular disease, renal dysfunction, active alcohol consumption, malignancy and pregnancy. Patients did not use lactulose, diuretics or antibiotics. The local ethics committee approved the study and written informed consent was obtained from all patients. Severity of liver disease was assessed by the Child-Pugh 
scoring system. Data on amino acids and ammonia metabolism in these patients have been published previously by our group. ${ }^{13}$

\section{Protocol}

The study was conducted after an overnight fast. Portography was performed under analgesia (pethidine, $1 \mathrm{mg} / \mathrm{kg}$ bodyweight) and conscious sedation (midazolam, $0.1 \mathrm{mg} / \mathrm{kg}$ bodyweight). Organ plasma flow was measured as described previously. ${ }^{13}$ Blood samples were taken selectively from a hepatic vein not containing the TIPSS, the femoral artery and the portal vein. Samples were immediately put on ice.

\section{Sample preparation and liquid chromatography-mass spectrometry (LC-MS)}

Analysis of SCFA concentrations in plasma was performed as described recently. ${ }^{14}$ In short, plasma samples were deproteinized by adding $100 \mu$ methanol to $50 \mu$ l plasma aliquots. After the aliquots were centrifuged, the clear supernatant was transferred to a WISP-style vial (Waters, Etten-Leur, the Netherlands) and closed with a PTFE selfsealing seal. Subsequently, it was injected in a liquid chromatography system combined with mass spectrometry (Thermo Electron, Breda, the Netherlands). SCFA concentrations were determined using the external standard method by calibration curves of SCFA. The coefficients of variance were $4.2 \%, 9.8 \%$ and $5.1 \%$ for acetate, propionate and butyrate in human venous plasma, respectively. The lower limits of detection were $0.1,0.05$ and $0.05 \mu \mathrm{mol} / \mathrm{l}$ for acetate, propionate and butyrate, respectively.

\section{Calculations}

Plasma flows ( $\mathrm{ml} / \mathrm{kg}$ bodyweight/min) across the portal vein and liver were calculated using formulae based on the method of indicator dilution and Fick's principle. ${ }^{13}$ Substrate fluxes ( $\mu \mathrm{mol} / \mathrm{kg}$ bodyweight/min) across organs were calculated as the venous-arterial (V-A) concentration difference times plasma flow. To calculate substrate fluxes across the liver we used upper and lower bounds of liver fluxes using estimated portal-systemic shunting percentages of $70 \%$ and $90 \%$, respectively. These assumptions were used since in the present study, we were unable to determine the fraction of shunting through the TIPSS, which has been estimated to be approximately $90 \% .^{15}$.

1) Gut flux = portal plasma flow * (portal - arterial plasma concentration)

2) assuming $90 \%$ portal-systemic shunting: Liver flux $=$ (liver plasma flow $*$ hepatic venous concentration) - [(liver plasma flow $-0.1 *$ portal plasma flow) ${ }^{*}$ arterial concentration $)+(0.1 *$ portal plasma flow $) *$ portal venous concentration $)]$

3) assuming 70\% portal-systemic shunting: Liver flux $=$ (liver plasma flow ${ }^{*}$ hepatic venous concentration) - [(liver plasma flow $-0.3 *$ portal plasma flow) ${ }^{*}$ arterial concentration $)+(0.3 *$ portal plasma flow $) *$ portal venous concentration $)$ ] 
4) assuming 90\% portal-systemic shunting: Splanchnic flux $=90 \%$ liver flux (2)+ gut flux

5) assuming 70\% portal-systemic shunting: Splanchnic flux $=70 \%$ liver flux (3)+ gut flux

\section{Statistics}

Results are presented as means (SEM). Correlations between arterial concentrations and fluxes were calculated with Pearson's correlation coefficients. Student's t-test was used to test if fluxes were statistically different from zero. P-values lower than 0.05 were considered statistically significant. For statistical analysis SPSS version 15.0 for Windows (2006, SPSS Inc. Chicago, USA) was used.

\section{Results}

\section{General}

Twelve patients were included in the study. All patients had patent TIPSS, placed on average $25.0( \pm 3.5)$ months before, for treatment of variceal bleeding (Table 4.1). During the experiment, there were no unwanted side effects. The mean plasma flows of the group were: portal flow $723( \pm 100) \mathrm{ml} / \mathrm{min}$ and liver flow $609( \pm 95) \mathrm{ml} / \mathrm{min}$. These flows are comparable with literature data. ${ }^{16-18}$

Table 4.1 Baseline characteristics.

\begin{tabular}{ll}
\hline Male/Female & $10 / 2$ \\
Age (years) & $52.7(38-73)$ \\
Weight $(\mathrm{kg})$ & $84.9(40-110)$ \\
BMI $\left(\mathrm{kg} / \mathrm{m}^{2}\right)$ & $29.8(25.4-38.3)$ \\
Child Pugh score & \\
A & 8 \\
B & 2 \\
C & 2 \\
\hline
\end{tabular}

\section{Gut SCFA exchange}

To calculate the production of SCFA by the gut, the arterial and portal venous concentrations were measured. Arterial concentrations of acetate, propionate and butyrate were $124.5(12.5), 8.2(0.9)$ and $10.1(1.8) \mu \mathrm{mol} / \mathrm{l}$, respectively (Table 4.2) while higher portal venous SCFA concentrations were measured: 177.5 (21.1), 15.6 (2.4) and 19.5 (4.3) $\mu \mathrm{mol} / \mathrm{l}$ for acetate, propionate and butyrate, respectively. Since the portal concentrations exceeded the arterial concentrations, there was net production of SCFA by the gut. The corresponding fluxes were 542.0 (235.6), 80.0 
(22.6) and $102.7(36.2) \mu \mathrm{mol} \cdot \mathrm{kg} \mathrm{bw}^{-1} \cdot \mathrm{min}^{-1}$ for acetate, propionate and butyrate, respectively (Figure 4.1 and 4.2 ).

A.

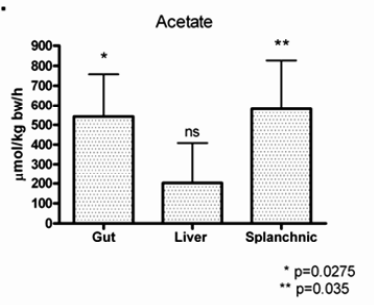

C

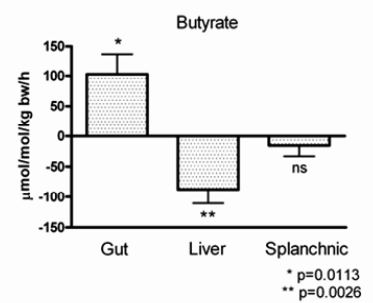

B

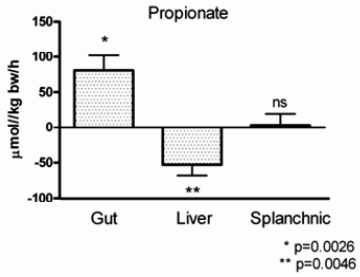

Figure 4.1 Organ fluxes across une gut, ıver driu spianicinic drea of A) acetate, B) propionate and C) butyrate with the assumption of $70 \%$ shunting through the transjugular intrahepatic portosystemic shunt (TIPSS). * statistically different from zero, which means net release in case of a positive flux and net uptake in case of a negative flux. NS: non significantly different from zero.

A.

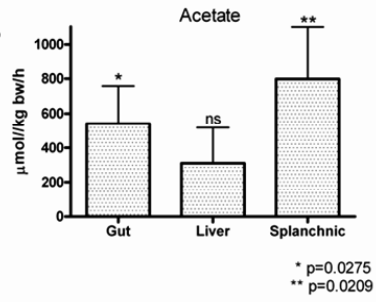

B

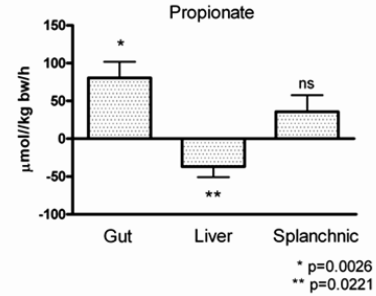

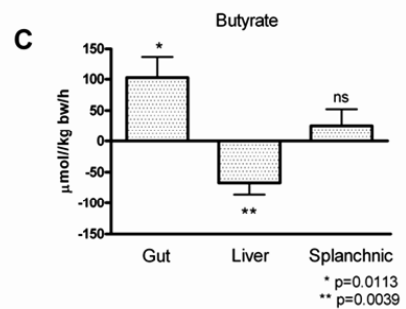

Figure 4.2 Organ fluxes across the gut, liver and splanchnic area of A) acetate, B) propionate and C) butyrate with the assumption of $90 \%$ shunting through the transjugular intrahepatic portosystemic shunt (TIPSS). * flux is statistically different from zero, which means net release in case of a positive flux and net uptake in case of a negative flux. NS: non significantly different from zero. 
Table 4.2 Short chain fatty acids concentrations $(\mu \mathrm{mol} / \mathrm{l})$.

\begin{tabular}{lccc}
\hline & Arterial & Portal vein & Hepatic vein \\
\hline Acetate & $124.5(12.5)$ & $177.5(21.1)$ & $157.3(21.5)$ \\
Propionate & $8.2(0.9)$ & $15.6(2.4)$ & $5.6(1.3)$ \\
Butyrate & $10.1(1.8)$ & $19.5(4.3)$ & $4.8(1.0)$ \\
\hline
\end{tabular}

\section{Liver SCFA exchange}

To calculate the flux of SCFA across the liver the arterial, portal venous and hepatic venous concentrations were measured. Hepatic venous concentrations were 157.3 (21.5), 5.6 (1.3) en 4.8 (1.0) $\mu \mathrm{mol} / \mathrm{l}$ for acetate, propionate and butyrate respectively. Acetate was released by the liver in both the $70 \%$ shunting (Figure $4.1 \mathrm{~A}, P=0.346$ ) and $90 \%$ shunting estimate (Figure 4.2A, $P=0.159$ ), whereas propionate and butyrate were taken up by the liver at both shunting estimates (Figure $4.1 \mathrm{~B}, 4.1 \mathrm{C}$ and $4.2 \mathrm{~B}, 4.2 \mathrm{C}$, $P<0.02)$.

Hepatic uptake of butyrate was strongly correlated with arterial butyrate concentrations $\left(r^{2}=0.78, P=0.002\right)$, while hepatic uptake of propionate and arterial propionate concentration were not $\left(r^{2}=0.42, P=0.150\right)$.

\section{Splanchnic SCFA exchange}

Since propionate and butyrate were taken up by the liver in significant amounts and equaled gut release, the amount released by the splanchnic area did not differ significantly from zero (Figure $4.1 \mathrm{~B}$ en $4.1 \mathrm{C}$ and Figure $4.2 \mathrm{~B}$ en $4.2 \mathrm{C}, P>0.129$ ). There was however significant splanchnic acetate release, at both $70 \%$ and $90 \%$ shunting estimates (Figure 4.1A and 4.2A, $P<0.035$ ).

\section{Discussion}

The results of the present study show that in patients with stable liver cirrhosis the gut produced significant amounts of acetate, propionate and butyrate after an overnight fast. The liver of patients with stable cirrhosis was able to take up butyrate and propionate, which prevented a rise of systemic concentrations. Acetate was not taken up by the liver, causing a net release from the splanchnic area. Furthermore, hepatic uptake of butyrate was strongly correlated with its arterial concentration. This implies that the liver played a key role in regulating the arterial concentrations of propionate and butyrate, in agreement with our recent findings in patients with normal liver function. ${ }^{19}$

Knowledge of interorgan metabolism of short chain fatty acids (SCFA) is important to understand the basic physiology of SCFA handling in humans, since prebiotic supplementation is increasingly used in Western diets. The presumed beneficial action of these prebiotics is thought to be mediated through synthesis of SCFA. To the best 
of our knowledge, this study showed for the first time in humans in vivo, that the cirrhotic liver was capable of using butyrate and propionate, which are the SCFA that are toxic in high systemic concentrations. ${ }^{10,11}$ Literature provides information about interorgan SCFA handling in sudden death individuals and from animal studies. ${ }^{20,21}$ Furthermore, several studies reported the kinetic aspects of acetate metabolism ${ }^{22-25}$, but the role of the liver is not specifically addressed in these studies. The present study used the unique situation of checking a portocaval shunt in humans as a model to study the role of the dysfunctional liver in SCFA handling.

Together with data from our previous study in patients with normal liver function, the current data give new insight in the large capacity of the liver to metabolize SCFA released from the gut. The arterial, portal venous and hepatic venous concentrations of propionate and butyrate are in keeping with values reported in literature, but the respective concentrations of acetate are higher than previously reported. ${ }^{6,26,27}$ Acetate in the systemic circulation has two major origins; an exogenous pool from colonic bacterial fermentation and an endogenous pool from other tissues and organs able to release acetate into the bloodstream. ${ }^{28,29}$ There could be more release from the gut as a result of the presence of more substrate in the colon for fermentation. Equally, there could be a larger endogenous pool, because of less acetate usage by peripheral tissues. As a consequence the systemic concentration may have increased. In the present study, acetate was not taken up by the liver and was released from the splanchnic area. The major sites of acetate uptake and release in humans are still unknown, but whole body oxidation of acetate has been suggested to account for up to $10-15 \%$ of energy expenditure. ${ }^{22,25}$ In the liver, acetate is partially retained and converted to acetoacetate, long chain fatty acids and glutamate. In the presence of ethanol less acetate is oxidized by the hepatocytes, while the majority is transported to peripheral tissues for oxidation. ${ }^{30}$ It can be hypothesized from the present data that the dysfunctional liver may be unable to convert acetate to acetoacetate and acetate is released in the systemic circulation.

We observed only minor differences between plasma concentrations in the present study and the recently published study by our group. ${ }^{12}$ The portal venous concentrations were almost two-fold lower in patients with stable liver cirrhosis as compared to subjects with normal liver function. This may imply decreased fermentation or less efficient uptake of SCFA by colonic mucosa in cirrhosis. Previously, Onori et al. showed impaired butyrate uptake by rectal mucosa in patients with stable cirrhosis of the liver ${ }^{31}$, which may explain the decreased portal venous concentrations of SCFA in the present study. Furthermore, arterial concentrations of propionate and butyrate were slightly higher in the present study, most likely due to portosystemic shunting. Hepatic venous concentrations were lower for propionate and butyrate in the patients with stable liver cirrhosis, which emphasizes once more that even the cirrhotic liver is able to scavenge SCFA.

In the liver acetate and butyrate are metabolized to acetyl-coA which enters the tricarboxylic acid (TCA) cycle and subsequently generates ATP and NADH. Propionate has an odd number of carbon atoms (C3) and therefore the terminal oxidation 
product is propionyl-CoA which is converted to succinyl-CoA and eventually glucose is generated. Patients with liver cirrhosis have a diminished liver glycogen storage capacity and more meals during the day are required to ensure glucose homeostasis. Future studies are required to investigate the potential beneficial effects of prebiotic supplementation to increase portal SCFA concentrations for energy expenditure.

It is important to note the lack of information about the exact fraction of shunting via the TIPSS in each patient, which could not be measured directly in this protocol. Walser et al. reported shunting fractions between 84 and $100 \%$ through the TIPSS. $^{15}$ In the present study the fluxes were calculated using two shunting estimates; 70 and $90 \%$. While the liver and splanchnic quantitative fluxes differed a little between both assumptions, the conclusions are similar.

The unknown colonic microbial composition of the patients is a limitation of the study, since this may lead to different amounts of SCFA release. However, the patients used a standard Western diet, had similar SCFA generation by the gut and did not use lactulose or antibiotics prior to the study, and we therefore assumed that the baseline composition was similar.

\section{Conclusion}

The present data show that the liver of patients with stable cirrhosis is able to take up butyrate and propionate, similar to the situation in healthy individuals. Furthermore, hepatic uptake of butyrate is correlated with arterial butyrate concentrations. This indicates a large capacity of the liver to take up butyrate, also evidenced by a low hepatic venous concentration. These findings add valuable information to the existing knowledge about the physiology of SCFA handling in humans and might be of importance for safe administration of prebiotics, particularly in patients with a dysfunctional liver. Monitoring butyrate plasma levels may be advisable during prebiotic treatment. 


\section{References}

1. Finney M, Smullen J, Foster HA, Brokx S, Storey DM. Effects of low doses of lactitol on faecal microflora, pH, short chain fatty acids and gastrointestinal symptomology. Eur J Nutr. 2007;46:307-14.

2. Cummings JH. Short chain fatty acids in the human colon. Gut 1981;22:763-79.

3. Topping DL, Clifton PM. Short-chain fatty acids and human colonic function: roles of resistant starch and nonstarch polysaccharides. Physiol Rev 2001;81:1031-64.

4. Cummings JH, Macfarlane GT, Englyst HN. Prebiotic digestion and fermentation. Am J Clin Nutr 2001; 73(2 Suppl):415S-420S.

5. Fleming SE, Fitch MD, Chansler MW. High-fiber diets: influence on characteristics of cecal digesta including short-chain fatty acid concentrations and pH. Am J Clin Nutr 1989;50:93-9.

6. Bach Knudsen KE, Serena A, Canibe N, Juntunen KS. New insight into butyrate metabolism. Proc Nutr Soc 2003;62:81-6.

7. Wachtershauser A, Stein J. Rationale for the luminal provision of butyrate in intestinal diseases. Eur J Nutr 2000;39:164-71.

8. Wong JM, de Souza R, Kendall CW, Emam A, Jenkins DJ. Colonic health: fermentation and short chain fatty acids. J Clin Gastroenterol 2006;40:235-43.

9. Cook SI, Sellin JH. Review article: short chain fatty acids in health and disease. Aliment Pharmacol Ther 1998;12:499-507.

10. Manns JG, Boda JM. Insulin release by acetate, propionate, butyrate, and glucose in lambs and adult sheep. Am J Physiol 1967;212:747-55.

11. Feliz B, Witt DR, Harris BT. Propionic acidemia: a neuropathology case report and review of prior cases. Arch Pathol Lab Med 2003;127:e325-8.

12. Bloemen JG, Venema K, van de Poll MC, Olde Damink SW, Buurman WA, Dejong CH. Short chain fatty acids exchange across the gut and liver in humans measured at surgery. Clin Nutr 2009;28:657-61.

13. Olde Damink SW, Jalan R, Redhead DN, Hayes PC, Deutz NEP, Soeters PB. Interorgan ammonia and amino acid metabolism in metabolically stable patients with cirrhosis and a TIPSS. Hepatology 2002; 36:1163-71.

14. van Eijk HM, Bloemen JG, Dejong $\mathrm{CH}$. Application of liquid chromatography-mass spectrometry to measure short chain fatty acids in blood. J Chromatogr B Analyt Technol Biomed Life Sci 2009;877: 719-24.

15. Walser EM, Harris VM, Harman JT, Park HM, Siddiqui AR. Quantification of intrahepatic portosystemic shunting after placement of a transjugular intrahepatic portosystemic shunt. J Vasc Interv Radiol 1996;7:263-7.

16. Burkart DJ, Johnson CD, Ehman RL. Correlation of arterial and venous blood flow in the mesenteric system based on MR findings. 1993 ARRS Executive Council Award. AJR Am J Roentgenol 1993;161: 1279-82.

17. Clemmesen JO, Kondrup J, Ott P. Splanchnic and leg exchange of amino acids and ammonia in acute liver failure. Gastroenterology 2000;118:1131-9.

18. Jalan R, Forrest EH, Redhead DN, Dillon JF, Hayes PC. Reduction in renal blood flow following acute increase in the portal pressure: evidence for the existence of a hepatorenal reflex in man? Gut 1997; 40:664-70.

19. Bloemen JG, Venema K, van de Poll MC, Olde Damink SW, Buurman WA, Dejong CH. Short chain fatty acids exchange across the gut and liver in humans measured at surgery. Clin Nutr. 2009;28:657-61

20. Cummings JH, Pomare EW, Branch WJ, Naylor CP, Macfarlane GT. Short chain fatty acids in human large intestine, portal, hepatic and venous blood. Gut 1987;28:1221-7.

21. Kristensen, N.B. and D.L. Harmon, Effect of increasing ruminal butyrate absorption on splanchnic metabolism of volatile fatty acids absorbed from the washed reticulorumen of steers. J Anim Sci, 2004;82:3549-59.

22. Pouteau E, Piloquet $H$, Maugeais $P$, Champ $M$, Dumon $H$, Nguyen $P$, Krempf $M$. Kinetic aspects of acetate metabolism in healthy humans using [1-13C] acetate. Am J Physiol 1996;271:E58-64. 
23. Skutches $\mathrm{CL}$, Holroyde $\mathrm{CP}$, Myers RN, Paul P, Reichard GA. Plasma acetate turnover and oxidation. J Clin Invest 1979;64:708-13.

24. van Hall G, Sacchetti M, Radegran G. Whole body and leg acetate kinetics at rest, during exercise and recovery in humans. J Physiol 2002;542:263-72.

25. Mittendorfer B, Sidossis LS, Walser E, Chinkes DL, Wolfe RR. Regional acetate kinetics and oxidation in human volunteers. Am J Physiol 1998;274:E978-83.

26. Dankert J, Zijlstra JB, Wolthers BG. Volatile fatty acids in human peripheral and portal blood: quantitative determination vacuum distillation and gas chromatography. Clin Chim Acta 1981;110: 301-7.

27. Peters SG, Pomare EW, Fisher CA. Portal and peripheral blood short chain fatty acid concentrations after caecal lactulose instillation at surgery. Gut 1992;33:1249-52.

28. Knowles SE, Jarrett IG, Filsell $\mathrm{OH}$, Ballard FJ. Production and utilization of acetate in mammals. Biochem J 1974;142:401-11.

29. Ballard FJ. Supply and utilization of acetate in mammals. Am J Clin Nutr 1972;25:773-9.

30. Knudsen CT, Quistorff B, Grunnet N. Ethanol inhibits acetate metabolism in rat hepatocytes. Pharmacol Toxicol 1995;76:133-5.

31. Onori L, Pimpo MT, Palumbo GC, Gili L, Marchetti G, Saltarelli P, Aggio A, Frieri G. N-Butyrate rectal transport in cirrhotic patients. Dig Dis Sci 2001;46:2084-8. 



\section{Chapter 5}

Effects of liver resection on hepatic short chain fatty acids

handling in humans

JG Bloemen*, JR van der Vorst*, MA van den Broek, K Venema,

WA Buurman, CHC Dejong

* these authors share first authorship

Submitted 


\section{Abstract}

\section{Background and aim}

Short chain fatty acids (SCFA: acetate, propionate, butyrate) are produced in the colon by bacterial fermentation. They play an important role in maintaining colonic epithelium integrity. SCFA are partially released in the portal vein and subsequently cleared by the liver. Since high systemic concentrations are toxic, information about clearance is important before therapeutic supplementation can be considered. Aim of the present study was to determine whether patients with an acute loss of liver function are still able to metabolize SCFA.

\section{Methods}

Thirty patients undergoing liver surgery were included. Blood was sampled from the radial artery, portal and hepatic veins before and after hepatic resection. Plasma SCFA levels were measured on a liquid-chromatography/mass-spectrometry system. Fluxes were calculated across the gut and liver. Functional remnant liver volume was estimated by CT liver volumetry. Differences between pre- and post-resection SCFA concentrations and fluxes were assessed.

\section{Results}

The gut produced significant amounts of acetate, propionate and butyrate, $37.5 \pm 12.7,6.2 \pm 1.3$ and $9.7 \pm 2.6 \mu \mathrm{mol} \cdot \mathrm{kgbw}^{-1} \cdot \mathrm{h}^{-1}$ and this did not significantly change after partial hepatectomy $(P>0.244)$. Hepatic uptake of propionate and butyrate was $6.3 \pm 1.2$ and $9.6 \pm 2.4$ before and $5.9 \pm 1.7$ and $9.2 \pm 2.4 \mu \mathrm{mol} \cdot \mathrm{kgbw}^{-1} \cdot \mathrm{h}^{-1}$ respectively, after partial hepatectomy $(P>0.05)$. Acetate uptake by the liver was non-significant. Arterial concentrations of SCFA did not differ significantly before and after partial hepatectomy $(P=0.733)$.

\section{Conclusion}

No differences between systemic SCFA concentrations and hepatic uptake before and after partial hepatectomy were found. These findings implicate that the liver has an extensive capacity to clear butyrate and propionate from the portal blood. 


\section{Introduction}

Short chain fatty acids (SCFA, i.e. acetate, propionate and butyrate) constitute the main products of bacterial fermentation of indigestible carbohydrates in the human colon. ${ }^{1}$ Once produced, SCFA are mainly metabolized by colonocytes, but approximately $5 \%$ is taken up from the gut and released in the portal vein. ${ }^{2}$ Acetate and butyrate are metabolized to acetyl-coA in the liver and enter the tricarboxylic acid (TCA) cycle to generate ATP and NADH. Propionate is the main precursor for gluconeogenesis.

There is growing interest in functional foods that affect the composition of gut microbiota and subsequently the generation of SCFA. ${ }^{3}$ There is now a good body of evidence that SCFA improve intestinal wound healing, enhance epithelial proliferation and differentiation and improve absorptive function. ${ }^{4,5}$ In this context, SCFA supplementation has been investigated in clinical settings including ulcerative colitis, diversion colitis and short bowel syndrome. ${ }^{6,7}$

In previous studies, our group has elucidated part of the interorgan metabolism of SCFA in humans in vivo. ${ }^{8}$ This is important knowledge since high systemic concentrations of especially propionate and butyrate are toxic. ${ }^{9,10}$ In that context, intestinal supplementation of SCFA would require knowledge of whether such supplementation is safe, i.e. whether the SCFA do not escape clearance by the liver. First, the role of the gut and liver was investigated in patients undergoing major upper abdominal surgery. It was shown that SCFA, notably butyrate and propionate, are produced by the gut and taken up by the liver in these patients. In a study examining the SCFA metabolism in patients with reduced liver function it was demonstrated that even patients with a cirrhotic liver were still able to clear SCFA efficiently and thereby prevent increased systemic concentrations of propionate and butyrate. ${ }^{11} \mathrm{~A}$ potential drawback of this study was the possible occurrence of shunting of blood from the portal system to the systemic circulation in patients with a cirrhotic liver. This makes exact quantification of the role of the liver difficult, particularly in a situation of potentially diminished liver function.

We therefore decided to study SCFA metabolism in a controlled situation of acute loss of liver function, namely surgical removal of major parts of the liver. The primary aim of the current study was to investigate the exchange of SCFA across the gut and liver and systemic concentrations of propionate and butyrate in patients undergoing liver resection and to obtain information about any potential excess capacity of the liver to clear SCFA.

\section{Patients and Methods}

The study was approved by the Local Medical Ethics Committee of Maastricht University Medical Center and was performed in accordance with the ethical standards of the Helsinki Declaration of 1975. A total of 30 patients planned to 
undergo liver resection as treatment of benign or malignant tumors were included. All patients provided informed consent. Patients with known parenchymal liver disease, inborn errors of metabolism and use of antibiotics prior to the operation were excluded from the study. All patients were on a stable, Western diet and did not receive antibiotics in a period of four weeks before surgery. All patients received a single intravenous dose of $2200 \mathrm{mg}$ amoxicillin/clavulanic acid as antibiotic prophylaxis directly before surgery.

\section{Study protocol}

Anaesthesia was performed according to institutional routines and has been described previously. ${ }^{12}$ Briefly, the procedure included placement of two peripheral venous catheters, an epidural catheter for per- and postoperative analgesia, an arterial line, and a central venous line. Anaesthesia was maintained using sevoflurane and propofol. Liver resection started with mobilization of the liver, whereupon intraoperative ultrasound (Aloka, Zug, Switzerland) was used to determine the definitive surgical procedure. Liver transection was performed using a Cavitron Ultrasonic Surgical Aspirator (CUSA, system 200 Macrodissector; Cavitron Surgical Systems, Stamford, CT). Argon beam coagulation (Force GSU Systems; Valleylab, Boulder, CO), clips and sutures were used to achieve hemostasis. ${ }^{12}$

When the portal and hepatic veins were exposed (mostly within one hour after skin incision, but before liver transection), blood was drawn from the portal vein and a hepatic vein by direct puncture simultaneously with arterial blood sampling, as described before by our group. ${ }^{12}$ Directly after hepatic transection, blood was sampled again from the portal vein, a hepatic vein and the radial artery. Blood was collected in EDTA vacuum tubes (BD Vacutainer, Franklin Lakes, $\mathrm{NJ}$ ) and placed on ice. Blood was centrifuged at $3,500 \mathrm{~g}$, plasma was stored at $-80^{\circ} \mathrm{C}$ until analysis. Finally, the liver resection specimens were weighed.

\section{Sample preparation and liquid chromatography-mass spectrometry (LC-MS)}

Deproteinization and subsequent preparation of plasma samples for analysis of SCFA was performed as recently reported. ${ }^{13}$ Briefly, plasma samples were deproteinized using methanol, after which they were centrifuged at $50,000 \mathrm{~g}$ for 10 minutes at $4^{\circ} \mathrm{C}$. The clear supernatant was transferred to a $300 \mu$ l glass micro-insert into a WISP-style vial. Analysis was performed using a liquid chromatography system combined with mass spectrometry. SCFA concentrations were determined using the external standard method by calibration curves of SCFA. The detection limits for acetate, propionate and butyrate of this method were $0.1,0.05$ and $0.05 \mu \mathrm{mol} / \mathrm{l}$, respectively. The coefficients of variance were $4.2 \%, 9.8 \%$ and $5.1 \%$ for acetate, propionate and butyrate in human venous plasma, respectively. 


\section{CT-volumetry}

Liver volumetry was performed using OsiriX ${ }^{\infty}$, as described previously by our group. ${ }^{14}$ Briefly, series of axial images in the portal venous phase of the preoperative computed tomography (CT) scans were used. A slice thickness of either 3 or $5 \mathrm{~mm}$, depending on the CT-scanner was used. The outline of the total liver, future resection specimen and tumors were traced manually on each slice. On all slices, the gall bladder and the inferior caval vein were excluded, whereas intrahepatic vascular and biliary structures were included. Osirix ${ }^{\circledR}$ was then used to automatically calculate total liver, resection and tumour volumes. Then, 3D images were created and virtual resections were performed according to the treatment plan. Functional volume was calculated as total liver volume minus tumor volume. Thereafter, these volumes were used to estimate the remnant liver volume in order to allow for the calculation of SCFA clearance per gram liver (assuming $1 \mathrm{ml}=1$ gram).

\section{Flux calculations}

Arteriovenous differences $(\triangle \mathrm{AV})$ and net organ fluxes (flow ${ }^{*} \Delta \mathrm{AV}$ ) were calculated across the liver, portal drained viscera (PDV) and the splanchnic area. In a previous study, our group measured plasma flow in the portal vein and hepatic artery and because that patient group was comparable to the patients in the present study, these plasma flows were used to calculate fluxes. ${ }^{12}$ Furthermore, we demonstrated that total hepatic plasma flow remains unchanged following major hepatectomy, which seemed to justify the use of pre-resection flow data for post-resection calculation. ${ }^{15}$

The corresponding $A V$ differences were calculated as follows: $\triangle A V_{P D V}=[P V]-[A]$ and $\Delta \mathrm{AV}_{\text {splanchnic area }}=[\mathrm{HV}]-[\mathrm{A}]$. Fluxes were calculated as $\mathrm{F}_{\mathrm{PDV}}=$ portal plasma flow $*[\mathrm{PV}]-[\mathrm{A}]$, $\mathrm{F}_{\text {splanchnic }}=$ splanchnic plasma flow $*[\mathrm{HV}]-[\mathrm{A}], \mathrm{F}_{\text {liver }}=\mathrm{F}_{\text {splanchnic }}-\mathrm{F}_{\mathrm{PDV}}$. In these equations [PV], [A] and [HV] indicate portal venous, radial artery and hepatic venous concentrations respectively, whereas $F_{\text {splanchnic, }} F_{\text {liver, }} F_{P D V}$ denote splanchnic flux, liver flux and PDV flux, respectively. Positive fluxes indicate release and negative fluxes indicate uptake. To estimate functional reserve, hepatic SCFA exchange was also calculated per gram of liver tissue using the volumetry data and assuming $1 \mathrm{ml}$ corresponds with 1 gram of liver tissue.

\section{Statistical analysis}

Results are presented as means (SEM). One sample t-test was used to test if fluxes were statistically different from zero. The paired Student's t-test was used to test if there were differences in fluxes and concentrations before and after partial hepatectomy. Correlations were calculated with Spearman's correlation coefficients. $P$-values below 0.05 were considered statistically significant. For statistical analysis SPSS version 15.0 for Windows (2006, SPSS Inc. Chicago, USA) was used. 


\section{Results}

\section{Patients}

Thirty patients were included in the study (Table 5.1). Sampling was performed in all patients according to protocol. Thirteen patients underwent major hepatectomy ( 3 or more segments), whereas 17 patients underwent minor liver resection. The median time required for transection was 110 (51-250) minutes.

Table 5.1 Baseline characteristics.

\begin{tabular}{ll}
\hline Baseline characteristics $(\mathrm{n}=30)$ & \\
\hline Sex (male) & 20 \\
Age (years) & $62(41-79)$ \\
BMI & $25.1(20.3-33.3)$ \\
Neo-adjuvant chemo therapy & 20 \\
Indication & \\
CLM & 26 \\
Cholangiocarcinoma & 1 \\
Carcinoid & 1 \\
HCC & 2 \\
Type of hepatic resection & \\
minor & 13 \\
major & 17 \\
Plasma flows (ml/min) & \\
portal vein & $320(42)$ \\
hepatic artery & $110(23)$ \\
splanchnic flow & $430(47)$ \\
\hline
\end{tabular}

BMI; body mass index, CLM; colorectal liver metastases, HCC; hepatocellular carcinoma.

The gut produced significant amounts of acetate, propionate and butyrate before transection, since the portal venous concentrations exceeded the arterial concentrations. The corresponding fluxes were $37.5 \pm 12.7,6.2 \pm 1.3$ and $9.7 \pm 2.6 \mu \mathrm{mol}$ $\cdot \mathrm{kg} \mathrm{bw}^{-1} \cdot \mathrm{h}^{-1}$ for acetate, propionate and butyrate, respectively $(P<0.01$, Figure 5.1$)$. The production of SCFA by the gut was not statistically different directly after partial hepatectomy compared with baseline production ( $P>0.244$, Figure 5.1).

\section{Liver SCFA fluxes}

Liver uptake of acetate did not differ significantly from zero $(-23.2 \pm 13.0 \mu \mathrm{mol} \mathrm{kg}$ $\left.\mathrm{bw}^{-1} \cdot \mathrm{h}^{-1}, P=0.085\right)$ at baseline. After partial hepatectomy, hepatic acetate uptake

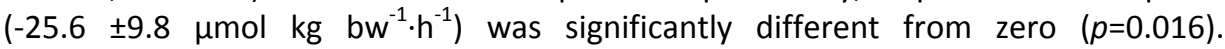
Propionate and butyrate were taken up by the liver at baseline as well as after partial hepatectomy. The corresponding fluxes at baseline were $-6.3 \pm 1.2$ and 
$-9.6 \pm 2.4 \mu \mathrm{mol} \cdot \mathrm{kg} \mathrm{bw}^{-1} \cdot \mathrm{h}^{-1}$ for propionate and butyrate, respectively $(P<0.001)$. After partial hepatectomy the uptake of these SCFA did not change significantly: $-5.9 \pm 1.7$ and $-9.2 \pm 2.4 \mu \mathrm{mol} \cdot \mathrm{kg} \mathrm{bw}^{-1} \cdot \mathrm{h}^{-1}$ for propionate and butyrate, respectively $(P>0.791$, Figure 5.1).

A

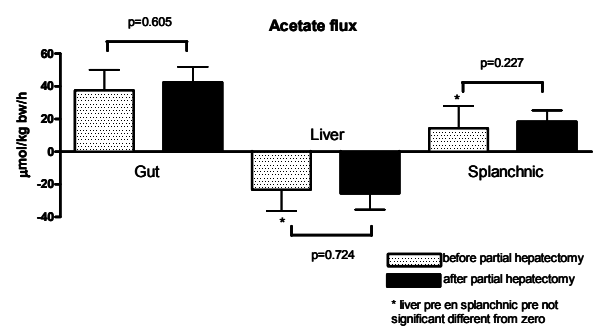

B

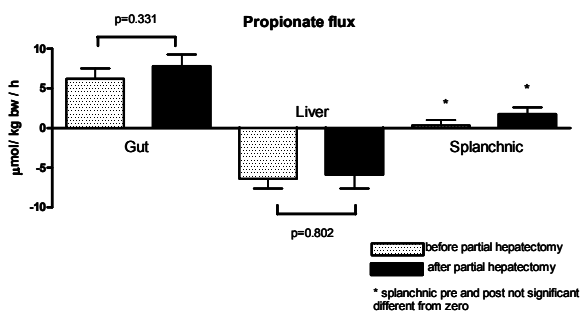

C

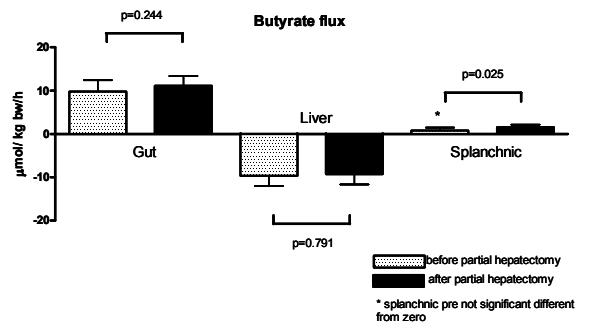

Figure 5.1 Short chain fatty acids fluxes. Short chain fatty acid fluxes as a measure of release or uptake by the gut, liver and splanchnic area. ${ }^{*}$ flux is not significantly different from zero.

\section{Splanchnic SCFA fluxes and systemic concentrations}

Since propionate and butyrate release from the gut equalled hepatic uptake at baseline and after partial hepatectomy, there was no significant splanchnic release at both time points $(P>0.05$, Figure 5.1). The arterial propionate and butyrate concentrations were not significantly different before and immediately after major and minor hepatectomy (Table 5.2).

Acetate was not taken up by the liver completely at baseline and as a consequence it was partially released from the splanchnic area before and also after partial hepatectomy $(18.4 \pm 6.9, P=0.012)$. However, this did not result in an increased arterial acetate concentration after partial hepatectomy (Table 5.2). 
Table 5.2 Arterial concentrations before and after transection $(n=30)$.

\begin{tabular}{lccc}
\hline & Before & After & $P$-value \\
\hline Acetate & $176.9(17.3)$ & $142.3(12.5)$ & 0.183 \\
Propionate & $7.2(1.4)$ & $5.6(0.6)$ & 0.377 \\
Butyrate & $4.3(0.7)$ & $3.6(0.6)$ & 0.733 \\
\hline
\end{tabular}

Concentrations in $\mu \mathrm{mol} / \mathrm{l}$.

\section{Volume and SCFA liver uptake}

Mean total liver volume was $1692 \pm 88 \mathrm{ml}$ and mean functional liver volume (total liver volume minus tumor volume) was $1584 \pm 116 \mathrm{ml}$. Mean estimated remnant liver volume was $1186 \pm 106 \mathrm{ml}$. The resection specimens weighed on average $475 \pm 60 \mathrm{gr}$, which represented $31 \%$ (7-67\%) of total liver volume.

Uptake of acetate, propionate and butyrate by the liver is not correlated with the percentage functional remnant liver volume $(r=-0.19, r=-0.05$ and $r=0.15, P>0.35$, Figure 5.3). Furthermore, no differences were found between arterial acetate, propionate and butyrate concentrations in patients that underwent a minor resection compared to patients that underwent a major resection $(P>0.209)$.

When assessing the flux per gram liver tissue before and after hepatic resection, an apparent increase in uptake per gram liver tissue was seen for all SCFA, but this did not reach significance (Figure 5.2, $P>0.07$ ).

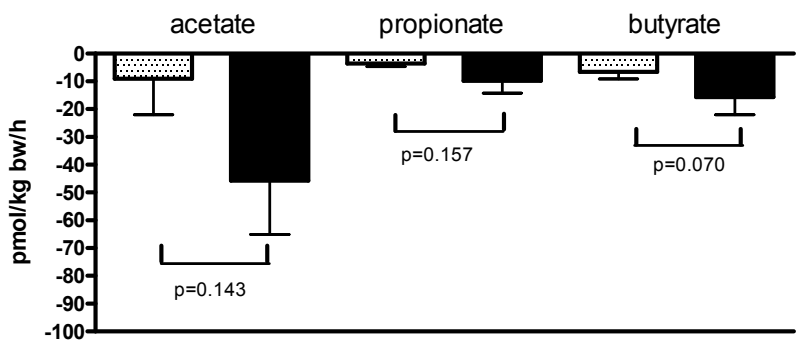

Figure 5.2 Short chain fatty acid fluxes per gram liver tissue before and after partial hepatectomy. 
A

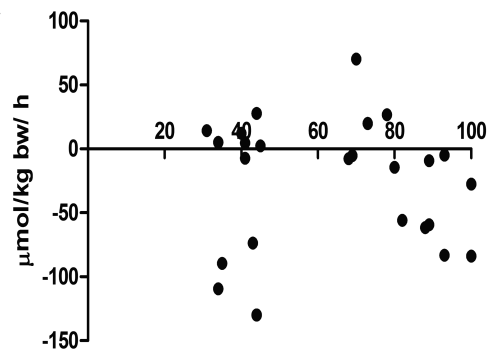

B

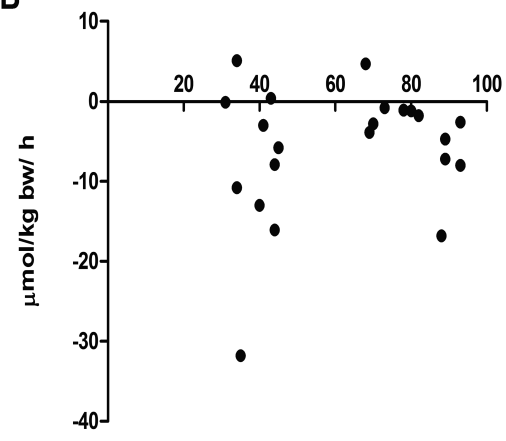

C

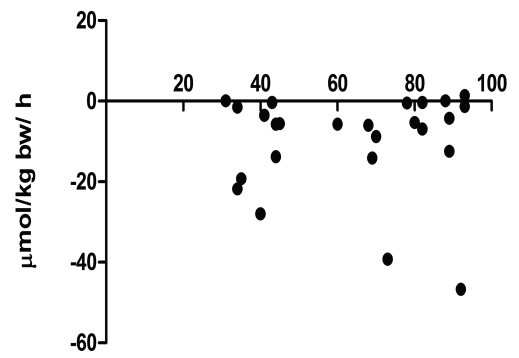

Figure 5.3 Correlation between hepatic uptake of acetate (A), propionate (B) and butyrate (C) with percentage functional remnant liver. $(r=-0.19, r=-0.05$ and $r=0.15, P>0.35)$.

\section{Discussion}

The present study investigated the effect of partial hepatectomy, as a model for sudden decrease of liver function, on interorgan exchange of short chain fatty acids (SCFA). The study showed that the liver is clearing propionate and butyrate adequately before and after partial hepatectomy. Furthermore, the extent of the resection did not affect the clearing capacity for propionate and butyrate. Acetate was not taken up by the liver and was released from the splanchnic area. After partial hepatectomy, the remnant liver showed a non-significant increase in propionate and butyrate clearance per gram remnant liver tissue. Last, there was no change in systemic concentrations of SCFA after partial hepatectomy compared with baseline situation.

Currently, there is much interest in prebiotic supplementation to Western diets to improve gut health. The positive local effect of the oral or enteral administration of SCFA in particular in inflammatory bowel disease, but also in bowel anastomosis healing has been described previously. ${ }^{16-19}$ Consequently, it would be attractive to 
administer SCFA or precursors into the gut. However, it is unclear if this can be safely done in humans. This is because knowledge on metabolic handling of such SCFA administered into the gut is currently limited. Thus, not much is known about interorgan exchange of SCFA in humans. This interorgan exchange in particular is important because high systemic levels of propionate and butyrate are toxic. ${ }^{9,10}$ It is known at present that the gut produces and the liver clears SCFA. ${ }^{11}$ Thus, if the liver does not clear SCFA administered enterally, they may attain toxic levels in the circulation.

Recently, our group elucidated the role of the liver in patients with a normal liver function and in patients with stable liver cirrhosis. The findings of the current study add valuable information to the knowledge on SCFA physiology and their metabolism in humans, because we used a unique situation to study the effect of acute loss of liver function on SCFA clearance. In the current study we show that the liver is still able to take up and clear virtually all propionate and butyrate in an acute situation of liver function loss. Combining these results with our findings in stable cirrhotic patients implies that the liver has an extensive capacity to clear SCFA. In the present study, no therapeutic dose of SCFA (or precursors) has been administered, and therefore further studies must be performed to ensure that supplementation of SCFA in patients is safe.

In the current study, the future remnant liver volume was estimated using CTvolumetry to analyse the effect of the extent of the liver resection on the clearance capacity of the liver. No correlation was found between the extent of resection and the liver fluxes of the SCFA. A possible explanation for these findings is that the liver has such an extensive residual capacity that even in patients that underwent a major resection, the remnant liver cleared a substantial part of the SCFA. These findings are in concordance with previously published work on liver synthesis of urea and clearance of ammonia. ${ }^{15}$

Flux calculations give a quantitative measure of the net production of a certain substance (i.e. SCFA). This mathematical approach to estimate net production of a certain substance has been used in the past and gives valuable information. ${ }^{15,20,21} \mathrm{~A}$ potential drawback of this method is that it does not shed light on qualitative aspects of the substance, i.e. nothing can be said about which pathways are involved in short chain fatty acids metabolism in the liver or elsewhere. To overcome this problem a study with stable isotopes will be informative.

\section{Conclusion}

This in vivo study in humans shows that the gut produces significant quantities of short chain fatty acids. Acute hepatic functional loss did not influence the systemic concentrations of SCFA, because the remnant liver increased the capacity of clearing propionate and butyrate. This implicates that the liver has a large reserve capacity to metabolize propionate and butyrate to prevent any increase of arterial 
concentrations. This may be interpreted as circumstantial evidence for the safety of SCFA administration even in patients with limited liver function. Acetate was also produced by the gut in significant amounts, but escaped hepatic metabolism, as described earlier. 


\section{References}

1. Roberfroid, M. Prebiotics: the concept revisited. J Nutr 2007;137(3 Suppl 2):830S-7S.

2. Topping $D L$, Clifton PM. Short-chain fatty acids and human colonic function: roles of resistant starch and nonstarch polysaccharides. Physiol Rev 2001;81:1031-64.

3. Watzl B, Girrbach S, Roller M. Inulin, oligofructose and immunomodulation. Br J Nutr 2005;93 Suppl 1:S49-55.

4. Kristensen NB, Harmon DL. Effect of increasing ruminal butyrate absorption on splanchnic metabolism of volatile fatty acids absorbed from the washed reticulorumen of steers. J Anim Sci, 2004;82:3549-59.

5. Wachtershauser A, Stein J. Rationale for the luminal provision of butyrate in intestinal diseases. Eur J Nutr 2000;39:164-71.

6. Welters CF, Heineman E, Thunnissen FB, van den Bogaard AE, Soeters PB, Baeten CG. Effect of dietary inulin supplementation on inflammation of pouch mucosa in patients with an ileal pouch-anal anastomosis. Dis Colon Rectum 2002;45:621-7.

7. Tedelind S, Westberg F, Kjerrulf M, Vidal A. Anti-inflammatory properties of the short-chain fatty acids acetate and propionate: a study with relevance to inflammatory bowel disease. World J Gastroenterol 2007;13:2826-32.

8. Bloemen JG, Venema K, van de Poll MC, Olde Damink SW, Buurman WA, Dejong CH.Short chain fatty acids exchange across the gut and liver in humans measured at surgery. Clin Nutr 2009;28:657-61.

9. Manns JG, Boda JM. Insulin release by acetate, propionate, butyrate, and glucose in lambs and adult sheep. Am J Physiol 1967;212:747-55.

10. Feliz, B, Witt DR, Harris BT. Propionic acidemia: a neuropathology case report and review of prior cases. Arch Pathol Lab Med 2003;127:e325-8.

11. Bloemen JG, Olde Damink SW, Venema K, Buurman WA, Jalan R, Dejong CH. Short chain fatty acids exchange: Is the cirrhotic, dysfunctional liver still able to clear them? Clin Nutr 2010;29:365-9.

12. van de Poll MC, Siroen MP, van Leeuwen PA, Soeters PB, Melis GC, Boelens PG, Deutz NE, Dejong CH. Interorgan amino acid exchange in humans: consequences for arginine and citrulline metabolism. Am J Clin Nutr 2007;85:167-72.

13. van Eijk HM, Bloemen JG, Dejong $\mathrm{CH}$. Application of liquid chromatography-mass spectrometry to measure short chain fatty acids in blood. J Chromatogr B Analyt Technol Biomed Life Sci 2009;877: 719-24.

14. van der Vorst JR, van Dam RM, van Stiphout RS, van den Broek MA, Hollander IH, Kessels AG, Dejong $\mathrm{CH}$. Virtual liver resection and volumetric analysis of the future liver remnant using open source image processing software. World J Surg 2010;34:2426-33.

15. van de Poll MC, Wigmore SJ, Redhead DN, Beets-Tan RG, Garden OJ, Greve JW, Soeters PB, Deutz NE, Fearon KC, Dejong CH. Effect of major liver resection on hepatic ureagenesis in humans. Am J Physiol Gastrointest Liver Physiol 2007;293:G956-62.

16. Thibault R, Blachier F, Darcy-Vrillon B, de Coppet P, Bourreille A, Segain JP. Butyrate utilization by the colonic mucosa in inflammatory bowel diseases: a transport deficiency. Inflamm Bowel Dis 2010;16:684-95.

17. Mathew AJ, Wann VC, Abraham DT, Jacob PM, Selvan BS, Ramakrishna BS, Nair AN.The effect of butyrate on the healing of colonic anastomoses in rats. J Invest Surg 2010;23:101-4.

18. Fa-Si-Oen P, van de Gender P, Putter H, Ectors N, D'Hoore A, Topal B, Penninckx F. The effect of polyethylene glycol and butyrate on anastomotic healing in the rat colon. Tech Coloproctol 2006;10:308-11.

19. De Preter V, Bulteel V, Suenaert P, Geboes KP, De Hertogh G, Luypaerts A, Geboes K, Verbeke K, Rutgeerts $P$. Pouchitis, similar to active ulcerative colitis, is associated with impaired butyrate oxidation by intestinal mucosa. Inflamm Bowel Dis 2009;15:335-40.

20. Clemmesen JO, Kondrup J, Ott P. Splanchnic and leg exchange of amino acids and ammonia in acute liver failure. Gastroenterology 2000;118:1131-9. 
21. Deferrari G, Garibotto G, Robaudo C, Canepa A, Bagnasco S, Tizianello A. Leg metabolism of amino acids and ammonia in patients with chronic renal failure. Clin Sci (Lond) 1985;69:143-51. 



\section{Chapter 6}

Randomized placebo controlled study of the effects of butyrate enemas on systemic concentrations and splanchnic fluxes of short chain fatty acids

JG Bloemen, MA van den Broek , K Venema, WA Buurman, CHC Dejong Submitted 


\section{Abstract}

\section{Background and aim}

Short chain fatty acids (SCFA) are products of fermentation in the colon. Their presence in the gut is considered beneficial in gastrointestinal diseases, but high systemic concentrations are possibly toxic. Hence, before administering SCFA, information about systemic clearance is needed. The aim was to investigate the effect of administration a rectal enema containing butyrate on interorgan exchange of butyrate.

\section{Methods}

15 patients undergoing upper abdominal surgery were included. During surgery they received either a butyrate or a placebo enema. Before and 5, 15 and 30 minutes after administering, samples were taken from radial artery, hepatic and portal vein. The samples were analysed for SCFA. Liver, splanchnic and systemic fluxes were calculated.

\section{Results}

Portal butyrate concentrations reached a peak concentration following the enema after 5 minutes $(92(27) \mu \mathrm{mol} / \mathrm{l}$ compared to $14.2(3) \mu \mathrm{mol} / \mathrm{l}$ in the placebo enema group, $P=0.021)$. Arterial butyrate concentration reached a peak after 15 minutes $((20.5(13)$ vs. $0.72(0.21)$ $\mu \mathrm{mol} / \mathrm{l}, P<0.013)$. Gut release increased directly after administering the butyrate enema [23.9 $(9.0 \mu \mathrm{mol} / \mathrm{kg}$ bodyweight $/ \mathrm{h}$ ] and liver uptake increased [29.5(7.5) $\mu \mathrm{mol} / \mathrm{kg}$ bodyweight $/ \mathrm{h}$ ] resulting in insignificant release by the splanchnic area [6.1(1.9) $\mu \mathrm{mol} / \mathrm{kg}$ bodyweight $/ \mathrm{h}$ ]. Fractional absorption of butyrate by the gut was estimated to be $22.5 \%$ during the 30 minutes of the study.

\section{Conclusion}

After administration a butyrate enema, butyrate uptake by the gut increases as well as the uptake by the liver, but this did not prevent a rise in systemic butyrate concentrations. These observations are important for the administration of SCFA in a safe way. 


\section{Introduction}

Prebiotics currently receive considerable attention because of their potential benefits for gut health. Prebiotics are food ingredients that pass the upper gastrointestinal tract relatively unaffected. Once in the colon, they are fermented and the end products of this fermentation process are short chain fatty acids (SCFA; mainly acetate, propionate and butyrate). SCFA are metabolized rapidly by the epithelial cells and act as an important energy source for colonocytes. Furthermore, they protect the colonocytes against mechanical, chemical and microbial damage. ${ }^{1}$ Especially butyrate is important in homeostasis and influences various cellular processes. ${ }^{2,3}$ It stimulates cell proliferation in normal colonocytes and inhibits cell proliferation in cancer cell lines in vitro. ${ }^{4}$ There is also evidence that butyrate alters the expression of signaling genes in the intestinal mucosa, which affect mucosal immunity. ${ }^{5,6}$ Propionate may have a direct beneficial effect on visceral adipose tissue, reducing obesity-associated inflammation and increasing lipogenesis and glucose uptake. ${ }^{7}$

In the clinical setting, several studies have investigated the effect of prebiotics or SCFA administration on the intestinal mucosa in patients with a variety of intestinal diseases, e.g. ulcerative colitis, Crohn's disease, pouchitis, diversion colitis, radiation proctitis and irritable bowel syndrome. ${ }^{8-11}$ Although the results are not consistent throughout these studies, there is evidence to support the concept that intestinal SCFA supplementation leads to improvement of clinical and histological scores. ${ }^{12-17}$

As mentioned above, much is known about the local, intestinal effects of butyrate and other SCFA. However, knowledge about the exchange of SCFA across the gut, liver and splanchnic area is scarce. Recently, our group confirmed that the intestine is the main SCFA releasing organ in humans and that the liver is capable to take up all propionate and butyrate released from the gut, even in a situation of chronic liver disease. ${ }^{18,19}$ These studies were performed in patients on a stable Western diet without prebiotic supplements. This physiologic information is important because in the near future prebiotics may be considered as therapeutic agents in certain intestinal diseases. On the other hand it should be realized that high systemic concentrations of butyrate are possibly toxic. Therefore information about trafficking and hepatic clearance of SCFA and notably butyrate is of importance prior to the administration of SCFA or their precursors in a secure manner.

The aim of this study was to investigate the effect of administration of a rectal enema containing butyrate, on the interorgan exchange across the splanchnic organs and systemic concentrations of butyrate and the other SCFA (i.e. acetate and propionate) in humans.

\section{Patients and Methods}

Patients were studied during upper abdominal surgery, either open liver resection or pancreaticoduodenectomy, at Maastricht University Medical Centre (MUMC) 
between June and November 2009. Patients with known parenchymal liver disease, use of antibiotics, or probiotics prior to the operation, presence of an ileo- or colostomy or inflammatory bowel disease were excluded from the study. Patients were on a stable, Western diet and did not receive antibiotics in the period ( 2 months) before surgery. Oral intake except water was ceased at 8:00 PM on the day of admission and all patients were transported to the operating theatre at approximately 8:00 AM the next day. All patients received a single intravenous dose of $2200 \mathrm{mg}$ amoxicillin/clavulanic acid as antibiotic prophylaxis, immediately preoperatively. The Medical Ethical Committee of MUMC approved the study and all patients gave written informed consent.

\section{Study protocol}

This study was performed according to a randomized blinded placebo-controlled design. We supposed that in the placebo group there would be less variance in SCFA plasma concentrations and we therefore decided to randomize in a 1 placebo enema versus 2 butyrate enema ratio (in total 5 patients receiving a placebo enema and 10 patients a butyrate enema). The pharmacist performed randomization and the enemas were numbered 1 to 15 . After the experiment was completed and the samples were analysed, the randomisation key was given by the pharmacist to the researcher. The enemas were kindly prepared and supplied by the pharmacist of Maastricht University Medical Centre, Maastricht and contained either a sodium butyrate solution ( $60 \mathrm{ml}, 100 \mathrm{mM}$ ) or a placebo solution $(60 \mathrm{ml}, 140 \mathrm{mM} \mathrm{NaCl}$ ) with a neutral $\mathrm{pH}$. Patients were blinded for the type of enema. The investigators were also blinded, but the person administering the enema could not be blinded due to the odour of the butyrate enema. The investigators analysing the samples and managing the data were also blinded to the enema used. Hamer et al. have also used before these enemas in other studies at our institution. ${ }^{17}$

Anaesthetic management occurred according to institutional routines and has been described previously.[20] The procedure included placement of two peripheral venous catheters, an epidural catheter for per- and postoperative analgesia, an arterial line, and a central venous line. Anaesthesia was maintained using sevoflurane and propofol. After anaesthesia was induced, a silicon foley balloon catheter (30 Ch) was placed transanally in the rectum and the balloon was filled with $10 \mathrm{ml} 0.9 \% \mathrm{NaCl}$ to prevent leakage. During laparotomy, when exposure of portal and hepatic veins was adequate (mostly within one hour following laparotomy and before organ transection), baseline blood samples were drawn from the portal vein and a hepatic vein by direct puncture, simultaneously with arterial blood sampling, as described before by our group. ${ }^{21}$ Directly thereafter a $60 \mathrm{ml}$ rectal enema containing either the sodium butyrate solution $(100 \mathrm{mmol} / \mathrm{l})$ or the placebo solution $(140 \mathrm{mmol} / \mathrm{I} \mathrm{NaCl})$ was administered through the catheter. Blood was drawn from the portal vein, a hepatic vein and the radial artery at three time points, namely 5, 15 and 30 minutes after the enema was administered. Blood was collected in EDTA vacuum tubes (BD Vacutainer, 
Franklin Lakes, NJ) and placed on ice. Blood was centrifuged at $3,500 \mathrm{~g}, 4^{\circ} \mathrm{C}$ and plasma was stored at $-80^{\circ} \mathrm{C}$ until analysis.

\section{Sample preparation and liquid chromatography-mass spectrometry (LC-MS)}

Deproteinization and subsequent preparation of plasma samples for analysis of SCFA was performed as reported previously. ${ }^{22}$ Briefly, plasma samples were deproteinized using methanol, after which they were centrifuged at 50,000 g for 10 minutes at $4^{\circ} \mathrm{C}$. The clear supernatant was transferred to a $300 \mu$ l glass micro-insert into a WISP-style vial. Analysis was performed using a liquid chromatography system combined with mass spectrometry. SCFA concentrations were determined using the external standard method by calibration curves of SCFA. The detection limits for acetate, propionate and butyrate of this method were $0.1,0.05$ and $0.05 \mu \mathrm{mol} / \mathrm{l}$ respectively. The coefficients of variance were $4.2 \%, 9.8 \%$ and $5.1 \%$ for acetate, propionate and butyrate in human venous plasma, respectively.

\section{Flux calculations}

Arteriovenous differences $(\triangle \mathrm{AV})$ and net organ fluxes (flow $\times \Delta \mathrm{AV}$ ) were calculated across the liver, portal drained viscera (PDV) and the splanchnic area, as described previously. ${ }^{19}$ The corresponding $\mathrm{AV}$ differences were calculated as follows: $\Delta \mathrm{AV}_{\mathrm{PDV}}=[\mathrm{PV}]-[\mathrm{A}]$ and $\Delta \mathrm{AV}_{\text {splanchnic area }}=[\mathrm{HV}]-[\mathrm{A}]$. Fluxes were calculated as $\mathrm{F}_{\mathrm{PDV}}=$ portal plasma flow * [PV]-[A], $\mathrm{F}_{\text {splanchnic }}=$ splanchnic plasma flow $*[\mathrm{HV}]-[\mathrm{A}], \mathrm{F}_{\text {liver }}=\mathrm{F}_{\text {splanchnic }}-\mathrm{F}_{\mathrm{PDV}}$. Splanchnic plasma flow was calculated as portal flow $(320 \mathrm{ml} / \mathrm{min})$ plus hepatic artery flow (110 $\mathrm{ml} / \mathrm{min})$. In these equations [PV], [A] and [HV] indicate portal venous, radial artery and hepatic venous concentrations respectively, whilst $F_{\text {splanchnic, }} F_{\text {liver, }} F_{P D V}$ denote splanchnic flux, liver flux and PDV flux, respectively. Positive fluxes indicate release, whilst negative fluxes indicate uptake. For plasma flow, data were used from a similar study conducted previously, as it was logistically impractical to repeatedly measure plasma flow at the indicated time points in the present study. ${ }^{21}$

\section{Statistics}

Continuous data are presented as mean (SEM) if normally distributed and as median (range) if not normally distributed. Differences in SCFA concentrations on subsequent time points were tested statistically using two way ANOVA for repeated measures with Bonferroni correction. Mean concentrations in both groups were compared using a Mann Whitney $U$ test. Fluxes were tested versus zero using a one-sample t-test with a theoretical mean of zero. A $P$-value of $<0.05$ was considered statistically significant. For fractional absorption the area under the curve of the portal venous concentration was calculated with a statistical programme (SPSS 18.0 for Mac OS). 


\section{Results}

\section{Patients}

Fifteen patients were included in the study. Two patients (both randomized to the butyrate enema group) were excluded from the final analysis, because the study protocol could not be finished due to technical failures (malfunction of the arterial catheter during the experiment in one patient and administration of the enema in the bladder instead of the rectum due to accidental swopping of the catheters by theatre staff in the other patient). As a result 13 patients (5 placebo enema and 8 butyrate enema group) were included in the final analysis (Figure 6.1, Table 6.1). The groups were not statistically different with respect to baseline characteristics as well as for baseline short chain fatty acids concentrations ( $P>0.068$, Table 6.2).

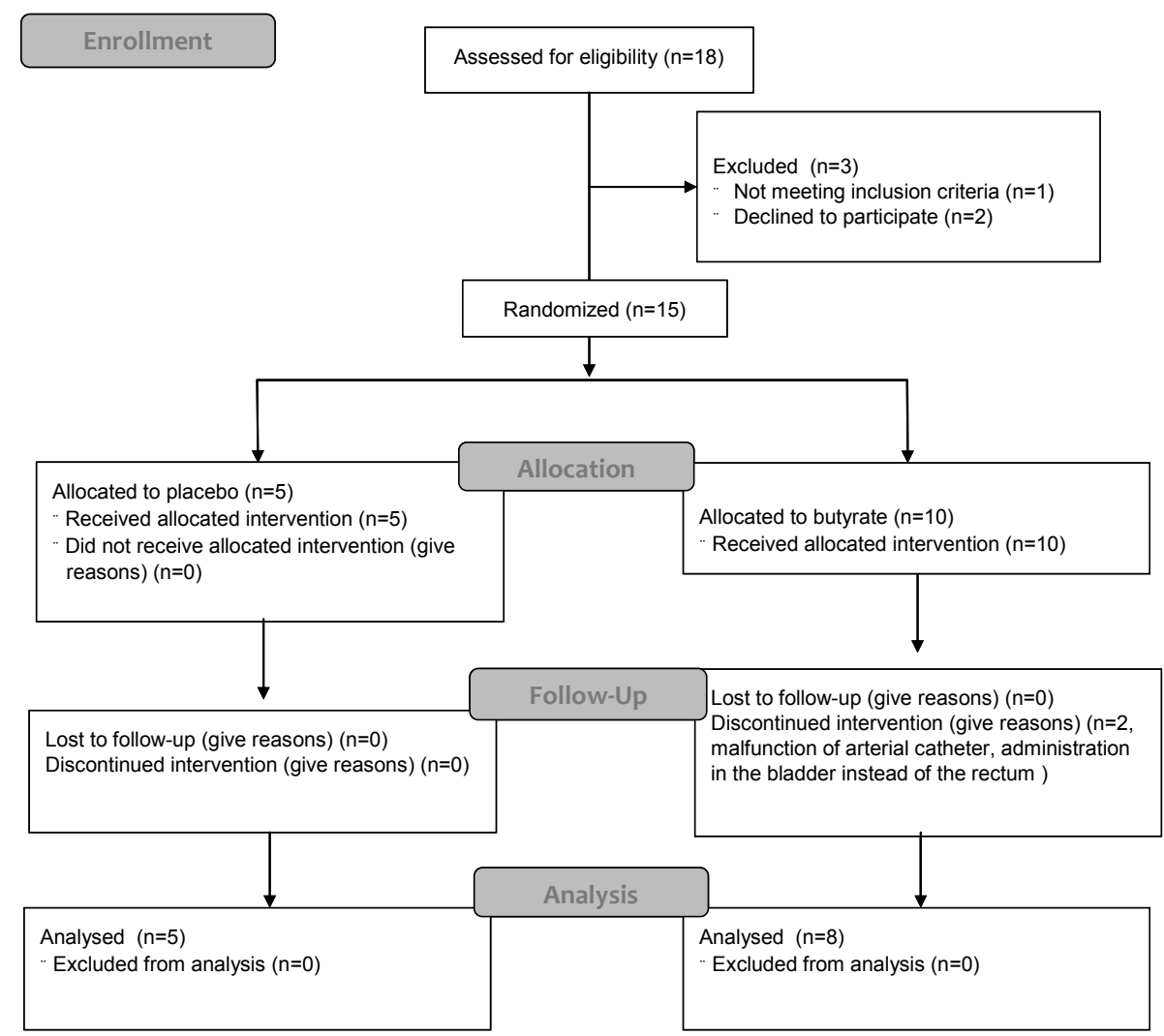

Figure 6.1 CONSORT diagram of patient inclusion and follow up. 
Table 6.1 Baseline characteristics.

\begin{tabular}{lcc}
\hline & Placebo $(\mathrm{n}=5)$ & Butyrate $(\mathrm{n}=8)$ \\
\hline Male & 2 & 3 \\
Age $(\mathrm{y})$ & $73(54-74)$ & $63(54-73)$ \\
BMI $(\mathrm{kg} / \mathrm{m} 2)$ & $24.6(18.4-29.0)$ & $22.7(18.7-34.0)$ \\
Indication & & \\
$\quad$ colorectal liver metastases & 0 & 6 \\
pancreatic pathology & 4 & 1 \\
biliary pathology & 1 & 1 \\
\hline
\end{tabular}

Table 6.2 Baseline SCFA concentrations $(\mu \mathrm{mol} / \mathrm{l})$ in both study groups. The baseline concentrations did not differ significantly between the placebo and butyrate enema group $(P>0.068)$.

\begin{tabular}{lcccccc}
\hline & Arterial & \multicolumn{3}{c}{ Portal } & \multicolumn{2}{c}{ Hepatic } \\
& P-enema & B-enema & P-enema & B-enema & P-enema & B-enema \\
\hline Acetate & $86.1(20.3)$ & $129.7(20.6)$ & $181.6(47.3)$ & $198.6(30.1)$ & $70.5(9.4)$ & $191.4(55.0)$ \\
Propionate & $0.9(0.1)$ & $1.6(0.4)$ & $30.1(11.4)$ & $18.1(6.3)$ & $0.8(0.1)$ & $4.9(1.5)$ \\
Butyrate & $0.7(0.2)$ & $1.2(0.3)$ & $15.0(3.5)$ & $24.8(13.7)$ & $0.5(0.1)$ & $5.4(2.1)$ \\
\hline
\end{tabular}

P-enema: placebo enema, B-enema: butyrate enema.

\section{Butyrate concentrations}

The mean portal venous butyrate concentrations were 15.0 (3.5) and 24.8 (13.7) $\mu \mathrm{mol} / \mathrm{I}$ in the placebo and butyrate enema group, respectively $(P=0.59$, Table 6.2). There was considerable variation in butyrate concentrations in the portal vein between patients.

After the enema was administered, portal venous butyrate concentrations increased significantly and reached their peak after 5 minutes (92.1(27.0) compared with 14.2 (3.3) $\mu \mathrm{mol} / \mathrm{l}$ in the placebo group) ( $P=0.028$, Figure 6.2A.) The mean increase in portal venous butyrate concentration at that time-point was $66.0(25.0) \mu \mathrm{mol} / \mathrm{l}$ in the butyrate enema group, whereas the mean change in the placebo enema group was -0.8 (1.8) $\mu \mathrm{mol} / \mathrm{l}$.

Arterial butyrate concentrations did not significantly differ between both groups at baseline $(P=0.43)$. Five minutes after administration of the enema, arterial butyrate concentrations were significantly higher in the butyrate enema group compared with placebo (7.0(2.1) and 0.6(0.1), respectively, $(P=0.009))$. Although the variance was quite large, after 15 and 30 minutes arterial concentrations were still significantly higher in the butyrate enema group compared with the placebo enema group $(P<0.013$, Figure 6.2B). Peak arterial concentrations were reached 10 minutes later than peak portal venous concentrations. Fifteen minutes after administration of the enema the arterial butyrate concentrations started to decrease. 


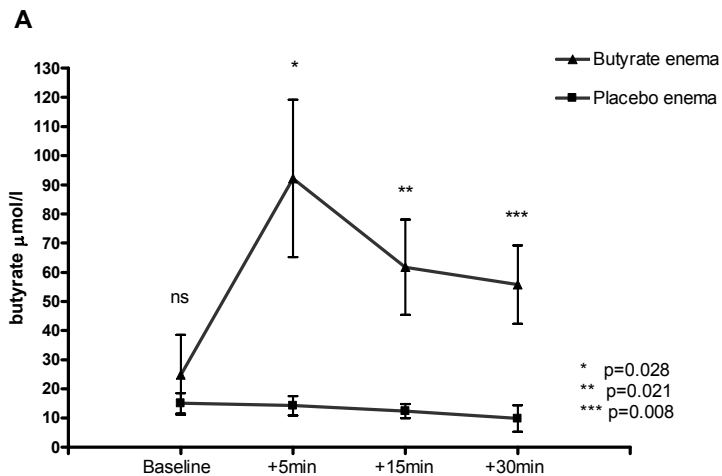

B

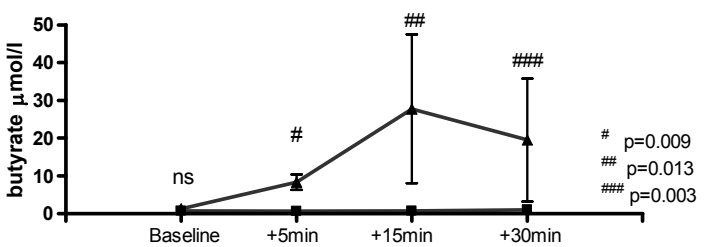

Figure 6.2 Butyrate concentrations (umol/l). A; portal venous concentrations, B: arterial concentrations.

\section{Butyrate exchange}

At baseline the net production of butyrate by the gut was $4.1 \pm 0.9$ and $5.2 \pm 2.8 \mu \mathrm{mol} \mathrm{kg}$ bodyweight ${ }^{-1} \mathrm{~h}^{-1}$ in the placebo and butyrate enema group, respectively, and did not significantly differ $(P=0.35)$. The liver scavenged $4.1 \pm 0.8 \mu \mathrm{mol} \mathrm{kg}$ bodyweight ${ }^{-1} \mathrm{~h}^{-1}$ $(P=0.009)$ at baseline in the placebo group and as a consequence the net release from the splanchnic area was insignificant $\left(-0.04 \pm 0.08 \mu \mathrm{mol} \mathrm{kg}\right.$ bodyweight $\left.{ }^{-1} \mathrm{~h}^{-1}, P=0.58\right)$ in the placebo group. Likewise, the liver scavenged most of the butyrate in the butyrate enema group at baseline (liver uptake $3.9 \pm 2.9 \mu \mathrm{mol} \mathrm{kg}$ bodyweight $\mathrm{h}^{-1} \mathrm{~h}^{-1}$ ) and as a result splanchnic release did not differ significantly from zero at baseline $\left(1.3 \pm 0.5 \mu \mathrm{mol} \mathrm{kg}\right.$ bodyweight $\left.{ }^{-1} \mathrm{~h}^{-1}, P>0.12\right)$.

Five minutes after butyrate enema administration, net butyrate release from the gut increased to $23.3 \pm 9.0 \mu \mathrm{mol} \mathrm{kg}$ bodyweight ${ }^{-1} \mathrm{~h}^{-1}$. After 15 and 30 minutes the release decreased again to $12.3 \pm 5.5$ and $12.7 \pm 3.8 \mu \mathrm{mol} \mathrm{kg}$ bodyweight $\mathrm{t}^{-1} \mathrm{~h}^{-1}$, respectively. Uptake by the liver increased to $29.5 \pm 7.8 \mu \mathrm{mol} \mathrm{kg}$ bodyweight $^{-1} \mathrm{~h}^{-1}$ after 5 minutes and then decreased slightly to $18.9 \pm 4.4$ and $24.4 \pm 6.6 \mu \mathrm{mol} \mathrm{kg}$ bodyweight ${ }^{-1} \mathrm{~h}^{-1}$, after 15 and 30 minutes respectively (Figure 6.3). Splanchnic release increased over this period and was significantly increased after $30 \mathrm{~min}(P=0.018)$. In the placebo enema 
group, gut release, liver uptake and splanchnic release of butyrate did not differ significantly at 5, 15 and 30 minutes after administration $(P>0.56)$.
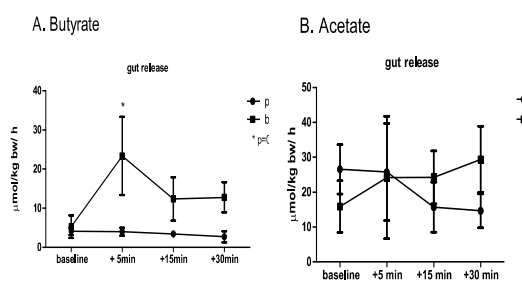

C. Propionate
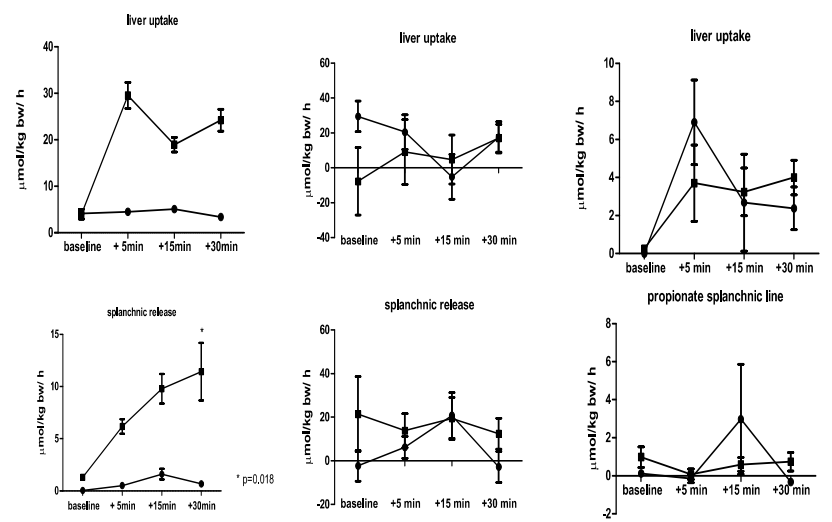

Figure 6.3 Butyrate (A), acetate (B) propionate (C) exchange across gut, liver and splanchnic area at baseline and 5,15 and 30 minutes after administering the butyrate or placebo enema.

\section{Propionate exchange}

Propionate was not released in significant amounts from the gut at baseline $-0.02 \pm 0.03$ and $0.7 \pm 0.3 \mu \mathrm{mol} \mathrm{kg}$ bodyweight ${ }^{-1} \mathrm{~h}^{-1}$ in the placebo and butyrate enema group, respectively $(P>0.08)$. As a consequence, there was no uptake by the liver or release from the splanchnic area (Table 6.3).

At 5 minutes after enema administration, the gut produced small, but significant amounts of propionate only in the placebo group; $6.8 \pm 2.2 \mu \mathrm{mol} \mathrm{kg}$ bodyweight ${ }^{-1} \mathrm{~h}^{-1}$ (Figure 6.3C, $P=0.08$ ). At 15 minutes both groups showed propionate release from the gut in significant amounts $\left(5.6 \pm 1.8\right.$ and $3.8 \pm 1.3 \mu \mathrm{mol} \mathrm{kg}$ bodyweight ${ }^{-1} \mathrm{~h}^{-1}$ in the placebo and butyrate enema group respectively). At 30 minutes, no significant propionate release was seen in either of the groups $(P=0.12)$.

The liver took up propionate in statistically significant amounts only at 15 minutes after administering a butyrate enema $\left(-3.2 \pm 1.2 \mu \mathrm{mol} \mathrm{kg}^{\text {bodyweight }}{ }^{-1} \mathrm{~h}^{-1}, P=0.04\right)$. There was no statistically significant release of propionate from the splanchnic area, neither in the placebo nor in the butyrate enema group at any time point $(P>0.07)$. 
Table 6.3 Baseline SCFA fluxes ( $\mu \mathrm{mol} / \mathrm{kg} \mathrm{bw} / \mathrm{h}$ ) in both study groups. P-enema: placebo enema, B-enema: butyrate enema.

\begin{tabular}{lcccccc}
\hline & Gut & \multicolumn{2}{c}{ Liver } & \multicolumn{3}{c}{ Splanchnic } \\
& P-enema & B-enema & P-enema & B-enema & P-enema & B-enema \\
\hline Acetate & $26.5(7.0)^{*}$ & $15.8(7.4)$ & $-29.5(8.7)$ & $7.6(19.3)^{*}$ & $-2.3(7.0)^{*}$ & $21.4(17.1)^{*}$ \\
Propionate & $-0.02(0.03)^{*}$ & $0.7(0.3)^{*}$ & $0.1(0.1)^{*}$ & $0.2(0.1)^{*}$ & $0.1(0.1)^{*}$ & $0.9(0.5)^{*}$ \\
Butyrate & $4.1(0.9)$ & $5.2(2.8)^{*}$ & $-4.1(0.8)^{*}$ & $-3.9(2.9)$ & $-0.04(0.08)^{*}$ & $1.3(0.5)^{*}$ \\
\hline
\end{tabular}

\section{Acetate exchange}

The gut released acetate at all time points in both groups, but these were statistically insignificant amounts and they did not differ significantly before and after administration of the enema (Figure 6.3B $P=0.67$ ). The liver did not take up significant amounts of acetate at 5, 15 and 30 minutes $(P>0.09)$. Furthermore, the splanchnic area released no acetate nor did it take up any acetate in significant quantities.

\section{Fractional absorption}

In the butyrate group, $60 \mathrm{ml}$ of a $100 \mathrm{mmol} / \mathrm{l}$ butyrate solution was administered, which compares to $6 \mathrm{mmol}$ of butyrate. The maximum increase in portal venous butyrate concentration was $68 \mu \mathrm{mol} / \mathrm{l}$ at 15 minutes. Thereafter there was still an increased portal venous butyrate concentration, but this decreased slowly. In total, as measured as area under the curve minus the baseline concentration, $1.35 \mathrm{mmol}$ of butyrate was taken up from the gut in the portal vein in 30 minutes. This was $22.5 \%$ of the total butyrate administered with the enema.

\section{Discussion}

In the present study we included patients undergoing upper abdominal surgery and randomized them in a 1:2 ratio in a double blinded design to receive either a placebo enema or a butyrate enema during surgery. The results of the present study showed an increased release of butyrate from the gut shortly after administration of a butyrate enema. Arterial butyrate concentrations increased significantly, with a peak at 5 minutes after administration. Furthermore, we observed that butyrate uptake by the liver increased after enema administration and returned to baseline levels after 30 minutes.

Most of the information comes from animal studies or in vitro studies. The experimental set up during upper abdominal surgery in humans gives the unique opportunity to administer an enema and sample from the portal vein and hepatic vein and radial artery at the same time. Together with our previous studies, these data give insight in interorgan SCFA trafficking in humans. The baseline arterial, portal venous 
and hepatic venous concentrations found in the present study were comparable with data from our previous studies. ${ }^{18,19}$

High systemic concentrations of butyrate and propionate are toxic, but the absolute values at which arterial or venous concentrations become toxic are unknown. In previous studies by our group butyrate solutions and precursors of SCFA have been administered in humans. Hamer et al. administered similar enemas during a period of 7 days. $^{17}$ Studies administering precursors of SCFA (i.e. inulin or fructooligosaccharides) reported increased intraluminal SCFA concentrations, but information about systemic changes in SCFA in plasma has not been reported. ${ }^{23-25}$ In the present study, as well as in the prolonged administration study by Hamer et al. no adverse effects were observed. These findings together with the results of the present study support the assumption that it is relatively safe to administer these amounts of SCFA.

During the study, we administered 6 mmols of butyrate, of which approximately $22 \%$ appeared in the portal vein during the $\mathbf{3 0}$ minutes study period after administration. Short chain fatty acids are rapidly and almost completely absorbed by colonocytes, and only 5 to $10 \%$ of SCFA are excreted in the faeces. ${ }^{26,27}$ Absorption of SCFA is concentration-dependent and the absorption rates are the same throughout the entire colon. ${ }^{6}$ Two mechanisms have been described to be responsible for absorption of SCFA; diffusion of protonated SCFA and anion exchange. ${ }^{28}$ Diffusion of SCFA plays the most important role, because most of the SCFA are present in their protonated form at the ambient $\mathrm{pH}$ in the colon (ranging from 5.5 to 7.5). ${ }^{29}$ Active transport involving cellular uptake by transport of $\mathrm{Na}$ en $\mathrm{K}$ accounts for less than $40 \%$ of absorption. ${ }^{30}$ Although absorption is a rapid process, only $22 \%$ of the administered SCFA were taken up in the portal vein in the present study. This may be explained by the fact that the colonic epithelium uses butyrate directly for energy expenditure and therefore the majority of butyrate does not appear in the portal vein. Furthermore, diffusion of butyrate is concentration dependent. As long as the concentration difference between the colonic lumen and blood is large enough, there is a driving force and the result is uptake of butyrate by the blood. To which extent both mechanisms, active or passive transport, contribute to the incomplete absorption of SCFA by the portal vein is unclear, since exact percentages of absorption, excretion and metabolism are currently not known. Last, the venous return from the rectal area constitutes of veins draining on the portal vein as well as veins draining on the internal iliac vein. In the current study, only the amount of butyrate draining on the portal vein was measured. This can also explain the relatively low fractional extraction of butyrate from the intestinal lumen.

It is remarkable that the liver uptake of butyrate is higher than the gut release of butyrate during the 30 minutes study period. The explanation for this can be that the absorption of butyrate from the gut takes place very quickly, and as a consequence the real peak release was missed because of the chosen sample points. For instance, the peak of butyrate release by the gut could be somewhere between zero and 5 minutes, and therefore due to the design of the study, the real peak concentration 
may not have been measured. This implicates a higher gut release in the first 5 minutes, which will be taken up by the liver.

For flux calculations across organs, data about plasma flow are needed, because fluxes are calculated as flow times arteriovenous concentration differences. As described before, in the present study data on plasma flow were used from a previous study, performed in the same operative setting with comparable patients. The plasma flow was measured in that study by intra-operative Duplex Doppler ultrasound. Recent literature has reported variable portal plasma flows ranging from 423 to $1129 \mathrm{ml} / \mathrm{min}$ and hepatic artery flows ranging from 74 to $337 \mathrm{ml} / \mathrm{min}$ when using Duplex flow measurements. ${ }^{31,32}$ These widely variable findings point to a potential disadvantage of this approach. Duplex flow measurements have considerable inter- and intra-observer variability, which introduce considerable variance. ${ }^{33,34}$ Also peri-operative sonographic evaluation is time consuming and it is not simply possible to assess plasma flow at any time point during surgery without interfering with the operation. Last, flow data are important to quantify substance exchange across organs, but even if the flow data are not that accurate, the qualitative measure is still informative. In this context, it is important to point out that our group recently confirmed by using the novel MRI based flow measurement, that mean flows are interchangeable and therefore mean plasma flow values can be used in flux calculations. ${ }^{32}$ In the future, pre-operative MRI could be used to estimate plasma flow, because interobserver variability is less and therefore the results are probably more reliable.

\section{Conclusion}

This randomized placebo controlled study showed the effects of butyrate administration on interorgan SCFA trafficking. It showed a quick and sharp increase in gut release of butyrate after administering it entirely. Furthermore, there was an increase in systemic arterial butyrate concentrations with a quick wash out. The liver scavenged most of butyrate administered with an enema. The other SCFA concentrations and uptake and release (i.e. acetate and propionate) did not change after butyrate administration, suggesting that there is no co-transport of acetate and propionate.

This study gives important information on the physiological trafficking of SCFA in humans following a butyrate enema, which may be of importance when using prebiotic supplementation on a therapeutic basis. 


\section{References}

1. Willemsen LE, Koetsier MA, van Deventer SJ, van Tol EA. Short chain fatty acids stimulate epithelial mucin 2 expression through differential effects on prostaglandin $E(1)$ and $E(2)$ production by intestinal myofibroblasts. Gut 2003; 52:1442-7.

2. Roediger WE. Role of anaerobic bacteria in the metabolic welfare of the colonic mucosa in man. Gut 1980;21:793-8.

3. Roediger WE. Utilization of nutrients by isolated epithelial cells of the rat colon. Gastroenterology 1982;83:424-9.

4. Lupton JR. Microbial degradation products influence colon cancer risk: the butyrate controversy. J Nutr 2004;134:479-82.

5. Forchielli ML, Walker WA. The role of gut-associated lymphoid tissues and mucosal defence. Br J Nutrition 2005;93 Suppl 1:S41-8.

6. Roy CC, Kien CL, Bouthillier L, Levy E. Short-chain fatty acids: ready for prime time? Nutr Clin Pract. 2006;21:351-66.

7. Al-Lahham S, Roelofsen H, Rezaee F, Weening D, Hoek A, Vonk R, Venema K. Propionic acid affects immune status and metabolism in adipose tissue from overweight subjects. Eur J Clin Invest. 2012; 42:357-64.

8. Welters CF, Heineman E, Thunnissen FB, van den Bogaard AE, Soeters PB, Baeten CG. Effect of dietary inulin supplementation on inflammation of pouch mucosa in patients with an ileal pouch-anal anastomosis. Dis Colon Rectum, 2002;45:621-7.

9. Hille A, Herrmann MK, Kertesz T, Christiansen H, Hermann RM, Pradier O, Schmidberger H, Hess CF. Sodium butyrate enemas in the treatment of acute radiation-induced proctitis in patients with prostate cancer and the impact on late proctitis. A prospective evaluation. Strahlenther Onkol, 2008;184:686-92.

10. Kles KA, Chang EB. Short-chain fatty acids impact on intestinal adaptation, inflammation, carcinoma, and failure. Gastroenterology 2006;130(2 Suppl 1):S100-5.

11. Leenen $\mathrm{CH}$, Dieleman LA. Inulin and oligofructose in chronic inflammatory bowel disease. J Nutr 2007;137(11 Suppl):2572S-2575S.

12. Harig JM, Soergel KH, Komorowski RA, Wood CM. Treatment of diversion colitis with short-chain-fatty acid irrigation. New Engl J Med 1989;320:23-8.

13. Guillemot F, Colombel JF, Neut C, Verplanck N, Lecomte M, Romond C, Paris JC, Cortot A. Treatment of diversion colitis by short-chain fatty acids. Prospective and double-blind study. Dis Colon Rectum 1991;34:861-4.

14. Roediger WE. The colonic epithelium in ulcerative colitis: an energy-deficiency disease? Lancet 1980; 2:712-5.

15. Breuer RI, Buto SK, Christ ML, Bean J, Vernia P, Paoluzi P, Di Paolo MC, Caprilli R.Rectal irrigation with short-chain fatty acids for distal ulcerative colitis. Preliminary report. Dig Dis Sci 1991;36:185-7.

16. Scheppach W, Sommer H, Kirchner T, Paganelli GM, Bartram P, Christl S, Richter F, Dusel G, Kasper H. Effect of butyrate enemas on the colonic mucosa in distal ulcerative colitis. Gastroenterology 1992; 103:51-6.

17. Hamer HM, Jonkers DM, Vanhoutvin SA, Troost FJ, Rijkers G, de Bruïne A, Bast A, Venema K, Brummer RJ.Effect of butyrate enemas on inflammation and antioxidant status in the colonic mucosa of patients with ulcerative colitis in remission. Clin Nutr 2010;29:738-44.

18. Bloemen JG, Olde Damink SW, Venema K, Buurman WA, Jalan R, Dejong CH. Short chain fatty acids exchange: Is the cirrhotic, dysfunctional liver still able to clear them? Clin Nutr 2010;29:365-9.

19. Bloemen JG, Venema K, van de Poll MC, Olde Damink SW, Buurman WA, Dejong CH. Short chain fatty acids exchange across the gut and liver in humans measured at surgery. Clin Nutr 2009;28:657-61.

20. van de Poll MC, Ligthart-Melis GC, Boelens PG, Deutz NE, van Leeuwen PA, Dejong CH. Intestinal and hepatic metabolism of glutamine and citrulline in humans. J Physiol 2007;581:819-27. 
21. van de Poll MC, Siroen MP, van Leeuwen PA, Soeters PB, Melis GC, Boelens PG, Deutz NE, Dejong CH. Interorgan amino acid exchange in humans: consequences for arginine and citrulline metabolism. Am J Clin Nutr 2007;85:167-72.

22. van Eijk HM, Bloemen JG, Dejong CH. Application of liquid chromatography-mass spectrometry to measure short chain fatty acids in blood. J Chromatogr B Analyt Technol Biomed Life Sci. 2009;877: 719-24.

23. Duncan SH, Belenguer A, Holtrop G, Johnstone AM, Flint HJ, Lobley GE. Reduced dietary intake of carbohydrates by obese subjects results in decreased concentrations of butyrate and butyrateproducing bacteria in feces. Appl Environ Microbiol 2007;73:1073-8.

24. Matsumoto N, Riley S, Fraser D, Al-Assaf S, Ishimura E, Wolever T, Phillips GO, Phillips AO. Butyrate modulates TGF-beta1 generation and function: potential renal benefit for Acacia(sen) SUPERGUM (gum arabic)? Kidney Int 2006;69:257-65.

25. Fernandes J, Morali G, Wolever TM, Blendis LM, Koo M, Jenkins DJ, Rao AV. Effect of acute lactulose administration on serum acetate levels in cirrhosis. Clin Invest Med 1994:17:218-25.

26. McNeil NI, Cummings JH, James WP. Short chain fatty acid absorption by the human large intestine. Gut 1978;19:819-22.

27. Roberfroid MB. Introducing inulin-type fructans. Br J Nutr 2005;93 Suppl 1:S13-25.

28. Cook SI, Sellin JH. Review article: short chain fatty acids in health and disease. Aliment Pharmacol Ther 1998;12:499-507.

29. Charney AN, Micic L, Egnor RW. Nonionic diffusion of short-chain fatty acids across rat colon. The Am J Physiol 1998;274:G518-24.

30. Fleming SE, Choi SY, Fitch MD. Absorption of short-chain fatty acids from the rat cecum in vivo. J Nutr 1991;121:1787-97.

31. Yzet T, Bouzerar R, Allart JD, Demuynck F, Legallais C, Robert B, Deramond H, Meyer ME, Balédent O. Hepatic vascular flow measurements by phase contrast MRI and doppler echography: a comparative and reproducibility study. J Magn Reson Imaging 2010;31:579-88.

32. Vermeulen MA, Ligthart-Melis GC, Buijsman R, Siroen MP, van de Poll MC, Boelens PG, Dejong CH, van Schaik C, Hofman MB, van Leeuwen PA. Accurate perioperative flow measurement of the portal vein and hepatic and renal artery: A role for preoperative MRI? Eir J Radiol 2012;81:2042-8.

33. de Vries PJ, van Hattum J, Hoekstra JB, de Hooge P. Duplex Doppler measurements of portal venous flow in normal subjects. Inter- and intra-observer variability. J Hepatol 1991;13:358-63.

34. Carlisle KM, Halliwell M, Read AE, Wells PN. Estimation of total hepatic blood flow by duplex ultrasound. Gut 1992;33:92-7. 


\section{Part III}

Clinical application of short chain fatty acids 



\section{Chapter 7}

Quality of life on the long-term in rectal cancer patients; association with severe postoperative complications and presence of a stoma

JG Bloemen, RG Visschers, W Truin, GL Beets, JL Konsten Dis Colon Rectum 2009;52;1251-1258 


\section{Abstract}

\section{Background and aim}

The aim of this study was to evaluate the impact of postoperative complications and the presence of a stoma on quality of life on the long-term in rectal cancer patients.

\section{Methods}

Consecutive patients with an adenocarcinoma of the rectum operated in Maastricht University Medical Centre or in VieCuri Medical Centre Venlo between 2003 and 2005 were included in this study. Data about surgical treatment and complications were collected. Severe postoperative complications were classified according to a standardized complication severity score. Quality of life was assessed by using the European Organisation for Research and Treatment of Cancer Quality of Life Questionnaire C30 and CR38.

\section{Results}

One hundred seventy patients received a questionnaire, 121 responded (71\%). Of the responders, $33(27.3 \%)$ patients suffered from severe postoperative complications. The median follow-up was 36 months. In the univariable analysis patients with severe postoperative complications reported a lower score on physical functioning (73 vs. $85, P=0.031)$ and a higher score on pain (17 vs. $0, P=0.025)$ and fatigue ( 33 vs. $22, P=0.036)$. Stoma construction $(n=51)$ was associated with a higher global health status ( 83 vs. $75, P=0.019$ ) and these patients reported less gastrointestinal complaints $(P=0.001)$.

\section{Conclusion}

Severe postoperative complications seem to be associated with several lower quality of life subscores on the long-term. In contrast, a stoma is associated with improved global health status and leads to less gastrointestinal complaints. In patients prone to complications it may be sensible to avoid creating a low anastomosis and construct a permanent stoma immediately. 


\section{Introduction}

Major improvements have been made in the treatment of rectal cancer during the last two decades. Better local control has been achieved after the introduction of the Total Mesorectal Excision (TME) technique with preoperative radiotherapy and neoadjuvant chemotherapy. ${ }^{1}$ However, modern rectal cancer treatment is still associated with a significant complication rate (46\%), including an anastomotic leakage rate of $10 \%^{2,3}$ and a mortality rate of $7 \%{ }^{4}$

Besides oncologic results and traditional clinical outcome measures such as morbidity and mortality, functional outcome has become an important parameter to define surgical performance as well. Quality of life (QoL) is a reflection of the patients' own appraisal of current physical and mental health status, social functioning, and general well being and can provide essential information about the consequences of a certain treatment. $^{5}$

Information regarding possible outcome can influence decisions regarding treatment strategies. Currently, these decisions mainly depend on tumor characteristics such as height, depth, and nodal status, weighed off against the patient's health status. ${ }^{6}$ However, patient's preferences should be strongly considered as well and may be determined by possible long-term clinical and functional outcome. Quality of life studies in patients with rectal cancer have focused mainly on the consequences of the presence of a stoma, ${ }^{7,8}$ whereas postoperative complications can have a major impact as well. Postoperative complications influence patient's condition, length of hospital stay, and even in hospital mortality. Sharma et al. also reported morbidity to be an independent risk factor for lower early postoperative QoL scores in colorectal cancer patients. ${ }^{9}$ The impact of complications on QoL in the long-term remains unknown and may be even more important when outlining treatment strategies. ${ }^{9}$

The aim of our study was to assess the impact of postoperative complications and the presence of a stoma on QoL after rectal cancer surgery on the long-term.

\section{Patients and Methods}

\section{Patients}

This study was approved by the medical ethics committee of both hospitals. The data of all consecutive patients with rectal cancer were collected in a general teaching hospital, (GTH, VieCuri Medical Centre, Venlo), and in the Maastricht University Medical Centre (MUMC) retrospectively. The patients were selected using the hospital operating and diagnosis coding system. Inclusion criteria were: histologically proven adenocarcinoma of the rectum, within $15 \mathrm{~cm}$ of the anal verge as measured on proctoscopy or MRI, and surgical treatment between January 2003 and December 2005. Patients with a recurrent carcinoma and with tumors which might require intraoperative brachytherapy were excluded from the study. Because the MUMC and 
GTH both adhered to the same treatment strategy, tertiary referred patients were excluded. Data were collected from the patient records including age, sex, concurrent medical illnesses, American Society of Anesthesiologist (ASA) classification (during initial surgery), tumor characteristics, and neoadjuvant treatment. The surgical procedure and reconstruction technique and the postoperative complications were recorded retrospectively. All these data were collected from the inpatient and outpatient records. The records were reviewed by two authors (JB and RV) who were blinded for each others results.

\section{Complications}

The complications were scored according to the classification of surgical complications described by Dindo et al. ${ }^{10}$ This scoring system mainly focuses on the surgical complications and consists of seven grades; Grade I any deviation of the normal postoperative course without the need of pharmacologic treatment or intervention, Grade II requiring pharmacologic treatment, Grade Illa complications requiring surgical, endoscopic, or radiologic intervention not under general anesthesia, Grade IIIb complications requiring surgical, endoscopic, or radiologic intervention under general anesthesia, Grade IVa life-threatening complication requiring management at the intensive care unit (ICU) with single organ failure, Grade IVb life-threatening complication requiring ICU management with multiorgan failure, Grade $\mathrm{V}$ death of a patient. Table 7.1 shows examples of the different categories.

To investigate the influence of complications on QoL, grades III or IV complications are defined as severe, whereas absence of complications or grades I and II complications are defined as absent/mild complications. We assume that only severe complications can be accountable for long-term effects on QoL.

Table 7.1 Classification of postoperative complications.

\begin{tabular}{|c|c|c|}
\hline Grade & Definition & Examples \\
\hline Grade I & $\begin{array}{l}\text { Any deviation from the normal postoperative } \\
\text { course, no pharmacologic treatment }\end{array}$ & Wound infection \\
\hline Grade II & Requiring pharmacotherapeutic intervention & $\begin{array}{l}\text { Urinary tract infection, ileus } \\
\text { requiring total parenteral } \\
\text { nutrition }\end{array}$ \\
\hline Grade III a & Complications needing reintervention & $\begin{array}{l}\text { Anastomotic leakage with } \\
\text { radiological drainage }\end{array}$ \\
\hline Grade III b & $\begin{array}{l}\text { Complications needing reintervention under } \\
\text { general anesthesia } \\
\text { Life-threatening complication requiring ICU }\end{array}$ & $\begin{array}{l}\text { Anastomotic leakage with } \\
\text { surgical reintervention } \\
\text { Sepsis }\end{array}$ \\
\hline Grade IV a & Single organ dysfunction & \\
\hline Grade IV b & Multiorgan dysfunction & \\
\hline Grade V & Death & \\
\hline
\end{tabular}




\section{Quality of Life}

QoL was assessed by using the validated European Organisation for Research and Treatment of Cancer Quality of life Questionnaires Core-30 and ColoRectal-38 (EORTC QLQ C30 and CR38). ${ }^{11-13}$ The C30 questionnaire assesses QoL in cancer patients. It contains 30 items that can be divided in five functional scales (physical, role, emotional, cognitive, and social functioning). The CR38 is a questionnaire developed for rectal cancer patients and quantifies four functional scales (body image, future perspective, sexual function, and sexual enjoyment) and eight symptom scales (micturition, gastrointestinal disorders, defecation, stomarelated and sexual problems, nausea and vomiting, and weight loss). The validity and reliability of both questionnaires have been established in Dutch patients. ${ }^{11,13}$ The scales range from 0 to 100; a higher score on functional scales indicates better functioning, whereas a higher score on symptom scales indicates a higher symptomatology. The questionnaires were sent by mail with an accompanying letter signed by the surgeon of GTH or MUMC. Patients who did not return the questionnaire within two weeks were called and asked again to complete the questionnaire. A new questionnaire was sent to these patients if needed. Patients who returned the questionnaire were defined as responders.

\section{Statistical analysis}

First, patients who were sent a questionnaire were compared with those who were excluded or died during follow-up regarding patient characteristics and tumor stage with Pearson's Chi-Squared test and Student's $t$-test for unpaired samples where appropriate. The responders were compared with the nonresponders regarding patient characteristics, concurrent medical illnesses, and tumor stage with the Pearson's Chi-Squared test and Student's $t$-test for unpaired samples, where appropriate as well. The association between patient characteristics, tumor stage, concurrent medical illnesses, and QoL was analyzed with the Mann-Whitney $U$ test and Kruskal-Wallis test where appropriate. Only when a variable had a $p$-value lower

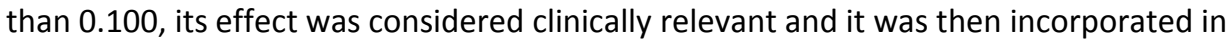
a linear multivariable regression model. Confounding was also checked using linear backward regression and no confounding factors were identified. All data are expressed as median and range, unless stated otherwise. Two-tailed $P$-values lower than 0.050 were considered significant. For statistical analysis SPSS version 15.0 for Windows (2006, SPSS Inc. Chicago, USA) was used. 


\section{Results}

\section{Patients}

In total, 236 patients ( 128 from GTH and 108 from MUMC) were eligible for the study of whom 66 patients were excluded for the following reasons: tertiary referred patients and/or patients requiring intraoperative brachytherapy $(n=10)$, inhospital death $(n=11)$, death during follow-up $(n=45)$. These excluded patients were significantly older and had more advanced tumor stage $(P<0.050)$ than patients who were eligible for this study. Consequently, 170 patients received the questionnaires of whom 121 patients (71\%) returned all forms (Table 7.2). The responders were significantly younger than the nonresponders $(P=0.041)$. However, sex, concurrent medical illnesses, ASA classification, tumor stage, and neoadjuvant treatment did not differ significantly between the responders and nonresponders $(P>0.367)$. The median duration of follow-up after surgery of the responders was 36 (16-51) months.

Patients from MUMC had more locally advanced tumors than GTH (77\% vs. 58\%, $P=0.009$ )

Table 7.2 Baseline characteristics.

\begin{tabular}{lc}
\hline Patients & $\mathrm{n}=170$ \\
\hline Male (\%) & 58 \\
Age (years) & $67(32-96)^{*}$ \\
Concurrent Medical IIInesses & 52 \\
Hypertension & 37 \\
Cardiovascular disease & 12 \\
Respiratory disease & 15 \\
Diabetes & 12 \\
Arthrosis & 10 \\
Malignancy & \\
TNM- Stage & $49(28.8)$ \\
Stage I & \\
Stage II & $57(33.5)$ \\
IIA & $3(1.8)$ \\
IIB & \\
Stage III & $6(3.5)$ \\
IIIA & $30(17.6)$ \\
IIIB & $11(6.5)$ \\
IIIC & $14(8.2)$ \\
Stage IV & \\
Neoadjuvant treatment & $12(7.1)$ \\
I None & $121(71.2)$ \\
II 5x5 Gray & $6(3.5)$ \\
III 50 Gray & $25(14.7)$ \\
IV Chemoradiation & $6(3.5)$ \\
V Unknown & \\
\hline &
\end{tabular}




\section{Surgery and Surgical Complications}

All included patients were operated between January 2003 and December 2005. The median duration of hospital stay was 13 (5-196) days. The surgical procedures performed in the responders were: 71 (59\%) patients underwent a low anterior resection (LAR) with a covering stoma, 15 (12\%) a LAR without a stoma, 10 (8\%) a LAR with J-pouch construction, and $25(21 \%)$ patients underwent an abdominoperineal resection (APR). A stoma was present in 75 (43.6\%) patients at time of the study.

The complication rate, as defined by the occurrence of one or more complications after surgery, was $48.8 \%$ (Table 7.3 ). In total, 33 (27.3\%) patients had a severe complication.

Patient characteristics, concurrent medical illnesses, tumor stage and ASA classification were not different in patients with or without severe complications $(P>0.092)$ or patients with and without a stoma $(P>0.197)$.

Table 7.3 Classification of postoperative complications in responders.

\begin{tabular}{ll}
\hline Complications & $\mathrm{n}=121$ \\
\hline No complications & $62(51.2)$ \\
Grade I & $11(9.1)$ \\
Grade II & $15(12.4)$ \\
Grade III & \\
a & $15(12.4)$ \\
b & $13(10.7)$ \\
Grade IV & \\
a & $0(0)$ \\
b & $5(4.1)$ \\
\hline
\end{tabular}

\section{Quality of Life}

The QoL questionnaires were sent to 170 patients (94 GTH and $76 \mathrm{MUMC}$ ) of whom 121 (71\%; GTH 85\%, MUMC 65\%) responded.

QoL scores were compared between patients with severe complications and without severe complications (Table 7.4) and showed that patients with severe complications reported significantly worse physical functioning ( $73 \mathrm{vs.} 85, P=0.031$ ), more pain and more interference of this pain with daily activities (17 vs. $0, P=0.025)$, suffered more of fatigue (33 vs. $22, P=0.036)$ and reported more weight loss ( 0 vs. $0, P=0.031)$ than patients without or with only mild complications after surgery.

Patients without a stoma reported significantly more gastrointestinal complaints (26 vs. $13, P=0.001$ ), diarrhea ( 0 vs. $0, P=0.036$ ) and constipation ( 0 vs. $0, P=0.019$ ) than patients with a stoma. They also reported a lower score on global health status, (75 vs. $83, P=0.019$ ) and future perspective (67 vs. $67, P=0.035$ ) (Table 7.5).

Of all variables, osteoarthritis was relevantly related with lower QoL scores on seven QoL subscores: role functioning $(P=0.019)$, fatigue $(P=0.020)$, nausea $(P=0.017)$, social 
functioning $(P=0.060)$, diarrhea $(P=0.052)$, future perspective $(P=0.087)$ and dyspnea $(P=0.019)$. The relation with the other $Q$ oL subscores was nonsignificant $(P>0.107)$.

Furthermore, patients with hypertension had lower QoL subscores on physical functioning $(P=0.009)$, role functioning $(P<0.001)$, emotional functioning $(P=0.096)$, social functioning $(P=0.005)$, diarrhea $(P=0.090)$ and future perspective $(P=0.082)$.

Table 7.4 Quality of life scores in patients with and without complications.

\begin{tabular}{|c|c|c|c|c|c|}
\hline & \multicolumn{2}{|c|}{$\begin{array}{c}\text { Grades III \& IV } \\
(n=33)\end{array}$} & \multicolumn{2}{|c|}{$\begin{array}{c}\text { None, Grades I \& II } \\
(\mathrm{n}=88)\end{array}$} & \multirow[b]{2}{*}{$P$-value } \\
\hline & Mean & Median (range) & Mean & Median (range) & \\
\hline \multicolumn{6}{|l|}{ Functional scales } \\
\hline Physical functioning & 71 & $73(13-100)$ & 80 & $85(20-100)^{*}$ & 0.031 \\
\hline Role functioning & 72 & $83(0-100)$ & 75 & $83(0-100)$ & 0.621 \\
\hline Emotional functioning & 75 & $83(17-100)$ & 82 & $92(8-100)$ & 0.471 \\
\hline Cognitive functioning & 83 & $83(50-100)$ & 85 & $100(0-100)$ & 0.283 \\
\hline Social functioning & 75 & $83(17-100)$ & 80 & $92(17-100)$ & 0.463 \\
\hline Global health status & 71 & $75(33-100)$ & 74 & $75(17-100)$ & 0.539 \\
\hline Future perspective & 57 & $67(0-100)$ & 65 & $67(0-100)$ & 0.165 \\
\hline Body image & 71 & $78(0-100)$ & 79 & $89(0-100)$ & 0.143 \\
\hline Sexual function & 19 & $17(0-67)$ & 16 & $0(0-67)$ & 0.350 \\
\hline Sexual enjoyment & $* *$ & $* *$ & $* *$ & $* *$ & NA \\
\hline \multicolumn{6}{|l|}{ Symptom scales } \\
\hline Fatigue & 35 & $33(0-100)$ & 25 & $22(0-100)^{*}$ & 0.036 \\
\hline Nausea & 8 & $0(0-67)$ & 7 & $0(0-67)$ & 0.944 \\
\hline Pain & 27 & $17(0-100)$ & 15 & $0(0-100)^{*}$ & 0.025 \\
\hline Dyspnoea & 21 & $0(0-100)$ & 14 & $0(0-100)$ & 0.277 \\
\hline Sleep disturbances & 15 & $0(0-67)$ & 22 & $0(0-100)$ & 0.296 \\
\hline Appetite loss & 12 & $0(0-67)$ & 9 & $0(0-100)$ & 0.517 \\
\hline Constipation & 13 & $0(0-100)$ & 17 & $0(0-100)$ & 0.339 \\
\hline Diarrhoea & 20 & $0(0-67)$ & 17 & $0(0-100)$ & 0.255 \\
\hline Financial worries & 9 & $0(0-100)$ & 9 & $0(0-100)$ & 0.867 \\
\hline Micturition problems & 29 & $33(0-67)$ & 28 & $33(0-83)$ & 0.795 \\
\hline GI problems & 25 & $22(0-73)$ & 21 & $20(0-100)$ & 0.421 \\
\hline Weight loss & 17 & $0(0-100)$ & 7 & $0(0-100)^{*}$ & 0.031 \\
\hline Defecation problems & 33 & $33(5-67)$ & 29 & $29(0-100)$ & 0.346 \\
\hline Stoma problems & 23 & $17(0-52)$ & 23 & $19(0-100)$ & 0.788 \\
\hline Chemo side-effects & 11 & $0(0-78)$ & 15 & $11(0-100)$ & 0.113 \\
\hline Male sexual problems & 69 & $75(0-100)$ & 70 & $83(0-100)$ & 0.967 \\
\hline Female sexual problems & $* *$ & $* *$ & $* *$ & $* *$ & NA \\
\hline
\end{tabular}

A high score (0-100) on a fuctional scale indicates a good function, whereas a high symptom score indicates a high degree of symptoms. $\mathrm{Gl}=$ Gastrointestinal. ${ }^{* *}$ too many missing values

According to the univariate analysis, osteoarthritis and severe postoperative complications were significantly associated with higher scores on the fatigue symptom scale. In a linear multivariable analysis the presence of osteoarthritis and severe 
postoperative complications were independently and significantly related to lower fatigue scores $(\beta=28.937, \mathrm{Cl} 10.52-47.34, P=0.002$ and $\beta=13.985, \mathrm{Cl} 4.05-23.92$, $P=0.006$, respectively). Furthermore, since in a univariate analysis severe postoperative complications and the presence of a stoma were both associated with a higher score on the weight loss subscale a linear multivariable analysis was also performed for these two variables. Severe postoperative complications showed a significant and independent relation with a higher weight loss score $(\beta=9.495, \mathrm{Cl} 0.88$ 18.11, $P=0.031$ ), whereas the presence of a stoma only showed a trend toward significance $(\beta=7.593, \mathrm{Cl}-0.21-15.40, P=0.056)$. Furthermore, severe complications and the presence of a stoma showed no significant relation.

Table 7.5 Quality of life scores in patients with and without stoma.

\begin{tabular}{|c|c|c|c|c|c|}
\hline & & $\begin{array}{l}\text { Stoma } \\
(n=51)\end{array}$ & & $\begin{array}{l}\text { Jo stoma } \\
(\mathrm{n}=70)\end{array}$ & \\
\hline & Mean & Median (range) & Mean & Median (range) & $P$-value \\
\hline \multicolumn{6}{|l|}{ Functional scales } \\
\hline Physical functioning & 78 & $80(20-100)$ & 78 & $80(13-100)$ & 0.811 \\
\hline Role functioning & 79 & $100(17-100)$ & 71 & $83(0-100)$ & 0.128 \\
\hline Emotional functioning & 83 & $92(33-100)$ & 78 & $83(8-100)$ & 0.324 \\
\hline Cognitive functioning & 85 & $83(0-100)$ & 84 & $83(0-100)$ & 0.887 \\
\hline Social functioning & 81 & 100 (17-100) & 77 & $83(17-100)$ & 0.276 \\
\hline Global health status & 77 & $83(33-100)^{*}$ & 70 & $75(17-100)^{*}$ & 0.019 \\
\hline Future perspective & 69 & $67(0-100)$ & 58 & $67(0-100)$ & 0.035 \\
\hline Body image & 76 & $89(0-100)$ & 78 & $89(0-100)$ & 0.933 \\
\hline Sexual function & 17 & $0(0-67)$ & 17 & $17(0-50)$ & 0.562 \\
\hline Sexual enjoyment & $* *$ & $* *$ & $* *$ & $* *$ & NA \\
\hline \multicolumn{6}{|l|}{ Symptom scales } \\
\hline Fatigue & 23 & $22(0-78)$ & 31 & $22(0-100)$ & 0.063 \\
\hline Nausea & 6 & $0(0-67)$ & 8 & $0(0-67)$ & 0.708 \\
\hline Pain & 15 & $0(0-100)$ & 21 & $0(0-100)$ & 0.289 \\
\hline Dyspnoea & 13 & $0(0-100)$ & 18 & $0(0-100)$ & 0.466 \\
\hline Sleep disturbances & 18 & $0(0-100)$ & 22 & $0(0-100)$ & 0.424 \\
\hline Appetite loss & 8 & $0(0-100)$ & 11 & $0(0-100)$ & 0.455 \\
\hline Constipation & 10 & $0(0-100)$ & 20 & $0(0-100)^{*}$ & 0.019 \\
\hline Diarrhoea & 12 & $0(0-100)$ & 22 & $0(0-100)^{*}$ & 0.036 \\
\hline Financial worries & 6 & $0(0-67)$ & 11 & $0(0-100)$ & 0.641 \\
\hline Micturition problems & 29 & $33(0-83)$ & 28 & $33(0-78)$ & 0.679 \\
\hline GI-problems & 17 & $13(0-67)$ & 26 & $26(0-100)^{*}$ & 0.001 \\
\hline Weight loss & 15 & $0(0-100)$ & 7 & $0(0-67)^{*}$ & 0.039 \\
\hline Defecation problems & NA & NA & 30 & $29(0-100)$ & NA \\
\hline Stoma problems & 23 & $19(0-100)$ & NA & NA & NA \\
\hline Chemo side-effects & 16 & $11(0-100)$ & 12 & $11(0-67)$ & 0.521 \\
\hline Male sexual problems & 77 & $100(0-100)$ & 65 & $67(0-100)$ & 0.099 \\
\hline Female sexual problems & $* *$ & $* *$ & $* *$ & $* *$ & NA \\
\hline
\end{tabular}

A high score on a fuctional scale indicates a good function, whereas a high symptom score indicates a high degree of symptoms. $\mathrm{GI}=$ Gastrointestinal. ${ }^{* *}$ too many missing values. 
In the univariate analysis presence of a stoma, hypertension, and osteoarthritis were associated with lower scores on future perspective. In a linear multivariable analysis hypertension showed a trend toward lower scores on future perspective $(\beta=-10.192$, $\mathrm{Cl}$-21.599-1.216, $P=0.079$ ), whereas osteoarthritis showed a trend toward higher scores $(\beta=20.616, \mathrm{Cl}-1.785-43.016, P=0.071)$.

Finally, osteoarthritis is significantly and independently related to higher scores on the diarrhea symptom scale $(\beta=22.810, \mathrm{Cl} 3.093-42.527, P=0.024)$, whereas the presence of a stoma showed a trend towards significance $(\beta=-9.313, \mathrm{Cl}-18.987-0.367, P=0.052)$ Overall, male patients reported a high symptom score on sexual problems $(83$, range $0-100)$ and a low score on sexual functioning (16, range $0-67)$. Only a minority of the female patients (17 patients, 33\%) answered the questions about sexual problems, sexual enjoyment, and sexual functioning, whereas a minority of the male patients (27 patients, 39\%) filled out the questions concerning sexual enjoyment. As a consequence, these values are missing in Tables 7.4 and 7.5.

Patients from MUMC reported a higher pain score (17 vs. $0, P=0.002$ ) and a higher score on chemotherapy side effects ( 20 vs. 6, $P=0.021)$ than patients from GTH. Other differences between both hospitals were not found.

\section{Discussion}

The present study was conducted to investigate the influence of severe postoperative complications and the presence of a stoma on quality of life on the long-term in rectal cancer patients. This study showed that severe postoperative complications were associated with lower scores on QoL on the long-term with respect to physical functioning and also with higher scores on pain experience, fatigue, and weight loss scores. Furthermore, presence of a stoma was related to higher global health status and future perspective and these patients reported less gastrointestinal problems than patients without a stoma. Remarkably, no differences were found in global health status between patients with mild and severe complications. Most likely, this can be explained by the effect called rejoice; this effect is a change in patients perceptions and expectations after the diagnosis of a life-threatening disease ${ }^{14,15}$ and is frequently reported in QoL studies. ${ }^{16}$

The complication rate found in our study is comparable with other studies, which reported an overall complication rate of 31 to $45 \% .{ }^{1,17}$ The classification of the complications according to Dindo et al. is a good approach, because it takes into account the therapeutic consequences of the complications and the burden on the patient. ${ }^{10}$ This is very valuable in this study, because a frequently observed complication in rectal cancer surgery is pelvic sepsis. A generally accepted definition for anastomotic leakage or pelvic sepsis is not available, ${ }^{18}$ but the consequences of pelvic sepsis vary greatly; from conservative treatment to radiologic or surgical reintervention to multiorgan failure. The current classification avoids the definition 
problem and emphasizes the consequences for the patient and the patient's condition.

A prospective study by Camilleri-Brennan and Steele showed the evolution of QoL before surgery until a year postoperatively. ${ }^{19}$ The scores 3 to 12 months after surgery are comparable with our data, with slightly higher scores on global health status in our study. Moreover, they showed that QoL scores already stabilized three months after surgery. According to Hofhuis et al. the most significant improvement in QoL scores in critically ill patients can be expected during the first weeks after ICU discharge. ${ }^{20}$ This would imply that the negative impact of surgical complications is already established in the early phase, stressing the importance of prompt and adequate management. In our population physical functioning and fatigue scores are impaired on the long-term, suggesting that physical training can be of additional value in the early postoperative period next to treatment of the complication itself.

Bruce et al. found that up to $18 \%$ of patients who had undergone gastrointestinal anastomotic surgery suffered from chronic postsurgical pain four years after the intervention. ${ }^{16}$ The present study shows that this mainly occurs in patients with severe postoperative complications. Compared with patients without severe postoperative complications their pain scores were significantly higher in patients with severe complications. Severe complications often require surgical or radiologic reintervention or ICU admission which can result, for instance, in extensive adhesions and critical illness neuropathy.

In the literature there is much debate on the effect of a stoma on QoL. Some found lower QoL scores for patients with a stoma, ${ }^{21,22}$ others found no difference between patients who underwent an APR or a LAR with a primary anastomosis. ${ }^{5,8,15,23}$ Our series supports the latter, with patients with a stoma reporting less gastrointestinal complaints such as constipation and diarrhea. Global health status is significantly higher in patients with a stoma. It is known that patients who have had a low anterior resection with a low anastomosis complain about "the low anterior syndrome" with frequent, incomplete defaecation. ${ }^{24}$ Although a study of Neuman et al. concluded that the EORTC C30 and CR38 are not sensitive instruments to assess differences in bowel function, ${ }^{25}$ the results from our study suggest that patients in the present study might indeed suffer from the low anterior syndrome.

This study is limited by its retrospective character and by the lack of baseline QoL scores. However, additional information about patient characteristics, ASA classification, tumor stage, and concurrent medical illnesses does give an indication about possible baseline values and the way current results can be interpreted. Age was significantly higher in the excluded population implying that their baseline QoL was lower. Age was significantly higher in the nonresponders group as well, whereas ASA-classification and concurrent medical illnesses were not significantly different in the responders and nonresponders group. Because, especially concurrent medical illnesses were shown to be strongly related with QoL, ${ }^{26,27}$ baseline QoL scores could have been the same among responders and nonresponders. Furthermore, variables were not significantly different in patients with and without severe complications and 
patients with and without a stoma showing that baseline QoL scores could be comparable. Only osteoarthritis and hypertension were significantly related with four or more QoL subscores. Subsequently, confounding was minimized by making a linear multivariable regression model for the subscores that were related with two variables. Despite these limitations, this study does document the importance of a thorough decision-making process, in which it is of utmost significance to consider the complication risk profile of the patient to select the optimal type of surgery in that particular patient. Furthermore, it may no longer be necessary to avoid a stoma at any expense, since QoL scores are comparable or even better in patients with a stoma. This emphasizes once more that the general belief that a stoma is equivalent to poor QoL is not true.

The majority of the patients experience sexual dysfunction after rectal cancer surgery, which is a result of damage to the autonomous plexuses that occurred due to surgery and radiotherapy. ${ }^{28,29}$ Also in our study, scores on sexual functioning and male sexual problems are high, which are comparable with other studies. ${ }^{30,31}$

Finally, the patient population in a university hospital may be different from a general teaching hospital with respect to complexity of presented problems, but by excluding tertiary referred patients we created homogenous groups. Nevertheless, in the MUMC there were still more locally advanced tumors than in GTH. In the MUMC, patients reported significantly more pain and side effects from chemotherapy. This may be explained by the fact that locally advanced tumors require aggressive treatment regimens receiving more intensive radiotherapy doses or administering new available drugs (i.e., Oxaliplatin, Irinitocan). ${ }^{32}$ Furthermore, surgery may be more extensive in locally advanced cases and adjuvant treatment is given more often in node positive tumors.

\section{Conclusion}

Our study indicates that complications after rectal cancer surgery are associated with several lower QoL subscores on the long term. In contrast, a permanent stoma is associated with improved global health status and is associated with less gastrointestinal problems. These findings suggest that in selected patients it can be wise to avoid a low anastomosis and construct a permanent stoma immediately. 


\section{References}

1. Kapiteijn E, Marijnen CA, Nagtegaal ID, Putter H, Steup WH, Wiggers T, Rutten HJ, Pahlman L, Glimelius B, van Krieken JH, Leer JW, van de Velde CJ; Dutch Colorectal Cancer Group. Preoperative radiotherapy combined with total mesorectal excision for resectable rectal cancer. $\mathrm{N}$ Engl J Med 2001;345:638-46.

2. Marijnen CA, Kapiteijn E, van de Velde CJ, Martijn H, Steup WH, Wiggers T, Kranenbarg EK, Leer JW; Cooperative Investigators of the Dutch Colorectal Cancer Group. Acute side effects and complications after short-term preoperative radiotherapy combined with total mesorectal excision in primary rectal cancer: report of a multicenter randomized trial. J Clin Oncol 2002;20:817-25.

3. Peeters KC, Tollenaar RA, Marijnen CA, Klein Kranenbarg E, Steup WH, Wiggers T, Rutten HJ, van de Velde CJ; Dutch Colorectal Cancer Group. Risk factors for anastomotic failure after total mesorectal excision of rectal cancer. Br J Surg 2005;92:211-6.

4. Lemmens VE, Janssen-Heijnen ML, Houterman S, Verheij KD, Martijn H, van de Poll-Franse L, Coebergh JW. Which comorbid conditions predict complications after surgery for colorectal cancer? World J Surg 2007;31:192-9.

5. Ko CY, Rusin LC, Schoetz DJ, Coller JA, Murray JJ, Roberts PL, Moreau L. Using quality of life scores to help determine treatment: is restoring bowel continuity better than an ostomy? Colorectal Dis 2002;4:41-47.

6. Beets-Tan RG, Beets GL. Rectal cancer: review with emphasis on MR imaging. Radiology 2004; 232:335-46.

7. Cornish JA, Tilney HS, Heriot AG, Lavery IC, Fazio VW, Tekkis PP. A meta-analysis of quality of life for abdominoperineal excision of rectum versus anterior resection for rectal cancer. Ann Surg Oncol 2007;14:2056-68.

8. Pachler J, Wille-Jorgensen P. Quality of life after rectal resection for cancer, with or without permanent colostomy. Cochrane Database Syst Rev 2004;(3):CD004323.

9. Sharma A, Sharp DM, Walker LG, Monson JR. Predictors of early postoperative quality of life after elective resection for colorectal cancer. Ann Surg Oncol 2007;14:3435-42.

10. Dindo D, Demartines N, Clavien PA. Classification of surgical complications: a new proposal with evaluation in a cohort of 6336 patients and results of a survey. Ann Surg 2004;240:205-13.

11. Sprangers MA, te Velde A, Aaronson NK. The construction and testing of the EORTC colorectal cancerspecific quality of life questionnaire module (QLQ-CR38). European Organization for Research and Treatment of Cancer Study Group on Quality of Life. Eur J Cancer 1999;35:238-47.

12. Kaasa S, Bjordal K, Aaronson N, Moum T, Wist E, Hagen S, Kvikstad A. The EORTC core quality of life questionnaire (QLQ-C30): validity and reliability when analysed with patients treated with palliative radiotherapy. Eur J Cancer 1995;31A:2260-3.

13. Aaronson NK, Ahmedzai S, Bergman B, Bullinger M, Cull A, Duez NJ, Filiberti A, Flechtner H, Fleishman SB, de Haes JC, et al. The European Organization for Research and Treatment of Cancer QLQ-C30: a quality-of-life instrument for use in international clinical trials in oncology. J Natl Cancer Inst 1993; 85:365-76.

14. Nord E. The significance of contextual factors in valuing health status. Health Policy 1989;13:189-98.

15. Gosselink MP, Busschbach JJ, Dijkhuis CM, Stassen LP, Hop WC, Schouten WR. Quality of life after total mesorectal excision for rectal cancer. Colorectal Dis 2006;8:15-22.

16. Bruce J, Krukowski ZH. Quality of life and chronic pain four years after gastrointestinal surgery. Dis Colon Rectum 2006;49:1362-70.

17. Bujko K, Nowacki MP, Kepka L, Oledzki J, Bebenek M, Kryj M; Polish Colorectal Study Group. Postoperative complications in patients irradiated pre-operatively for rectal cancer: report of a randomised trial comparing short-term radiotherapy vs chemoradiation. Colorectal Dis 2005;7:410-6.

18. Bruce J, Krukowski ZH, Al-Khairy G, Russell EM, Park KG. Systematic review of the definition and measurement of anastomotic leak after gastrointestinal surgery. Br J Surg 2001;88:1157-68.

19. Camilleri-Brennan J, Steele RJ. Prospective analysis of quality of life and survival following mesorectal excision for rectal cancer. Br J Surg 2001;88:1617-22. 
20. Hofhuis JG, Spronk PE, van Stel HF, Schrijvers GJ, Rommes JH, Bakker J. The impact of critical illness on perceived health-related quality of life during ICU treatment, hospital stay, and after hospital discharge: a long-term follow-up study. Chest 2008;133: 377-85.

21. Engel J, Kerr J, Schlesinger-Raab A, Eckel R, Sauer H, Hölzel D. Quality of life in rectal cancer patients: a four-year prospective study. Ann Surg 2003; 238:203-13.

22. Sprangers MA, Taal BG, Aaronson NK, te Velde A. Quality of life in colorectal cancer. Stoma vs. nonstoma patients. Dis Colon Rectum 1995;38:361-9.

23. Cornish JA, Tilney HS, Heriot AG, Lavery IC, Fazio VW, Tekkis PP. A meta-analysis of quality of life for abdominoperineal excision of rectum versus anterior resection for rectal cancer. Ann Surg Oncol. 2007;14:2056-68.

24. Ortiz H, Armendariz P. Anterior resection: do the patients perceive any clinical benefit? Int J Colorectal Dis 1996;11:191-5.

25. Neuman HB, Schrag D, Cabral C, Weiser MR, Paty PB, Guillem JG, Minsky BD, Wong WD, Temple LK. Can differences in bowel function after surgery for rectal cancer be identified by the european organization for research and treatment of cancer quality of life instrument? Ann Surg Oncol. 2007;14:1727-34.

26. Kriegsman DM, Deeg DJ, Stalman WA. Comorbidity of somatic chronic diseases and decline in physical functioning:; the Longitudinal Aging Study Amsterdam. J Clin Epidemiol 2004;57:55-65.

27. Kriegsman DM, Deeg DJ, van Eijk JT, Penninx BW, Boeke AJ. Do disease specific characteristics add to the explanation of mobility limitations in patients with different chronic diseases? A study in The Netherlands. J Epidemiol Community Health 1997;51:676-85.

28. Marijnen CA, van de Velde CJ, Putter $H$, van den Brink M, Maas CP, Martijn $H$, Rutten HJ, Wiggers T, Kranenbarg EK, Leer JW, Stiggelbout AM. Impact of short-term preoperative radiotherapy on healthrelated quality of life and sexual functioning in primary rectal cancer: report of a multicenter randomized trial. J Clin Oncol 2005;23:1847-58.

29. Hendren SK, O'Connor BI, Liu M, Asano T, Cohen Z, Swallow CJ, Macrae HM, Gryfe R, McLeod RS. Prevalence of male and female sexual dysfunction is high following surgery for rectal cancer. Ann Surg 2005;242:212-23.

30. Gervaz P, Bucher P, Konrad B, Morel P, Beyeler S, Lataillade L, Allal A. A Prospective longitudinal evaluation of quality of life after abdominoperineal resection. J Surg Oncol 2008;97:14-9.

31. Pietrzak L, Bujko K, Nowacki MP, Kepka L, Oledzki J, Rutkowski A, Szmeja J, Kladny J, Dymecki D, Wieczorek A, Pawlak M, Lesniak T, Kowalska T, Richter P; Polish Colorectal Study Group. Quality of life, anorectal and sexual functions after preoperative radiotherapy for rectal cancer: report of a randomised trial. Radiother Oncol 2007;84:217-25.

32. Urso E, Serpentini S, Pucciarelli S, De Salvo GL, Friso ML, Fabris G, Lonardi S, Ferraro B, Bruttocao A, Aschele C, Nitti D. Complications, functional outcome and quality of life after intensive preoperative chemoradiotherapy for rectal cancer. Eur J Surg Oncol 2006;32:1201-8. 


\section{Chapter 8}

Butyrate enemas improve

intestinal anastomotic strength in a rat model

JG Bloemen, MH Schreinemacher, AP de Bruine, WA Buurman, ND Bouvy, CHC Dejong

Dis Colon Rectum 2010;53:1069-1075 


\section{Abstract}

\section{Background and aim}

Anastomotic leakage is a common clinical complication with incidences up to $10-17 \%$ in colorectal surgery, leading to high morbidity and mortality. Butyrate is the product of colonic fermentation of indigestible carbohydrates and is considered beneficial to gastrointestinal healing. The aim of this study was to investigate the effect of intraluminal supplementation of butyrate on colonic anastomotic strength in a rat model.

\section{Methods}

Wistar rats were randomly assigned to one of three groups (18 animals each). All rats underwent a $1-\mathrm{cm}$ left colonic resection and end-to-end anastomosis with four interrupted sutures. Group I underwent no other treatment and served as the control, group II received daily $5 \mathrm{ml}$ of $60 \mathrm{mM}$ sodium butyrate enemas postoperatively and group III received placebo enemas. On the third or seventh postoperative day, rats ( $n=9$ per time point) were anesthetized and anastomotic bursting strength was assessed.

\section{Results}

As a consequence of anastomotic leakage, three rats (16.6\%) in group I, one rat (5.6\%) in group II and two rats (11.2\%) in group III died. Mean anastomotic bursting pressures at day three were not significantly different between groups $(53,64$ and $68 \mathrm{mmHg}$ for group I, II and III, respectively, $P=0.777)$. At day seven, bursting pressures were 118,225 and $129 \mathrm{mmHg}$ for groups I, II and III, respectively $(P=0.0006))$. Group II showed an increased mature to immature collagen ratio $((p P=0.035)$.

\section{Conclusion}

Postoperative intestinal butyrate supplementation enhances anastomotic bursting strength in a left sided partial colonic resection rat model. 


\section{Introduction}

Anastomotic leakage is a common and serious complication after colorectal surgery. Incidences up to $10-17 \%$ are reported, depending on the method of defining and confirming anastomotic leakage and the site of the anastomosis. ${ }^{1-3}$ Anastomotic leakage results in high morbidity and mortality, prolonged hospital stay and even has an adverse effect on oncological outcome. ${ }^{4}$ Several factors are reported to be associated with anastomotic dehiscence, e.g., male sex, ischemia of the anastomotic region, age, neo-adjuvant chemotherapy and irradiation, smoking, obesity and diabetes mellitus. ${ }^{1,5-8}$

Previous attempts to increase anastomotic strength have mainly focused on the prevention of peri-operative ischemia or hypoperfusion of the gut, the administration of growth factors and the use of different suture techniques. ${ }^{9-14}$ Supplementation of specific nutritional components constitutes a different approach to improve anastomotic strength. Therefore, a nutritional approach to increasing anastomotic strength was chosen in the present study. Butyrate is a short chain fatty acid (SCFA) which is a product of the fermentation of indigestible carbohydrates (e.g., fibers, resistant starch) by anaerobic bacteria in the colon. ${ }^{15,16}$ Butyrate is an important energy source for colonocytes, and it stimulates re-epithelialization and may reduce the rate of collagen lysis because of a decrease in matrix metalloproteinase (MMP) release. ${ }^{17-19}$

The aim of this study was to assess the effect of postoperative intraluminal butyrate administration on anastomotic strength in a rat model. Assuming an improved anastomotic strength in the butyrate group would be found, we also investigated some markers of potential mechanisms responsible for enhanced anastomotic healing.

\section{Materials and Methods}

Fifty-four male Wistar rats, weighing 300 to $350 \mathrm{~g}$ were purchased from Harlan BV (Horst, the Netherlands). Animals were housed two per cage under standardized conditions of temperature and humidity and were given access to standard chow and water ad libitum. The animals were allowed to become accustomed to laboratory conditions for seven days before the start of the experiment. The Animal Ethics Committee of Maastricht University Medical Center approved the study.

\section{Design and operative procedure}

Animals were anesthetized using isoflurane (induction 4-5\%, maintenance $2.5 \%$ ) and were given $0.1 \mathrm{mg} / \mathrm{kg}$ of subcutaneous buprenorphine for analgesia. Access to the peritoneal cavity was obtained by median laparotomy under semi-sterile conditions. The operations were performed by one of two persons (JB or MS). 
Abdominal access was achieved by a midline incision. A 1-cm segment of the left colon $2 \mathrm{~cm}$ above the peritoneal reflection was resected, and this specimen was snap frozen in liquid nitrogen and stored at $-80^{\circ} \mathrm{C}$ until analysis. A standardized end-to-end anastomosis was then constructed with four interruptured, single-layer, 6.0 polypropylene sutures. The laparotomy wound was closed in two separate layers. First, the fascia and abdominal muscles were closed using running sutures with absorbable vicryl 4.0. The skin was closed with an intracutaneous suture using monocryl 3.0.

The rats were assigned to one of the three experimental groups ( $n=18$ per group) by random drawing a sealed opaque envelope after construction of the anastomosis. The first group only underwent resection of the colon and construction of an anastomosis. The second group underwent the same surgical procedure and received an enema containing $5 \mathrm{ml}$ of $60 \mathrm{mM}$ butyrate in $0.9 \% \mathrm{NaCl}$ solution postoperative, daily. The third group received an enema containing only the $0.9 \% \mathrm{NaCl}$ vehiculum postoperative, daily. The rats were sacrificed either three or seven days after the operation ( $n=9$ per time point).

The enemas were administered with the rat in a head-down position, without anesthesia. A canule was inserted in the rectum and the enema was given by infusion. Afterwards, rats were held in the head down position for 30 seconds to ensure equal distribution of the liquid.

\section{Bursting pressure measurements}

Bursting pressure of the anastomotic region was measured in situ before the rats were sacrificed. The rats were anesthetized with isoflurane (induction 4-5\%, maintenance $2.5 \%$ ). The midline incision was reopened and the anastomosis was identified. The anastomotic region was manipulated minimally and if there were any adhesions, they were left in situ. The colon was transected approximately $3 \mathrm{~cm}$ above the anastomosis, and the tube of a manometer (OJB Industries, Lucan, Canada) was inserted and stabilized with a vicryl suture. The distal part of the colon was clamped distal to the anastomosis, above the anal verge. Subsequently, the abdomen was filled with warm $0.9 \% \mathrm{NaCl}$ in such a way that the anastomotic region was submerged. Using the manometer, pressure was manually increased by inflating the colon with air at a constant rate. Consequently, bursting pressure was achieved when air escaped from the anastomosis. The bursting pressure measurement was done by one person, who was unaware of the treatment given.

After bursting pressure was established, arterial blood was obtained by aortic puncture and collected in EDTA vacuum tubes (BD Vacutainer, Becton Dickinson Diagnostics, Aalst, Belgium). Subsequently, rats were sacrificed by opening the diaphragm. The anastomotic region was resected and one half was immersed in $4.0 \%$ formaldehyde fixative (Unifix, Klinipath, Duiven, The Netherlands) and incubated at room temperature overnight, after which the specimens were embedded in paraffin. 
The other half of the resected specimen was snap frozen in liquid nitrogen and stored at $-80^{\circ} \mathrm{C}$ (Figure 8.1 ). EDTA plasma was stored at $-80^{\circ} \mathrm{C}$ until analysis.

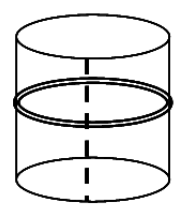

a

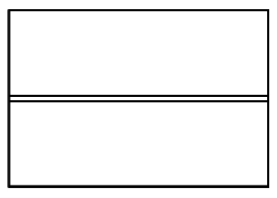

b

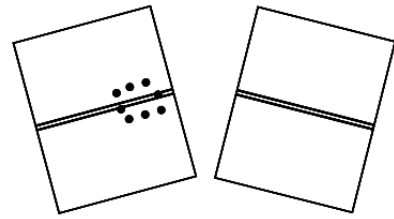

C

Figure 8.1 Model of the resected specimen. The double black line represents the anastomosis. First, the anastomotic specimen was opened longitudinally across the dotted line (a), which turned the tubular fragment into a rectangle (b). A portion of the anastomosis was then isolated (c, dotted box) and snap frozen for MMP analysis.

\section{Histological assessment}

Paraffin-embedded sections were prepared. Sections were stained with hematoxylin and eosin (H\&E) using standard histological techniques. To assess the influx of neutrophils, myeloperoxidase immunostaining was performed as described previously. ${ }^{20}$ In short, paraffin sections were deparaffinized in xylene and rehydrated in graded ethanol to distilled water. Endogenous peroxidase activity was blocked using $0.3 \%$ hydrogen peroxide in methanol for $12 \mathrm{~min}$. After blocking non-specific antibody binding using 5\% BSA, the sections were incubated with primary antibody (polyclonal antibody A0398, DakoCytomation, Glostrup, Denmark) for $1 \mathrm{~h}$. After washing, specific antibody binding was detected using a biotinylated swine anti-rabbit secondary antibody (E0432, DakoCytomation). Signal enhancement was achieved by peroxidase-conjugated avidin biotin complexes. Staining was visualized by 3-amino-9ethylcarbazole (AEC) followed by hematoxylin (Sigma, St. Louis, MO) nuclear counterstaining.

\section{Collagen ratio}

Anastomotic tissue sections of 4- $\mu$ m thickness were deparaffinized and rehydrated, after which they were pretreated with $0.2 \%$ phosphomolybdic acid (PMA) for 5 min. Thereafter, the sections were stained for $90 \mathrm{~min}$ in Picro Sirius solution $(0.1 \%$ solution of Picro Sirius red in saturated aqueous picric acid). The sections were washed for 2 min in $0.01 \mathrm{~N} \mathrm{HCl}$, dehydrated and mounted in entallan. Pictures of the anastomotic and peri-anastomotic region were taken (200x magnification) using cross polarization light microscopy. The relative collagen areas in the anastomotic and perianastomotic region were quantified as a percentage of total tissue surface using the Qwin morphometry system (Leica QWin V3.5.1, Leica Microsystems, Switzerland). In this type of staining, mature collagen fibers appear red under cross polarization 
microscopy, whereas immature, thin collagen fibers appear pale green. After quantification of the amount of red and green shades, the red versus green ratio was calculated.

\section{MMP-2 and pro-MMP-2 analysis}

Protein was isolated from the anastomotic region that was snap frozen in liquid nitrogen. Matrix metalloproteinase (MMP)-2 activity was visualized using zymography, as described previously. ${ }^{21}$ Gelatin (final concentration $6.6 \mathrm{mg} / \mathrm{ml}$ ) was added to a $10 \%$ standard Laemmli acrylamide gel. Each lane was loaded with $5 \mu \mathrm{g}$ of protein to analyze MMP-2 content. Following electrophoresis, gels were rinsed two times for 15 min each in $2.5 \%$ Triton $\mathrm{X}-100$ and incubated overnight at $37^{\circ} \mathrm{C}$ in substrate buffer (50 mmol// Tris HCl, pH 8.5, $5 \mathrm{mmol} / \mathrm{l} \mathrm{CaCl} 2$ and $0.02 \% \mathrm{NaN3}$ ). After incubation, gels were stained using $0.1 \%$ Coomassie Blue in acetic acid, methanol and water and destained in the same solution without Coomassie Blue. The zones of proteolytic activity were visualized as clear bands against a dark background. Two bands can be identified: one is the active form (MMP) and the other is the inactive form of MMP (pro-MMP), which are separated on the gel based on molecular weight. The gels were digitized and analyzed with image analysis software (Quantity One, version 4.5.0, BioRad Laboratories Inc., California, USA). The integrated optical density of the individual bands was determined and normalized against the value of a standard sample that was run on each gel.

\section{Plasma analysis}

Liver fatty acid binding protein (L-FABP; a marker of hepatocyte or colonic damage) levels were measured in plasma by means of a commercially available enzyme-linked immunosorbent assay (ELISA) which was used according the manufacturer's guidelines (Hycult Biotech, Uden, The Netherlands).

Butyrate was measured using the method recently described. ${ }^{22}$ In short, plasma samples were deproteinized by adding $100 \mu \mathrm{l}$ of methanol to $50 \mu \mathrm{l}$ plasma aliquots. After the aliquots were centrifuged, the clear supernatant was transferred to a WISPstyle vial (Waters, Etten-Leur, the Netherlands) and closed with a PTFE self-sealing seal. Subsequently, the supernatant was injected in a liquid chromatography system combined with mass spectrometry (Thermo Electron, Breda, the Netherlands). Butyrate concentrations were determined using the external standard method with calibration curves of butyrate. This test yielded a coefficient of variance of $5.1 \%$ in human venous plasma. The lower limit of detection was $0.05 \mu \mathrm{mol} / \mathrm{l}$.

\section{Statistical analysis}

All data are expressed as mean \pm SEM. ANOVA for repeated measures with post-hoc Bonferroni correction were used for group comparisons. A $P$-value $<0.05$ was 
considered statistically significant. For statistical analysis, SPSS version 15.0 for Windows (2006, SPSS Inc. Chicago, USA) was used.

\section{Results}

\section{Animals and experimental groups}

The rats weighed $327 \pm 4$ grams at the start of the experiment. During postoperative day one to three the rats lost on average $6.8 \pm 0.7 \%$ of initial body weight, which did not differ significantly between the groups $(P=0.125)$. After day three, weight increased and returned to pre-operative levels at day seven. Three (16.6\%) rats died in the control group, one (5.6\%) rat died in the butyrate enema group and two (11.2\%) rats died in the placebo enema group, all as a consequence of anastomotic leakage. Post-mortem examination of these rats showed dehiscence of the anastomosis and severe peritonitis as a result of fecal contamination of the abdomen.

\section{Bursting pressure}

Bursting pressures after three days (Figure 8.2a) were not significantly different between the groups: $64 \pm 15,68 \pm 16$ and $53 \pm 12 \mathrm{mmHg}$ for the butyrate enema, placebo enema and control group, respectively $(P=0.770)$. After seven days (Figure $8.2 \mathrm{~b}$ ), bursting pressures in the butyrate enema group $(225 \pm 17 \mathrm{mmHg})$ were significantly higher than in the placebo enema group $(129 \pm 25 \mathrm{mmHg}, P=0.006)$ and control group $(118 \pm 31 \mathrm{mmHg}, P=0.011)$. The bursting pressures in the placebo enema and control group did not differ significantly $(P=0.604)$.

Almost no adhesions were found in the anastomotic region; some scrotal fat was attached to the anastomotic site in a minority of the rats.

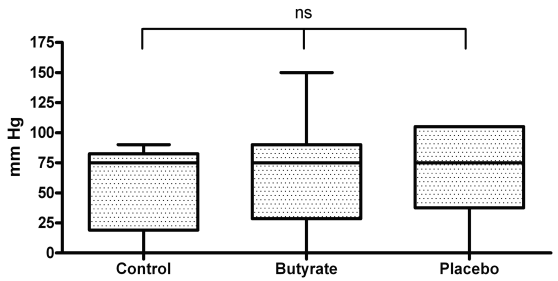

a

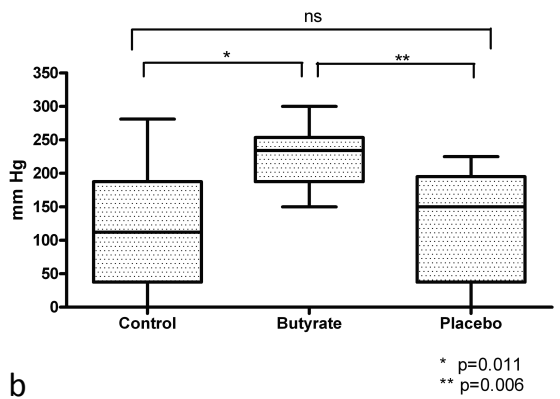

Figure 8.2 Bursting pressure assessed after three days and seven days. After three days, no significant differences between the treatment groups (8.2a) were found. After seven days, a significantly higher bursting pressure was found in the butyrate enema group (8.2b). 


\section{Collagen ratio}

The butyrate enema group had a significantly increased mature versus immature collagen ratio in the anastomotic region, but not in the peri-anastomotic region, compared with the control and placebo enema groups $(P=0.035$, Table 8.1). Furthermore, the collagen percentage did not significantly differ between the groups.

Table 8.1 Total collagen and mature/immature collagen ratio.

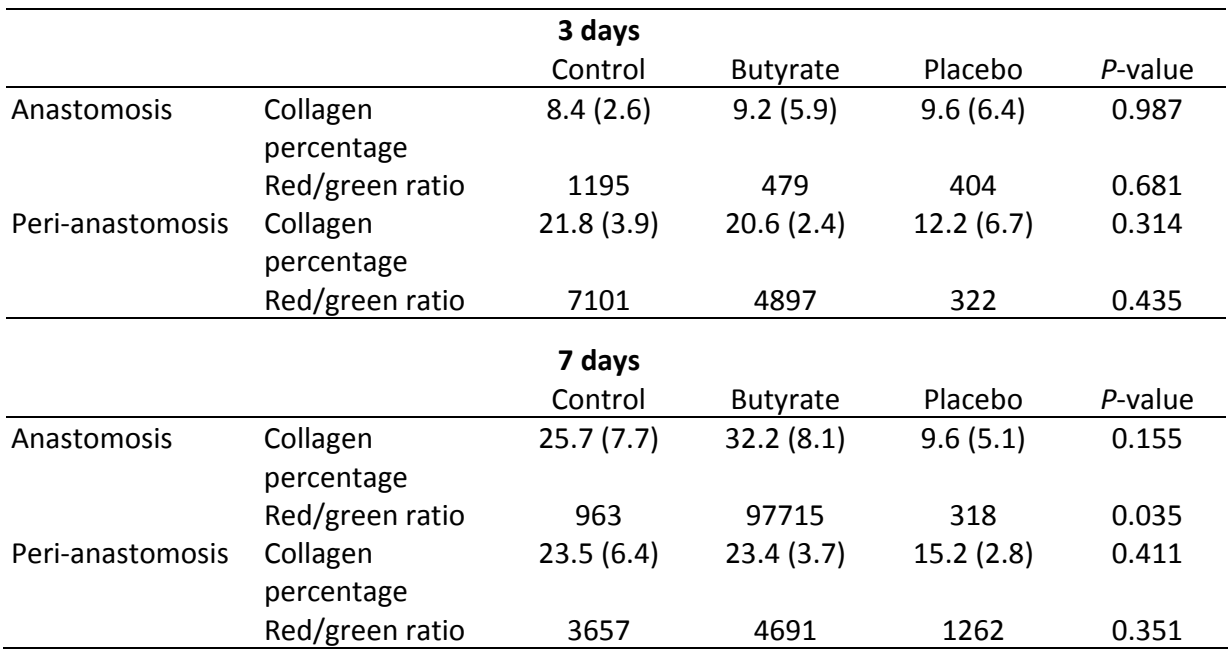

\section{Histology}

$H \& E$ sections of the anastomotic regions showed an ulcer at the site of the anastomosis, with influx of granulocytes, a fibrin clot covering the defect and degradation of the muscularis propria. The sections from the rats sacrificed at day seven showed a more organized wounded area with fibroblasts, tissue macrophages and collagen deposition. Furthermore, re-epithelialization was minimal. However, qualitative differences between the groups were not observed between time points or between the different treatment strategies.

\section{MMP analysis}

The concentrations of active and inactive MMP-2 in the anastomotic region were significantly higher in the butyrate enema group compared with the placebo enema group ( $P=0.022$, Figure 8.3A and $\mathrm{B}$ ). Active MMP-2 was higher in the butyrate enema group after seven days, compared with the control group $(P=0.008$, Figure 8.3B), whereas there were no differences between pro-MMP-2 levels in the butyrate enema and control group. Furthermore, differences in pro-MMP-2 and MMP-2 levels after 
three and seven days were analyzed. Pro-MMP-2 activity was only significantly different for the placebo group, i.e., increased pro-MMP-2 activity after seven days compared to three days $(P=0.048)$. The other treatment groups did not differ significantly in pro-MMP-2 levels $(P>0.101)$. There was a significant increase in MMP-2 activity after seven days in the butyrate enema group $(P=0.0023)$ and in the placebo enema group $(P=0.0025)$, but not in the control group $(P=0.294)$.

A

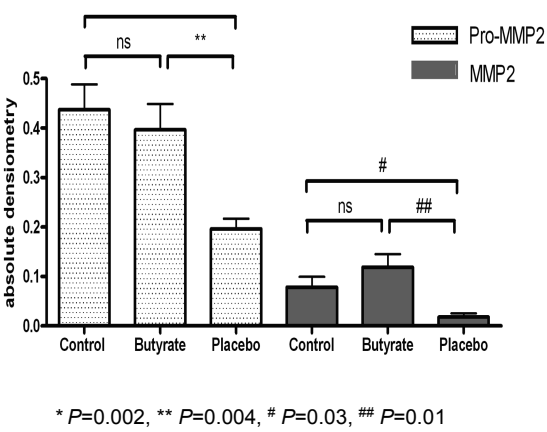

B

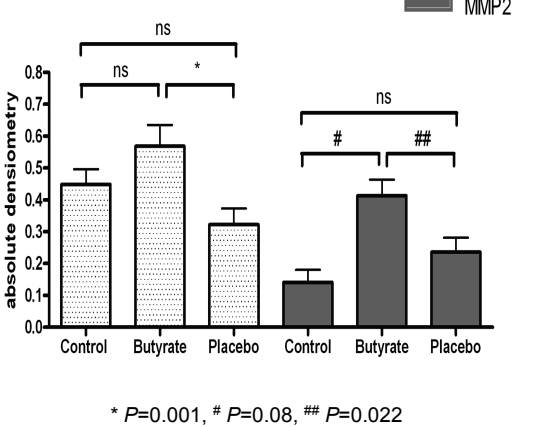

Figure 8.3 MMP-2 and pro-MMP2 activity measured after three days (A) and seven days (B). * $P=0.002,{ }^{* *} P=0.004, \# P=0.03$, \#\# $P=0.01$.

\section{L-FABP and SCFA}

Plasma levels of L-FABP were significantly higher in the butyrate enema group at seven days compared with the control $(P<0.05)$ and placebo enema group $(P<0.01$, Figure 8.4). L-FABP levels were not significantly different between the control, placebo and butyrate enema groups after three days $(P>0.533)$.

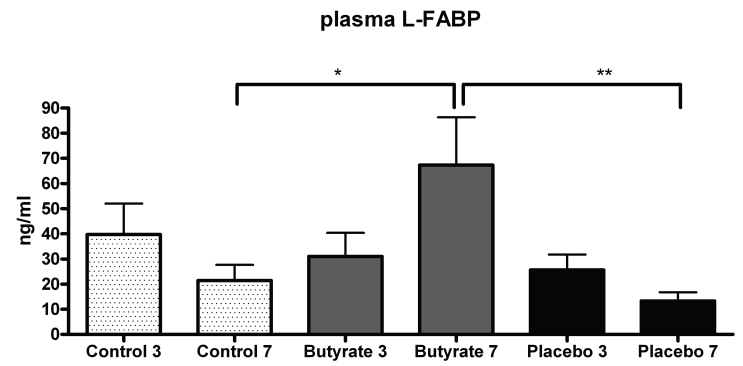

Figure 8.4 L-FABP concentrations measured in plasma. $* P<0.05 ; * * P<0.01$. 


\section{Butyrate concentrations}

The arterial butyrate concentration in the butyrate enema group was significantly higher compared with the control and placebo enema groups after three days, $4.3 \pm 1.4$ vs. $1.2 \pm 0.4$ and $0.7 \pm 0.2 \mu \mathrm{mol} / \mathrm{l}$, respectively $(P=0.043)$. After seven days, there was no statistically significant difference between the groups: the arterial concentrations were $8.7 \pm 2.8,5.8 \pm 3.0$ and $5.8 \pm 3.1 \mu \mathrm{mol} / \mathrm{l}$ in the control, butyrate and placebo enema group, respectively $(P=0.693)$.

\section{Discussion}

The present study clearly demonstrated a beneficial effect of postoperative intestinal butyrate administration on colonic anastomotic strength in a rat model. A significant increase in bursting pressure seven days postoperatively and an increased mature/immature collagen ratio were observed in the butyrate enema group.

Butyrate is a product of colonic fermentation of indigestible carbohydrates and is known to be one of the most important energy sources for epithelial cells. ${ }^{23}$ Furthermore, it has been hypothesized that SCFAs enhance re-epithelialization after injury of the epithelial lining. ${ }^{17,24}$ The anastomotic region in the present study did not show any re-epithelialization after three days or after seven days. After three days, a fibrin clot had formed in the gap between the distal and proximal part of the colon. At seven days, there was fibrosis of the anastomosis, but no evident re-epithelialization of the ulcers in the anastomotic area. This finding may be explained by the fact that four sutures were used to construct the anastomosis. The space between the sutures is relatively large and the proximal and distal ends are therefore not meticulously connected circumferentially. However, circumferentially connection of the proximal and distal colon is a prerequisite for primary wound healing, of which re-epithelialization is the first step. ${ }^{25}$

After three to four days, granulocytes constitute the predominant cell type present in the anastomotic region, marking the beginning of the proliferative phase. They release cytokines and growth factors to stimulate collagen synthesis, which is predominantly synthesized by smooth muscle cells and fibroblasts under the influence of TGF- $\beta$ and IL-1. ${ }^{26}$ During the remodeling phase, the collagen matures and forms crosslinks to increase anastomotic strength. Picris Sirius red staining enables quantification of collagen content. In addition, it is possible with cross polarization light microscopy to qualify the composition of the collagen fibers: thick or mature collagen and thin or immature collagen. The finding that rats treated with butyrate showed an increased mature to immature collagen ratio supports the finding of an increased bursting pressure of the anastomoses and, thus, a stronger anastomosis.

During the first days after injury, the extracellular matrix (ECM) will be degraded to remove damaged tissue and to permit vessel ingrowth and cell migration. ${ }^{27}$ Matrix metalloproteinases (MMPs) are responsible for this degradation, especially 
collagenase (MMP-1), gelatinases (MMP-2 and -9) and stromelysin (MMP-3). ECM degradation is an essential process in wound healing, but it may be hypothesized that high concentrations of MMP may have deleterious effects on the strength of the bowel wall in the anastomotic region. Kuwamara et al. demonstrated that SCFAs had a suppressive effect on MMP release. In the present study, constant levels of pro-MMP-2 were seen after day three and day seven, and increased MMP-2 levels were observed in all treatment groups after seven days compared to three days. Remarkably, butyrate administration resulted in significantly higher MMP-2 activity than the other groups. Furthermore, placebo enemas led to lower MMP-2 activity, but not to increased bursting strength. The unexpected finding of higher MMP-2 levels needs further investigation.

Increased collagen content was found in the butyrate enema group. This increase can be a consequence of an increased synthesis of collagen, but also from diminished breakdown of the ECM. Since the MMP activity is higher in the butyrate enema group compared with the control and placebo enema groups, it can be hypothesized that butyrate increases collagen synthesis and maturation.

This is the first study showing a beneficial effect of postoperative butyrate enemas compared with control animals and placebo enema treated animals. Other studies have investigated the effect of an anastomosis in combination with radiotherapy or with perioperative ischemia of the colon. These studies showed an increased bursting pressure after treatment with short chain fatty acids in the groups pretreated with radiotherapy or ischemia. Remarkably, there was no difference between the control groups, in which there was only an anastomosis constructed, and the groups that received short chain fatty acids after construction of the anastomosis. ${ }^{17,28}$ The beneficial effect in the present model can be explained by the experimental set up. Rats are relatively resistant to infection and, as a consequence, anastomoses heal relatively well in a rat model. ${ }^{29}$ Therefore, a rat model with four sutures was developed to mimic a situation that is comparable with the human clinical setting; approximately $15 \%$ of the low anastomosis tend to have anastomotic leakage in clinical practice. Van der Ham et al. also described a rat model with four sutures, but they did not report an increase in spontaneous dehiscence compared to a model with 12 sutures. ${ }^{30}$ However, the present data showed an anastomotic dehiscence rate in the control group comparable to the human situation. Furthermore, butyrate enemas seemed to prevent anastomotic leakage, but this result did not reach significance, because the group size was determined on bursting pressure as the primary outcome measure.

L-FABP is a small cytosolic protein that is expressed predominantly in the liver and colon. ${ }^{31}$ After injury, these proteins leak from the damaged cells into the circulation and elevated plasma levels can be observed. Although there was an increase in bursting strength, a higher L-FABP level was found in the butyrate enema group at seven days. This observation may be explained by the fact that butyrate stimulates colonic cell proliferation and there might therefore be higher cell turnover, which would lead to elevated plasma L-FABP levels. Another source of L-FABP is the liver, 
and it can be hypothesized that butyrate supplementation induces liver damage. However, this possibility is unlikely because the liver has an extensive capacity to clear butyrate from the circulation in rats as well as in humans. ${ }^{32-34}$ In case the liver is not able to clear the released butyrate from the gut, elevated arterial butyrate concentrations could be expected, but these concentrations did not differ significantly between the treatment groups after seven days.

\section{Conclusion}

The present data show improved anastomotic healing with postoperative luminal intestinal butyrate administration, which increased bursting strength after seven days. This result can be explained by increased cell proliferation, collagen synthesis and maturation. Further research is needed to unravel the exact mechanism of action of butyrate enemas on intestinal healing. 


\section{References}

1. Peeters KC, Tollenaar RA, Marijnen CA, Klein Kranenbarg E, Steup WH, Wiggers T, Rutten HJ, van de Velde CJ; Dutch Colorectal Cancer Group. Risk factors for anastomotic failure after total mesorectal excision of rectal cancer. Br J Surg 2005;92:211-6.

2. Bruce J, Krukowski ZH, Al-Khairy G, Russell EM, Park KG. Systematic review of the definition and measurement of anastomotic leak after gastrointestinal surgery. Br J Surg 2001;88:1157-68.

3. Marijnen CA, Kapiteijn E, van de Velde CJ, Martijn H, Steup WH, Wiggers T, Kranenbarg EK, Leer JW; Cooperative Investigators of the Dutch Colorectal Cancer Group. Acute side effects and complications after short-term preoperative radiotherapy combined with total mesorectal excision in primary rectal cancer: report of a multicenter randomized trial. J Clin Oncol 2002;20:817-25.

4. Ptok H, Marusch F, Meyer F, Schubert D, Gastinger I, Lippert H; Study Group Colon/Rectum Carcinoma (Primary Tumour). Impact of anastomotic leakage on oncological outcome after rectal cancer resection. Br J Surg 2007;94:1548-54.

5. Makela JT, Kiviniemi H, Laitinen S. Risk factors for anastomotic leakage after left-sided colorectal resection with rectal anastomosis. Dis Colon Rectum 2003;46:653-60.

6. Matthiessen $P$, Hallböök O, Andersson M, Rutegård J, Sjödahl R. Risk factors for anastomotic leakage after anterior resection of the rectum. Colorectal Dis 2004;6:462-9.

7. Alves A, Panis Y, Trancart D, Regimbeau JM, Pocard M, Valleur P. Factors associated with clinically significant anastomotic leakage after large bowel resection: multivariate analysis of 707 patients. World J Surg 2002;26:499-502.

8. Karliczek A, Zeebregts CJ, Benaron DA, Coppes RP, Wiggers T, van Dam GM. Preoperative irradiation with $5 \times 5 \mathrm{~Gy}$ in a murine isolated colon loop model does not cause anastomotic weakening after colon resection. Int J Colorectal Dis 2008;23:1115-24.

9. Kanellos, I., et al., Healing of colon anastomoses covered with fibrin glue after immediate postoperative intraperitoneal administration of 5-fluorouracil. Dis Colon Rectum 2004;47:510-5.

10. Attard JA, Raval MJ, Martin GR, Kolb J, Afrouzian M, Buie WD, Sigalet DL. The effects of systemic hypoxia on colon anastomotic healing: an animal model. Dis Colon Rectum 2005;48:1460-70.

11. Matthiessen P, Hallböök O, Rutegård J, Simert G, Sjödahl R. Defunctioning stoma reduces symptomatic anastomotic leakage after low anterior resection of the rectum for cancer: a randomized multicenter trial. Ann Surg 2007;246:207-14.

12. Mantzoros I, Kanellos I, Demetriades H, Christoforidis E, Kanellos D, Pramateftakis MG, Zaraboukas T, Betsis D. Effects of steroid on the healing of colonic anastomoses in the rat. Tech Coloproctol 2004;8 Suppl 1:s180-3.

13. Folkesson J, Nilsson J, Påhlman L, Glimelius B, Gunnarsson U. The circular stapling device as a risk factor for anastomotic leakage. Colorectal Dis 2004;6:275-9.

14. Inglin RA, Baumann G, Wagner OJ, Candinas D, Egger B. Insulin-like growth factor I improves aspects of mycophenolate mofetil-impaired anastomotic healing in an experimental model. $\mathrm{Br} J \mathrm{Surg}$ 2008;95:793-8.

15. Cummings JH, Macfarlane GT, Englyst HN. Prebiotic digestion and fermentation. Am J Clin Nutr 2001; 73(2 Suppl):415S-420S.

16. Macfarlane S, Macfarlane GT, Cummings JH. Review article: prebiotics in the gastrointestinal tract. Aliment Pharmacol Ther 2006;24:701-14.

17. Terzi C, Sevinç Al, Koçdor H, Oktay G, Alanyali H, Küpelioğlu A, Ergör G, Füzün M. Improvement of colonic healing by preoperative rectal irrigation with short-chain fatty acids in rats given radiotherapy. Dis Colon Rectum 2004;47:2184-94.

18. Bach Knudsen KE, Serena A, Canibe N, Juntunen KS. New insight into butyrate metabolism. Proc Nutr Soc 2003;62:81-6.

19. Kawamura T, Andoh A, Nishida A, Shioya M, Yagi Y, Nishimura T, Hashimoto T, Tsujikawa T, Yasui H, Fujiyama Y. Inhibitory Effects of Short-Chain Fatty Acids on Matrix Metalloproteinase Secretion from Human Colonic Subepithelial Myofibroblasts. Dig Dis Sci. 2009;54:238-45. 
20. Matthijsen RA, Derikx JP, Kuipers D, van Dam RM, Dejong CH, Buurman WA. Enterocyte shedding and epithelial lining repair following ischemia of the human small intestine attenuate inflammation. PLoS One 2009;4:e7045.

21. Creemers E, Cleutjens J, Smits J, Heymans S, Moons L, Collen D, Daemen M, Carmeliet P. Disruption of the plasminogen gene in mice abolishes wound healing after myocardial infarction. Am J Pathol 2000;156:1865-73.

22. van Eijk HM, Bloemen JG, Dejong $\mathrm{CH}$. Application of liquid chromatography-mass spectrometry to measure short chain fatty acids in blood. J Chromatogr B Analyt Technol Biomed Life Sci 2009;877:719-24.

23. Roediger WE. Role of anaerobic bacteria in the metabolic welfare of the colonic mucosa in man. Gut, 1980;21:793-8.

24. Wachtershauser A, Stein J. Rationale for the luminal provision of butyrate in intestinal diseases. Eur J Nutr 2000;39:164-71.

25. Mammen JM, Matthews JB. Mucosal repair in the gastrointestinal tract. Crit Care Med 2003;31(8 Suppl):S532-7.

26. Campos AC, Groth AK, Branco AB. Assessment and nutritional aspects of wound healing. Curr Opin Clin Nutr Metab Care 2008;11:281-8.

27. Singer AJ, Clark RA. Cutaneous wound healing. N Engl J Med 1999;341:738-46.

28. Topçu O, Karaday K, Kuzu MA, Ulukent S, Erkek B, Alaçayir I. Enteral and intraluminal short-chain fatty acids improves ischemic left colonic anastomotic healing in the rat. Int J Colorectal Dis 2002;17:171-6.

29. Komen N, van der Wal HC, Ditzel M, Kleinrensink GJ, Jeekel H, Lange JF. Colorectal anastomotic leakage: a new experimental model. J Surg Res 2009;155:7-12.

30. van der Ham AC, Kort WJ, Weijma IM, Jeekel H. Transient protection of incomplete colonic anastomoses with fibrin sealant: an experimental study in the rat. J Surg Res 1993;55:256-60.

31. Monbaliu D, de Vries B, Crabbé T, van Heurn E, Verwaest C, Roskams T, Fevery J, Pirenne J, Buurman WA. Liver fatty acid-binding protein: an early and sensitive plasma marker of hepatocellular damage and a reliable predictor of graft viability after liver transplantation from non-heart-beating donors. Transplant Proc 2005;37:413-6.

32. Bloemen JG, Venema K, van de Poll MC, Olde Damink SW, Buurman WA, Dejong CH. Short chain fatty acids exchange across the gut and liver in humans measured at surgery. Clin Nutr 2009;28:657-61.

33. Remesy C, Demigne C, Chartier F. Origin and utilization of volatile fatty acids in the rat. Reprod Nutr Dev 1980;20:1339-49.

34. Demigne C, Yacoub C, Remesy C. Effects of absorption of large amounts of volatile fatty acids on rat liver metabolism. J Nutr 1986;116:77-86. 


\section{Chapter 9}

Discussion \& perspectives for the future 
The results of the studies described in this thesis answer questions about measuring SCFA in plasma accurately (chapter 2), short chain fatty acids interorgan exchange in humans (chapter $3,4,5,6$ ), quality of life after rectal cancer surgery (chapter 7 ) and the possible application of SCFA in colorectal surgery (chapter 8). However, as with all scientific studies new questions arise during the study period. In this chapter, the most important observations and the implications of the observations are discussed. Furthermore, possible directions for further research are explored.

In chapter 2 a method is described to measure concentrations of short chain fatty acids in human plasma using liquid chromatography-mass spectrometry. ${ }^{1,2}$ Other methods that have been published use gas chromatography, which is a laborious method while the required complex sample preparations can influence the recovery of short chain fatty acids, because they are volatile. ${ }^{3-5}$ Furthermore, proteins in human plasma constitute a problem in liquid chromatography, because they contaminate the chromatographic column and as a consequence the analytical time increases and the reproducibility of the assay decreases. Another challenge is the relatively low concentration of SCFA in human plasma. The improved method developed in this thesis uses a combined approach of liquid chromatography and mass spectrometry. The method is based on reversed phase chromatography followed by post-column neutralization of the mobile phase with ammonia and consecutive measurement of the SCFAs ammonia adducts using negative electro spray ionization. This results in an accurate assay with low coefficients of variance and a low limit of detection. Altogether, the improvement of this assay allows investigation of the physiology of SCFA in the splanchnic area. Moreover, it allows studies on the effect of diet supplementation with prebiotics on plasma SCFA levels.

After the assay to measure SCFA adequately had been developed, we conducted four studies in patients. As sampling blood from intra-abominal vessels in healthy volunteers is impossible, we developed a model to allow for sampling during upper abdominal surgery in humans. ${ }^{6,7}$ This gave us the unique opportunity to sample from different blood vessels in such a way that interorgan SCFA exchange across organs could be calculated. In all studies enclosed in this thesis (chapter 3, 4, and 6), net release of short chain fatty acids from the gut was observed. The liver in patients with normal liver function as well as in patients with chronic hepatic failure took up propionate and butyrate. Acetate was not taken up by the liver and was released in the systemic circulation. ${ }^{8,9}$ Short chain fatty acid interorgan exchange in the hepatosplanchnic area in humans is a poorly studied subject, because it is difficult to access various splanchnic vessels for blood sampling. Valuable, though limited, information was gathered in the past by others from sudden death individuals and patients undergoing gall bladder surgery. ${ }^{10-12}$ Furthermore, acetate metabolism has been studied in humans using stable isotopes. ${ }^{13-15}$ However, since data on plasma flow and hepatic venous concentrations have hitherto been lacking, it has until now not been possible to calculate a quantitative measure of SCFA exchange across the gut, liver or splanchnic area. It is important to expand our knowledge on interorgan SCFA exchange because of two reasons. First, high systemic concentrations of propionate 
and butyrate are toxic and this is important to know when SCFA or precursors are supplemented in diets or as therapeutic agent. ${ }^{16,17}$ Secondly, the use of prebiotics as a food additive increases, because of their postulated beneficial effects on gut health in people with intestinal disease as well as in healthy individuals. ${ }^{18-20}$

Interorgan exchange can be calculated using fluxes. Fluxes are a quantitative measure of substance (i.e. SCFA) exchange across an organ and are calculated by multiplying plasma flow with arteriovenous concentration differences. Plasma flow across splanchnic organs is difficult to assess and was measured during surgery with Duplex Doppler ultrasound. A potential disadvantage of this method is its significant interand intra-observer variability, which introduce considerable variance. ${ }^{21,22}$ Also perioperative sonographic evaluation is time consuming and it is not always possible to assess plasma flow at any time point during surgery without interfering with the operation. Last, flow data are important to quantify substance exchange across organs, but even if the flow data are not that accurate, the qualitative measure is still informative. In this context, it is important to point out that our group recently confirmed, by using the novel MRI based flow measurement, that the mean flows are interchangeable and therefore mean plasma flow values can be used in flux calculations. ${ }^{23}$ In future, pre-operative MRI could be used to estimate plasma flow, because interobserver variability is less and therefore the results are probably more reliable.

A potential disadvantage of flux calculation is that it gives information about the quantitive exchange, but no information about what is happening inside the organ. This "black box" can be further clarified with stable isotope studies in which SCFA are labelled with ${ }^{13} \mathrm{C}$, for example. A recently published study by Verbeke et al. showed nicely that the ${ }^{13} \mathrm{C}$-acetate, ${ }^{13} \mathrm{C}$-propionate and ${ }^{13} \mathrm{C}$-butyrate concentrations in peripheral blood and urine increased after eating a meal with resistant starch and non-starch polysaccharides. ${ }^{24}$ In a next study, analysing arterial and hepatic and portal venous samples after giving patients a ${ }^{13} \mathrm{C}$-enriched meal or a ${ }^{13} \mathrm{C}$-butyrate enema will give more information about the metabolism of SCFA in the liver and splanchnic area and peripheral tissue.

In chapter 6 the results of an intervention study concerning the effects of a butyrate enema on systemic butyrate concentrations are described. The role of the liver, gut and splanchnic area were investigated at different time points during the study. In conclusion, rectal butyrate administration lead to increased portal venous butyrate concentrations and to slight, transiently increased arterial concentrations. Since extra supplementation of butyrate to the gut did not lead to significantly and prolonged increased systemic concentrations, it would be reasonable to conclude that rectal butyrate administration is safe in patients with normal liver function.

Another application of the experimental model in upper abdominal surgery can be the monitoring of gut release and systemic concentrations when aiming for a higher gut release to benefit from SCFA systemically. The beneficial effects of SCFA are not restricted to intestinal effects and systemic effects on glucose and lipid metabolism have been described as well. ${ }^{25-28}$ Propionate and acetate have direct effects on 
adipose tissue. $^{29,30}$ Adipose tissue is known to secrete various signalling peptides, which influence feeding behaviour, insulin sensitivity and inflammation. ${ }^{24}$ Obesity is worldwide a growing health problem and has been linked with substantial changes in the composition and metabolic function of gut microbiota. ${ }^{31}$ Adipose tissue could therefore be a link between SCFA production and metabolic effects. Furthermore, obesity is associated with a pro-inflammatory state, which may lead to non-alcoholic steatohepatitis (NASH). The anti-inflammatory effects of propionate can, partly, be explained by the altered function of macrophages and altered cytokine release. ${ }^{32}$ These preliminary results are promising and may help prevent the detrimental effects of obesity. If oral supplementation with precursors of SCFA is considered, it is important to know if there is also an increase in systemic availability of these short chain fatty acids. The experimental set up in this thesis can probably be used to investigate the effect of oral supplementation of SCFA or their precursors on systemic availability of SCFA.

\section{Clinical application of SCFA in gastro-intestinal surgery}

Colorectal cancer surgery is still associated with high morbidity and mortality rates. Also, anastomotic leakage is a major problem, especially after construction of leftsided colorectal anastomoses. In the past decades, research in rectal cancer has focused mainly on local control, i.e. avoidance of local recurrences. This has been successful since local recurrence rates are reduced to $3-5 \%$ with neoadjuvant radioand chemotherapy. ${ }^{33,34}$ However, these intensified treatment schemes have their disadvantages as well. For example, radiation proctitis and sexual dysfunction after rectal cancer therapy are frequently reported and are disabling for the patient. ${ }^{35-38}$ Therefore, functional outcome as reported by the patient is as important as morbidity and mortality rates and must be seen as a determinant of successful surgery as well.

Pre-operatively, most patients are afraid of the thought to end up with a stoma. However, the study presented in chapter 7 showed that patients with a stoma reported higher scores on global health status and reported less gastro-intestinal complaints. Furthermore, patients with severe postoperative complications report impaired quality of life on the long term (3 years after surgery). With the results of this study and thorough counselling of the patient it would seem justifiable to construct a stoma in patients prone to severe complications, because it is associated with better postoperative functional outcome. ${ }^{39}$

Anastomotic healing after colorectal surgery constitutes a major problem in daily practice. Besides disappointing functional outcome after severe complications, it is associated with high morbidity and mortality. ${ }^{40}$ High incidences of anastomotic leakage are reported, especially after construction of a left sided anastomosis. ${ }^{41,42}$ Many attempts have been made to reduce the risk of anastomotic leakage and many risk factors have been identified in the past. ${ }^{43-46}$ In this thesis an experimental model 
in rats was developed that had comparable rates of anastomotic leakage as have been observed in patients. This model was used in chapter 8.

In chapter 8 the effect of butyrate administration on anastomotic healing was investigated. Butyrate is one of the most important energy sources for epithelial cells of the intestine and is produced by fermentation of non-digestible carbohydrates. ${ }^{47,48}$ It has been hypothesized that butyrate stimulates re-epithelialization and may reduce the rate of collagen lysis, because of a decrease in matrix metalloproteinase (MMP) release. $^{49-51}$ The study showed that postoperative butyrate enemas enhance anastomotic healing after colonic anastomosis construction in a rat model. The improved bursting pressure seems to be a result of enhanced collagen maturation after butyrate enema treatment. The results of this experimental study are promising, but additional research is needed to apply it in clinical practice. An important drawback of the experimental rat model used is the resistance of rats to infection. ${ }^{52}$ The next step in evaluating the effect of SCFA on anastomotic healing could be the development of a porcine model. The intestine of a pig has many similarities with the human intestine and pigs are omnivores. The focus of this research should probably be on the mechanistic effects of butyrate administration on intestinal healing. It is important to determine some parameters/outcome measures that are directly influenced by butyrate therapy.

To test the effects of butyrate administration in a human situation is challenging because of two problems. First, the anastomotic area is hard to investigate directly postoperatively. Endoscopic examination of the region is not standard practice and most surgeons are rather reserved to use endoscopy in the early postoperative days, because anastomotic leakage is such a big problem. Secondly, anastomotic leakage as primary outcome measure demands a large sample size. Because of the large sample size, a different or a combined end point may have to be taken. An experimental animal set up could be a good opportunity to search for such altered outcome measures. 


\section{References}

1. van Eijk HM, Bloemen JG, Dejong $\mathrm{CH}$. Application of liquid chromatography-mass spectrometry to measure short chain fatty acids in blood. J Chromatogr B Analyt Technol Biomed Life Sci 2009;877: 719-724.

2. Meesters RJ, van Eijk HM, Ten Have GA, de Graaf AA, Venema K, et al. Application of liquid chromatography-mass spectrometry to measure the concentrations and study the synthesis of short chain fatty acids following stable isotope infusions. J Chromatogr B Analyt Technol Biomed Life Sci 2007;854: 57-62.

3. Moreau NM, Goupry SM, Antignac JP, Monteau FJ, Le Bizec BJ, et al. Simultaneous measurement of plasma concentrations and 13C-enrichment of short-chain fatty acids, lactic acid and ketone bodies by gas chromatography coupled to mass spectrometry. J Chromatogr B Analyt Technol Biomed Life Sci. 2003;784: 395-403.

4. Morrison DJ, Cooper K, Waldron S, Slater C, Weaver LT, et al. A streamlined approach to the analysis of volatile fatty acids and its application to the measurement of whole-body flux. Rapid Commun Mass Spectrom. 2004;18: 2593-2600.

5. Pouteau E, Meirim I, Metairon S, Fay LB. Acetate, propionate and butyrate in plasma: determination of the concentration and isotopic enrichment by gas chromatography/mass spectrometry with positive chemical ionization. J Mass Spectrom 2001;36: 798-805.

6. van de Poll MC, Soeters PB, Deutz NE, Fearon KC, Dejong $\mathrm{CH}$. Renal metabolism of amino acids: its role in interorgan amino acid exchange. Am J Clin Nutr 2004;79: 185-197.

7. van de Poll MC, Ligthart-Melis GC, Boelens PG, Deutz NE, van Leeuwen PA, et al. Intestinal and hepatic metabolism of glutamine and citrulline in humans. J Physiol 2007;581: 819-827.

8. Bloemen JG, Venema K, van de Poll MC, Olde Damink SW, Buurman WA, et al. Short chain fatty acids exchange across the gut and liver in humans measured at surgery. Clinical nutrition 2009;28: 657-661.

9. Bloemen JG, Olde Damink SW, Venema K, Buurman WA, Jalan R, et al. Short chain fatty acids exchange: Is the cirrhotic, dysfunctional liver still able to clear them? Clin Nutr 2010;29: 365-369.

10. Cummings JH, Pomare EW, Branch WJ, Naylor CP, Macfarlane GT. Short chain fatty acids in human large intestine, portal, hepatic and venous blood. Gut 1987;28: 1221-1227.

11. Dankert J, Zijlstra JB, Wolthers BG. Volatile fatty acids in human peripheral and portal blood: quantitative determination vacuum distillation and gas chromatography. Clin Chim Acta 1981;110: 301-307.

12. Peters SG, Pomare EW, Fisher CA. Portal and peripheral blood short chain fatty acid concentrations after caecal lactulose instillation at surgery. Gut 1992;33: 1249-1252.

13. Pouteau E, Vahedi K, Messing B, Flourie B, Nguyen $P$, et al. Production rate of acetate during colonic fermentation of lactulose: a stable-isotope study in humans. Am J Clin Nutr 1998;68: 1276-1283.

14. Pouteau E, Nguyen P, Ballevre O, Krempf M. Production rates and metabolism of short-chain fatty acids in the colon and whole body using stable isotopes. Proc Nutr Soc 2003;62: 87-93.

15. Kien CL, Kepner J, Grotjohn K, Ault K, McClead RE. Stable isotope model for estimating colonic acetate production in premature infants. Gastroenterology 1992;102: 1458-1466.

16. Feliz B, Witt DR, Harris BT. Propionic acidemia: a neuropathology case report and review of prior cases. Arch Pathol Lab Med 2003;127: e325-328.

17. Manns JG, Boda JM. Insulin release by acetate, propionate, butyrate, and glucose in lambs and adult sheep. Am J Physiol 1967;212: 747-755.

18. Clark MJ, Robien K, Slavin JL. Effect of prebiotics on biomarkers of colorectal cancer in humans: a systematic review. Nutr Rev 2012;70: 436-443.

19. Welters CF, Deutz NE, Dejong CH, Soeters PB, Heineman E. Supplementation of enteral nutrition with butyrate leads to increased portal efflux of amino acids in growing pigs with short bowel syndrome. J Pediatr Surg 1996;31: 526-529.

20. Wong JM, de Souza R, Kendall CW, Emam A, Jenkins DJ. Colonic health: fermentation and short chain fatty acids. J Clin Gastroenterol 2006;40: 235-243. 
21. de Vries PJ, van Hattum J, Hoekstra JB, de Hooge P. Duplex Doppler measurements of portal venous flow in normal subjects. Inter- and intra-observer variability. J Hepatol 1991;13: 358-363.

22. Carlisle KM, Halliwell M, Read AE, Wells PN. Estimation of total hepatic blood flow by duplex ultrasound. Gut 1992;33: 92-97.

23. Vermeulen MA, Ligthart-Melis GC, Buijsman R, Siroen MP, van de Poll MC, et al. Accurate perioperative flow measurement of the portal vein and hepatic and renal artery: $A$ role for preoperative MRI? Eur J Radiol. 2012;81:2042-2048.

24. Verbeke K, Ferchaud-Roucher V, Preston T, Small AC, Henckaerts L, et al. Influence of the type of indigestible carbohydrate on plasma and urine short-chain fatty acid profiles in healthy human volunteers. Eur J Clin Nutr 2010;64: 678-684.

25. Wolever TM, Fernandes J, Rao AV. Serum acetate:propionate ratio is related to serum cholesterol in men but not women. J Nutr 1996;126: 2790-2797.

26. Wolever TM, Josse RG, Leiter LA, Chiasson JL. Time of day and glucose tolerance status affect serum short-chain fatty acid concentrations in humans. Metabolism 1997;46: 805-811.

27. Fushimi T, Suruga K, Oshima Y, Fukiharu M, Tsukamoto $Y$, et al. Dietary acetic acid reduces serum cholesterol and triacylglycerols in rats fed a cholesterol-rich diet. Br J Nutr 2006;95: 916-924.

28. Venter CS, Vorster $\mathrm{HH}$, Cummings $\mathrm{JH}$. Effects of dietary propionate on carbohydrate and lipid metabolism in healthy volunteers. Am J Gastroenterol 1990;85: 549-553.

29. Higgins JA, Brown MA, Storlien LH. Consumption of resistant starch decreases postprandial lipogenesis in white adipose tissue of the rat. Nutr J 2006;5: 25.

30. Higgins JA, Higbee DR, Donahoo WT, Brown IL, Bell ML, et al. Resistant starch consumption promotes lipid oxidation. Nutr Metab (Lond). 2004;1: 8.

31. Vrieze A, van Nood E, Holleman F, Salojarvi J, Kootte RS, et al. Transfer of Intestinal Microbiota From Lean Donors Increases Insulin Sensitivity in Individuals With Metabolic Syndrome. Gastroenterology 2012.

32. Al-Lahham SH, Roelofsen H, Priebe M, Weening D, Dijkstra M, et al. Regulation of adipokine production in human adipose tissue by propionic acid. Eur J Clin Invest. 2010;40: 401-407.

33. van Gijn W, Marijnen CA, Nagtegaal ID, Kranenbarg EM, Putter H, et al. Preoperative radiotherapy combined with total mesorectal excision for resectable rectal cancer: 12-year follow-up of the multicentre, randomised controlled TME trial. Lancet Oncol 2011;12: 575-582.

34. Siegel R, Burock S, Wernecke KD, Kretzschmar A, Dietel M, et al. Preoperative short-course radiotherapy versus combined radiochemotherapy in locally advanced rectal cancer: a multi-centre prospectively randomised study of the Berlin Cancer Society. BMC cancer 2009; 9: 50.

35. Peeters KC, van de Velde CJ, Leer JW, Martijn H, Junggeburt JM, et al. Late side effects of short-course preoperative radiotherapy combined with total mesorectal excision for rectal cancer: increased bowel dysfunction in irradiated patients--a Dutch colorectal cancer group study. J Clin Oncol 2005;23: 61996206.

36. Bruheim K, Guren MG, Dahl AA, Skovlund E, Balteskard L, et al. Sexual function in males after radiotherapy for rectal cancer. Int J Radiat Oncol Biol Phys. 2010;76: 1012-1017.

37. Bruheim K, Guren MG, Skovlund E, Hjermstad MJ, Dahl O, et al. Late side effects and quality of life after radiotherapy for rectal cancer. Int J Radiat Oncol Biol Phys. 2010;76: 1005-1011.

38. Pollack J, Holm T, Cedermark B, Altman D, Holmstrom B, et al. Late adverse effects of short-course preoperative radiotherapy in rectal cancer. Br J Surg 2006;93: 1519-1525.

39. Bloemen JG, Visschers RG, Truin W, Beets GL, Konsten JL. Long-term quality of life in patients with rectal cancer: association with severe postoperative complications and presence of a stoma. Dis Colon Rectum 2009;52: 1251-1258.

40. Krarup PM, Jorgensen LN, Andreasen AH, Harling H. A nationwide study on anastomotic leakage after colonic cancer surgery. Colorectal Dis. 2012;14:e661-e667.

41. Bruce J, Krukowski ZH, Al-Khairy G, Russell EM, Park KG. Systematic review of the definition and measurement of anastomotic leak after gastrointestinal surgery. Br J Surg 2001;88: 1157-1168.

42. Makela JT, Kiviniemi H, Laitinen S. Risk factors for anastomotic leakage after left-sided colorectal resection with rectal anastomosis. Dis Colon Rectum 2003;46: 653-660. 
43. Bertelsen $\mathrm{CA}$, Andreasen $\mathrm{AH}$, Jorgensen $\mathrm{T}$, Harling $\mathrm{H}$ (2010) Anastomotic leakage after anterior resection for rectal cancer: risk factors. Colorectal Dis. 12010;2: 37-43.

44. Hananel N, Gordon PH. Effect of 5-fluorouracil and leucovorin on the integrity of colonic anastomoses in the rat. Dis Colon Rectum 1995;38: 886-890.

45. Shashidharan M, Lin KM, Ternent CA, Smyrk TC, Thorson AG, et al. Influence of arginine dietary supplementation on healing colonic anastomosis in the rat. Dis Colon Rectum 1999;42: 1613-1617.

46. Schreinemacher MH, Bloemen JG, van der Heijden SJ, Gijbels MJ, Dejong CH, et al. Collagen fleeces do not improve colonic anastomotic strength but increase bowel obstructions in an experimental rat model. Int J Colorectal Dis 2011;26: 729-735.

47. Macfarlane S, Macfarlane GT, Cummings JH. Review article: prebiotics in the gastrointestinal tract. Aliment Pharmacol Ther 2006;24: 701-714.

48. Roediger WE. Role of anaerobic bacteria in the metabolic welfare of the colonic mucosa in man. Gut 1980;21: 793-798.

49. Terzi C, Sevinc Al, Kocdor H, Oktay G, Alanyali H, et al. Improvement of colonic healing by preoperative rectal irrigation with short-chain fatty acids in rats given radiotherapy. Dis Colon Rectum 2004;47: 2184-2194.

50. Bach Knudsen KE, Serena A, Canibe N, Juntunen KS. New insight into butyrate metabolism. Proc Nutr Soc 2003;62: 81-86.

51. Kawamura T, Andoh A, Nishida A, Shioya M, Yagi Y, et al. Inhibitory Effects of Short-Chain Fatty Acids on Matrix Metalloproteinase Secretion from Human Colonic Subepithelial Myofibroblasts. Dig Dis Sci. 2009;54:238-45.

52. Pommergaard HC, Rosenberg J, Schumacher-Petersen C, Achiam MP. Choosing the best animal species to mimic clinical colon anastomotic leakage in humans: a qualitative systematic review. EurSurg Res 2011;47: 173-181. 
Samenvatting 


\section{Samenvatting}

Korte keten vetzuren zijn eindproducten van bacteriële fermentatie van onder andere koolhydraten in de dikke darm (colon). Deze voor humane cellen onverteerbare koolhydraten worden ook wel prebiotica genoemd. Drie van de korte keten vetzuren die worden gevormd na fermentatie worden in dit proefschrift nader bestudeerd, te weten acetaat (azijnzuur), propionaat (propionzuur) en butyraat (boterzuur). In de voedingsmiddelenindustrie alsook in de geneeskunde is veel interesse in prebiotica en korte keten vetzuren, omdat beschreven wordt dat zij een gunstige invloed hebben op de darmgezondheid alsmede dat er therapeutische toepassingen van prebiotica en hun eindproducten worden beschreven bij verschillende darmziekten (oa. chronische darmontsteking, prikkelbare darmsyndroom en darmgenezing na chirurgie).

Korte keten vetzuren worden in de dikke darm door bacteriën geproduceerd, waarna ze deels worden gebruikt als brandstof door darmcellen, deels worden opgenomen via de darm in de bloedsomloop en deels worden uitgescheiden met de ontlasting. Hoewel deze korte keten vetzuren een belangrijke voedingsbron zijn voor darmcellen kunnen zij bij hoge concentraties in het bloed ook negatieve, toxische effecten hebben. Er is echter zeer weinig bekend in de wetenschappelijke literatuur over het systemische effect van korte keten vetzuren. Daarnaast is het interessant om te weten wat de opnamecapaciteit van de darm, lever en het splanchnische gebied is. Dit is complex om te onderzoeken, aangezien er uit verschillende bloedvaten in de buik bloedsamples nodig zijn, welke tijdens normale activiteiten niet goed toegankelijk zijn. In hoofdstuk 2 wordt een methode beschreven om korte keten vetzuren te meten in humaan plasma middels een gecombineerd systeem van vloeistof chromatografie en massa-spectometrie. Aangezien korte keten vetzuren zeer vluchtig zijn, zijn samples lastig op te vangen en te bewaren. Daarnaast kunnen plasma-eiwitten zorgen voor contaminatie van de vloeistof chromatografie kolom, waardoor de metingen minder goed reproduceerbaar zijn en de analysetijd verlengd is. Deze problemen kunnen grotendeels voorkomen worden door onteiwitting van het humane plasma met methanol en scheiding van de verschillende componenten middels reversed phase chromatografie gevolgd door massa-spectometrie. Dit leidt tot een lage detectielimiet en een lage variatiecoëfficiënt.

Om in de mens de uitwisseling van korte keten vetzuren tussen verschillende organen te onderzoeken, hebben we een model ontwikkeld bij patiënten die bovenbuikchirurgie ondergaan, waarvan de resultaten worden beschreven in deel $\mathbf{2}$ van dit proefschrift. Dit zijn veelal patiënten met een kwaadaardigheid van de alvleesklier of lever, die daarvoor een operatie ondergingen. Tijdens deze ingrepen is de exposure van verschillende bloedvaten en organen zodanig dat we op verschillende momenten bloed konden afnemen uit de vena portae (bloed van de darm naar de lever), vena hepatica (bloed dat uit de lever komt) en de arterie radialis (polsslagader). Ook werd de bloedflow gemeten in deze vaten. Met deze data worden 
fluxen berekend, een kwantitatieve maat voor opname danwel uitscheiding van bijvoorbeeld korte keten vetzuren door een orgaan.

In hoofdstuk 3 wordt een studie beschreven waarin de rol van de lever, darm en het splanchnisch gebied wordt onderzocht. De fluxen die berekend zijn, laten zien dat de darm korte keten vetzuren opneemt uit het lumen en afgeeft aan het portale systeem. Dit is het systeem dat bloed van de darm naar de lever transporteert. Butyraat en propionaat worden vervolgens door de lever volledig opgenomen, zodat er in het splanchnische gebied geen korte keten vetzuren vrij komen. Voor acetaat geldt echter niet dat ze worden opgenomen door de lever, deze lijken verbruikt te worden door het spanchnische gebied. Daarnaast werd gekeken naar het effect van partiële darmresectie op de productie van korte keten vetzuren. Daar de meeste patiënten werden geopereerd in verband met uitzaaiingen van darmkanker in de lever, hadden zij in het verleden een darmresectie ondergaan. Uit onderzoek blijkt dat in het eerste deel van de dikke darm de meeste korte keten vetzuren worden opgenomen, wat zou kunnen betekenen dat patiënten waarbij het eerste deel van de dikke darm is verwijderd lagere concentraties korte keten vetzuren in het bloed hebben. De studieresultaten laten dit echter niet zien; een darmresectie heeft geen invloed op de hoeveelheid korte keten vetzuren die uit de darm werden opgenomen in de portale circulatie.

Hoofdstuk 4 en 5 gaan dieper in op de rol van de lever in het korte keten vetzuur metabolisme in de mens. In hoofdstuk $\mathbf{4}$ worden patiënten bestudeerd met chronisch leverfalen op basis van cirrose. Door cirrose is de druk in het portale systeem te hoog, waardoor het bloed andere wegen gaat zoeken. Een daarvan is via de vorming van "spataders" (varices) rondom de slokdarm. Een gevaar hiervan is ernstige bloedingen. Een van de mogelijke behandelingen van portale hypertensie is het aanbrengen van een transjugulaire intrahepatische portosystemische shunt (TIPSS). Dat wil zeggen dat er een directe verbinding wordt gemaakt door middel van een metalen stent tussen de vena porta en de vena hepatica, zodat de druk op het portale systeem minder wordt.

Patiënten met een dergelijke stent werden geïncludeerd in een studie om zo de gevolgen van chronisch verminderde leverfunctie op het korte keten vetzuur metabolisme te bestuderen. Er werden 12 patiënten geïncludeerd. Het bleek dat ook in het geval van chronisch leverfalen de darm significante hoeveelheden korte keten vetzuren produceerde. De lever was ook in staat om propionaat en butyraat op te nemen, zodat er vrijwel niets in het splanchnische gebied vrij kwam. Voor acetaat gold hetzelfde als in de patiënten met een normale leverfunctie; afgifte door de darm en opname door het splanchnische gebied. In dit model moet rekening gehouden worden met een bepaald percentage shunting dat optreedt; een significant deel van het bloed wordt rechtstreeks om de lever heen gestuurd. In eerdere studies werd gevonden dat tussen de 70 en $95 \%$ van het bloed wordt geshunt en dus ontsnapt aan de lever. Mathematisch hebben we twee scenario's uitgewerkt, in het ene geval 
wordt $70 \%$ van het bloed geshunt, in het andere geval $90 \%$. Kwalitatief veranderde er niets aan het butyraat, propionaat en acetaat metabolisme door darm, lever en splanchnische gebied.

Vervolgens wordt in hoofdstuk 5 beschreven wat het effect van acuut leverfunctie verlies is op de klaring en het metabolisme van korte keten vetzuren. Als model werden hier patiënten die een partiële leverresectie ondergaan onderzocht. Doordat vooraf de resectie werd gepland kon het resterende levervolume worden gemeten middels CT volumetrie. Er werden prospectief 30 patiënten geïncludeerd. Er werden samples afgenomen voor en na de resectie. Wederom werden er fluxen berekend en bleek opnieuw dat de lever in staat is om alle butyraat en propionaat dat door de darm wordt afgegeven aan het portale systeem te klaren, zowel voor als na de resectie.

De voornoemde 3 studies geven inzicht in de fysiologie van het metabolisme van korte keten vetzuren op orgaanniveau. In hoofdstuk 6 wordt een dubbelblind gerandomiseerde studie beschreven waarin er extra butyraat wordt toegediend in de darm, waarna er fluxen werden berekend over de verschillende organen. Het doel van deze studie was om te bestuderen of er een effect van een dergelijk klysma was op de systemische concentratie van butyraat, propionaat en acetaat. Aangezien we al eerder vermelden dat met name hoge concentraties propionaat en butyraat mogelijk schadelijke effecten kunnen hebben, is het noodzakelijk om te weten of suppletie van dergelijke producten of precursors hiervan systemische effecten hebben. Er werden 15 patiënten geïncludeerd, waarvan 5 patiënten een placeboklysma ontvingen tijdens bovenbuik chirurgie en 10 patiënten een klysma met butyraat. Op verschillende tijdpunten werden er samples afgenomen, waarmee fluxberekeningen gedaan zijn. Vijf minuten na toediening van het klysma werd een piek gezien in de portale concentratie van butyraat, wat overeenkomt met een snelle opname door de darm en transport naar de portale circulatie. De arteriële concentratie van butyraat stijgt na 15 minuten, maar niet zo sterk als de portale concentratie. De lever flux nam na toediening van het butyraat klysma toe, terwijl de flux over het splanchnische gebied nagenoeg gelijk bleef. Dit laat zien dat de lever een grote capaciteit heeft voor het klaren van butyraat, ook na toediening van butyraat in de dikke darm. Dit suggereert wederom dat het toedienen van butyraat als veilig zou kunnen worden beschouwd. De fluxen van acetaat en propionaat veranderden niet, dit zou kunnen betekenen dat er geen co-transport optreedt tussen de korte keten vetzuren.

De studies beschreven in de hoofdstukken 3 tot en met 6 betekenen voor de praktijk dat korte keten vetzuren veilig gegeven kunnen worden, zonder dat daarbij rekening gehouden hoeft te worden met de leverfunctie van de patiënt of persoon.

In deel 3 van dit proefschrift wordt een mogelijke toepassing gevonden voor butyraat binnen de huidige chirurgische praktijk. Een van de belangrijkste complicaties na darmchirurgie is naadlekkage; nadat een stuk darm is weggenomen wordt de darm 
weer aan elkaar gezet, waarbij er na 3-5 dagen lekkage kan optreden van darmsappen naar de buikholte. De gevolgen hiervan zijn vaak ernstig voor de patiënt; langere ziekenhuisopname, re-operatie, periode van ernstig ziek zijn (intensive care opname) en zelfs overlijden. In de literatuur worden veel mogelijke oorzaken voor naadlekkage beschreven, maar opgehelderd is het mechanisme van naadlekkage nog allerminst.

In hoofdstuk 7 wordt een studie beschreven die als doel had de kwaliteit van leven te beschrijven van patiënten die geopereerd zijn aan endeldarmkanker (rectumcarcinoom), waarbij we met name geïnteresseerd waren in de effecten van postoperatieve complicaties (waaronder naadlekkage) en het hebben van een stoma op gerapporteerde kwaliteit van leven op de lange termijn. Er werden patiënten uit een academisch ziekenhuis (MUMC) en een perifere opleidingsziekenhuis (VieCuri MC, Venlo) geïncludeerd die in de periode 2003 tot en met 2005 een darmresectie hadden ondergaan in verband met rectumcarcinoom. Van deze patiënten werden retrospectief alle complicaties gerapporteerd. Verder ontvingen zij allen een vragenlijst met betrekking tot kwaliteit van leven, specifiek ontwikkeld en gevalideerd voor patiënten met kanker (EORTC QLQ C30) en colorectale kanker (EORTC QLQ CR38). De meest opvallende conclusies van deze studie zijn de volgende. Ten eerste rapporteerden patiënten die een ernstige complicatie (waaronder naadlekkage) hadden als gevolg van de initiële operatie, 3 jaar nadien nog steeds een mindere kwaliteit van leven ten opzichte van patiënten die geen ernstige complicatie hadden. Tevens rapporteerden patiënten met een stoma een betere kwaliteit van leven in vergelijking met patiënten die geen stoma hadden. Patiënten zonder stoma hadden met name last van continentieklachten, wat een bekende lange termijn complicatie is van de operatie. Hieruit hebben we geconcludeerd dat er niet per se naar een primaire anastomose (geen stoma) moet worden gestreefd, maar in overleg met patiënt besproken moet worden of een stoma of een primaire naad aangelegd zal worden. Informatie die bij dit gesprek aangedragen kan worden is dat de kwaliteit van leven verminderd is op de lange termijn na ernstige complicaties zoals naadlekkage en patiënten met een stoma niet slechter scoren op kwaliteit van leven en op een aantal punten zelfs beter (algemeen kwaliteit van leven, gastro-intestinale problemen, diarree en constipatie).

In hoofdstuk 8 van dit proefschrift wordt in een dierexperimentele studie gekeken naar het effect van butyraat op darmnaadgenezing. Van butyraat is beschreven dat het re-epithelialisatie bevordert, inflammatoire reacties afremt en mogelijk de afbraak van collageen vermindert. Dit zijn belangrijke aspecten van wondgenezing van de darm. Tijdens deze studie hebben we ratten dagelijks een butyraatklysma gegeven nadat een darmanastomose is aangelegd. Een tweede groep kreeg dagelijks een placeboklysma en een derde groep diende als controle groep en kreeg naast de operatie geen andere interventie. De darmgenezing werd bekeken op 3 en 7 dagen na de operatie. De primaire uitkomstmaat was de bursting strength van de naad; de darmnaad werd opgeblazen waarbij de druk werd gemeten op het moment dat de 
naad barstte. De ratten die een butyraatklysma kregen hadden een significant sterkere naad na 7 dagen. Het mechanisme dat hier verantwoordelijk voor lijkt te zijn is een verandering in het collageenmetabolisme; er is significant meer gematureerd collageen aanwezig rondom de darmnaden in ratten die dagelijks een butyraatklysma kregen.

Dit is een veelbelovende toepassing van butyraat bij een chirurgisch, klinisch zeer relevant, probleem. De stap van dierexperimenteel naar humaan onderzoek is echter groot. De vraag is wat de beste primaire uitkomstmaat is wanneer er een gerandomiseerde trial zou worden opgezet. Naadlekkage komt in ongeveer $10-15 \%$ van de linkszijdige colonanastomoses voor, de definitie is echter niet altijd eenduidig, waardoor de incidentiecijfers wisselen. Er zijn tal van factoren beschreven die invloed kunnen hebben op darmnaadgenezing, zodat het moeilijk is in te schatten hoe groot het effect is van een butyraatklysma en de daarop volgende reductie in naadlekkage. De consequentie daarvan is dat het gevaar bestaat dat de studie underpowered is. Een mogelijkheid voor toekomstig humaan onderzoek zou zijn om een alternatieve uitkomstmaat te kiezen, zoals bijvoorbeeld histopathologische parameters.

Verder is er in hoofdstuk 8 een voorzet gegeven voor het mogelijke mechanisme dat verantwoordelijk is voor de sterkere naad, sluitend is dit echter nog niet. Een logische stap zou zijn om onderzoek te doen naar het pathofysiologische mechanismen in de mens. Een vereiste daarvoor is een endoscopisch onderzoek in de postoperatieve fase, waarbij de naad geïnspecteerd kan worden en er biopten kunnen worden afgenomen om zo op zoek te gaan naar het werkingsmechanisme. Een andere mogelijkheid die verder onderzoek vereist is het toevoegen van extra vezels, prebiotica genaamd, aan de voeding om zo de korte keten vetzuur concentratie in de darm te verhogen en op die manier een betere darmgenezing te bewerkstelligen. 
Acknowledgements \& Dankwoord 


\section{Dankwoord}

Eindelijk is het dan zover, het boekje is af en het dankwoord mag geschreven worden. Mijn hele promotie-tijd heb ik uitgekeken naar dit moment: eindelijk een stukje schrijven dat niet gecorrigeerd hoeft te worden door derden op punten, komma's, zinsconstructies, suboptimaal Engels etc. Begrijp me niet verkeerd, deze correcties heb ik altijd erg gewaardeerd en hebben ervoor gezorgd dat dit proefschrift uiteindelijk tot stand is gekomen. $\mathrm{Nu}$ is het echter my finest moment wat betreft een aantal woorden van dank.

Allereerst mijn promotores: Professor Dejong, beste Proffi, CHC, Kees, Lejeune*. Ik weet nog als de dag van gister dat ik tijdens mijn vaardigheidstoets in jaar 6 een chirurgisch station "perifeer vaatlijden" kreeg waar jij de beoordelaar was. Nadat ik de casus had doorlopen was er nog wat tijd over en vroeg je wat ik eigenlijk wilde gaan doen als ik klaar was met geneeskunde. Ik zei heel stellig: "ik wil promoveren, dus als je nog ideeën hebt, dan hoor ik het graag." Waarop jij antwoordde dat ik maar eens moest komen praten en zie daar, een AIO-plek was het resultaat. Ik heb je tweeënhalf jaar gek gemaakt met mijn drang naar de kliniek, maar toch leek je me altijd te steunen. Bedankt voor de vrijheid die je me gaf om allerlei projecten te doen (van SCFA-stukken tot organisatie Pelerin en van commissie onderzoeksbeleid tot dierexperimenteel onderzoek). En ik zou je tekort doen als ik je niet zou bedanken voor de gezellige momenten ergens in de wereld aan (sporadisch ook wel eens onder) een bar met het leverteam!

Professor Buurman, beste Wim, bedankt voor het reviseren van manuscripten en de altijd aanwezig kritische noot. En natuurlijk voor de inzet voor het afronden van het proefschrift en het bereiken van de eindstreep.

Dr. Venema, beste Koen, bedankt voor de inbreng van ideeën, het nalezen van de manuscripten en de kritische input met betrekking tot de fysiologie van korte keten vetzuren vanuit een niet-medisch perspectief.

Graag wil ik de leden van de leescommissie bedanken voor de beoordeling, maar bovenal de goedkeuring, van mijn proefschrift: prof. dr. P.B. Soeters (voorzitter), prof. dr. A.A.M. Masclee, prof. dr. W. Bemelman, prof. dr. M. Kleerebezem en prof. dr. A. Schols.

Dan wil ik een aantal van mijn onderzoeksmaatjes in het bijzonder bedanken:

Maartje, heel veel patiënten hebben we geïncludeerd in even zoveel studies, ontelbare epjes beschreven en ingevroren. Een echte teamprestatie die we samen geleverd hebben. Lief en leed hebben we gedeeld daar op de $4^{\mathrm{e}}$ bij de cola-automaat, bloed, zweet en tranen, maar nu is het zover, onzer beider boekjes zijn af!

Lieve Eva, vanaf Suriname waren we onafscheidelijk en volgden we hetzelfde pad, tot jij zo nodig naar Amsterdam moest en ook nog uroloog wilde worden. Gelukkig zijn onze wegen niet echt gescheiden. Ik hoop dat we, als we later echt groot zijn, weer wat dichter bij elkaar kunnen wonen, zodat we om 17 uur in de kroeg kunnen gaan zitten als we er geen gat meer in zien... 
Ruben, elke ochtend tussen 8.00 en $8.15 u$ ging de telefoon om te vragen hoe de avond/nacht was geweest en om te inventariseren hoe de vlag er voor de dag die komen ging, bijhing. Ik mis ze nog dagelijks! Naast de dagelijkse gezamenlijke lunches wil ik je bedanken voor alle steun tijdens mindere tijden, je altijd goede humeur en voor het kritisch nalezen van mijn manuscripten (zelfs al stond je er zelf niet op).

Ronald van Dam, Ranoldo, El Dammios,* door jou heb ik ooit kennis gemaakt met databases maken, congressen bezoeken en de eerste stappen van het schrijven van een manuscript . Bedankt voor die kans, die heeft geleid tot dit boekwerk.

Lever-champagne-team, Ronald van Dam/Ronaldo/El dammios*, Marc Bemelmans/Bemel*, Steven Olde Damink/SOD/bandje 36*, Laurents Stassen, Kees/Proffi*, Jan Stoot/Johnny Punch*, Ruben Visschers/Rubi/de bijnaam moet jou nog steeds vinden*, Maartje van den Broek/Bonnie/Maria/Snip*, Joost van der Vorst/Proost van de Dorst/overloper*, Simon Dello/Submarine/PADje*,: jullie gaven promoveren net dat beetje extra en die champagneparties waren werkelijk onvergetelijk.

Mo, Sjaak, Hodini en Froekje, de allerbeste en gezelligste kamergenoten die ik me kon wensen. Het einde kwam toch ineens heel snel in zicht, maar ik heb 2,5 jaar met heel veel plezier samen met jullie de sociëteit bemand. De plaats waar Hodini's assertiviteitscursus (iets te goed) vorm kreeg om van het BescheidenBelgSyndroom te genezen, waar Sjaak bijna levend begraven was onder al zijn papieren, waar Froekje altijd maar 1 tafel had en waar Mo vaak in zijn glazen bol keek om te zien of nieuwe AIO's de eindstreep gingen halen. Mo, je mag het nu eerlijk zeggen, wat was je voorspelling voor mij toen ik voor het eerst binnenkwam?

Alle collega`s van de "labtijd" bedankt voor de gezellige en leerzame tijd; Joep G, Joep D, Bas, Iris, Geertje, Tim L, Nina, Tim W, Annemarie, Kim, Sander, Kaatje, Charlotte, Kirsten, Hans, Sedigheh, Babs, Liliane, Maarten en alle mensen ik onverhoopt nog vergeten ben.

Ik heb nooit zo begrepen waarom in een proefschrift allerlei mensen bedankt worden die ogenschijnlijk niets te maken hebben met het onderzoek. Maar aangezien ik nu de kans heb, neem ik het er toch even van!

Allure, oftewel Elles/LE, Annamarije/Anna, Marloes/poeskie en Carla/Annelies, 12 jaar geleden stonden we samen in de rode broek en een smerig wit t-shirt met een nummer op de borst bij de Saurus-intro. Sindsdien is er van alles veranderd, behalve onze vriendschap: Allure hey, Allure hey, Allure heyheyhey!

Lynn, heerlijk om door jou weer met beide voeten in de klei gezet te worden tijdens onze eigen gemaakte drie gangen diners, wandeltochten, en weekendtrips. Ik hoop je binnenkort weer wat vaker te zien, nu dit tot een eind is gebracht en jullie droompaleis (bijna) af is!

Marielle, onze vriendschap begon aan de Bloemenweg. Onze karakters verschillen nogal, en ook liggen onze specialisaties ver uit elkaar (geriater en chirurg), maar wat ons naast onze fijne vriendschap nog meer verbind is het feit dat we gelijktijdig voor het eerst moeder werden (13 en 14 juli). Twee prachtige dochters die ook nog bijna dezelfde naam hebben (Elise en Veerle Elise). Alsof het afgesproken was... 
Kees, onze vriendschap stamt uit het TBK-tijdperk en is er een die weinig woorden nodig heeft. Ik ben ontzettend blij met jouw Groningse nuchterheid op zijn tijd!

Otto, Otje*, mijn grote broertje, ook al woonde je aan de andere kant van het land, je was er altijd voor me. Samen hebben we onze weg gevonden en zijn we groot geworden, zonder onze ouders en Willem direct aan onze zijde in Nederland. Ook jij hebt inmiddels je hart verloren aan Canada en hebt Nederland vaarwel gezegd. Ik weet echter zeker dat onze sterke band reikt tot over de oceaan.

Willem, Bro*, ik denk dat je je vaak heb afgevraagd wat ik nu eigenlijk aan het doen was en hoop dat je vandaag met eigen ogen kan zien wat ik daadwerkelijk heb uitgevoerd de afgelopen jaren. Ik ben ontzettend trots dat ik 2 zulke kanjers van broers heb!

Mama en papa, twee gevleugelde uitspraken van jullie waar ik groot mee ben geworden en waar ik vaak aan gedacht heb tijdens het tot stand komen van dit boekwerk: "wie A zegt, moet B zeggen" en "als je geen zin hebt, dan maak je maar zin". Mama, bedankt voor het doorzettingsvermogen dat ik van jou heb gekregen (en geleerd)! Dank dat jullie ons altijd het blinde vertrouwen hebben gegeven bij alles wat we deden, daardoor zijn we zo zelfstandig geworden. En wat fantastisch dat jullie allemaal aanwezig zijn tijdens de promotie!

Lieve Sanne, mijn 2 meter lange rots in de branding, met jou is het altijd dikke prima en ik hoop van harte dat dat nog lang zo blijft! Samen met onze prachtige dochter Veerle weet ik zeker dat dat gaat lukken.

"Geluk dat maak jezelf en jij mij gelukkig ook Ik ben nog steeds onderweg naar jou, hoe de weg ook loopt Ik weet alleen dat de weg met jou lekker loopt, echt"

*bekend onder meerdere namen 
List of publications 


\section{List of publications}

van Eijk HM, Bloemen JG, Dejong $\mathrm{CH}$. Application of liquid chromatography-mass spectrometry to measure short chain fatty acids in blood. Journal of chromatography. $B$, Analytical technologies in the biomedical and life sciences. Mar 2009;877(8-9):719724.

Bloemen JG, Venema K, van de Poll MC, Olde Damink SW, Buurman WA, Dejong CH. Short chain fatty acids exchange across the gut and liver in humans measured at surgery. Clinical nutrition. Dec 2009;28(6):657-661.

Bloemen JG, Visschers RG, Truin W, Beets GL, Konsten JL. Long-term quality of life in patients with rectal cancer: association with severe postoperative complications and presence of a stoma. Diseases of the colon and rectum. Jul 2009;52(7):1251-1258.

Bloemen JG, Olde Damink SW, Venema K, Buurman WA, Jalan R, Dejong CH. Short chain fatty acids exchange: Is the cirrhotic, dysfunctional liver still able to clear them? Clinical nutrition. Jun 2010;29(3):365-369.

Bloemen JG, Schreinemacher MH, de Bruine AP, Buurman WA, Bouvy ND, Dejong CH. Butyrate enemas improve intestinal anastomotic strength in a rat model. Diseases of the colon and rectum. Jul 2010;53(7):1069-1075.

Dello SA, Stoot JH, van Stiphout RS, Bloemen JG, Wigmore SJ, Dejong $\mathrm{CH}$, van Dam RM. Prospective volumetric assessment of the liver on a personal computer by nonradiologists prior to partial hepatectomy. World journal of surgery. Feb 2011;35(2):386-392.

Bloemen JG, van den Broek MA, Dello SA, van de Poll MC, Olde Damink SW, Dejong $\mathrm{CH}$. Randomized controlled trial analyzing the effect of 15 or 30 min intermittent Pringle maneuver on hepatocellular damage during liver surgery. Journal of hepatology. Aug 2011;55(2):337-345.

Schreinemacher MH, Vijgen GH, Dagnelie PC, Bloemen JG, Huizinga BF, Bouvy ND. Incisional hernias in temporary stoma wounds: a cohort study. Archives of surgery. Jan 2011;146(1):94-99.

Schreinemacher MH, Bloemen JG, van der Heijden SJ, Gijbels MJ, Dejong CH, Bouvy ND. Collagen fleeces do not improve colonic anastomotic strength but increase bowel obstructions in an experimental rat model. International journal of colorectal disease. Jun 2011;26(6):729-735. 
Dello SA, Bloemen JG, van de Poll MC, van Dam RH, Stoot JH, van den Broek MA, Buurman WA, Bemelmans $\mathrm{MH}$, Olde Damink SW, Dejong $\mathrm{CH}$. Gut and liver handling of interleukin-6 during liver resection in man. HPB: the official journal of the International Hepato Pancreato Biliary Association. May 2011;13(5):324-331.

Gaens KH, Niessen PM, Rensen SS, Buurman WA, Greve JW, Driessen A, Wolfs MG, Hofker $\mathrm{MH}$, Bloemen JG, Dejong $\mathrm{CH}$, Stehouwer CD, Schalkwijk CG. Endogenous formation of Nepsilon-(carboxymethyl)lysine is increased in fatty livers and induces inflammatory markers in an in vitro model of hepatic steatosis. Journal of hepatology. Mar 2012;56(3):647-655.

Bloemen JG, van der Vorst JR, van den Broek MA, Buurman WA, Dejong CH. Effects of hepatic resection on short chain fatty acids handling in humans. Submitted

Bloemen JG, van den Broek MA, Venema K, Buurman WA, Dejong CH. Randomized placebo controlled study of the effects of butyrate enemas on systemic concentrations and splanchnic fluxes of short chain fatty acids. Submitted

Van den Broek MA, Shiri-Sverdlov R, Schreurs J, Bloemen JG, Bieghs V, Buurman WA, Dejong CHC, Olde Damink SWM. Liver manipulation during liver surgery in man is associated with hepatocellular damage and hepatic inflammation. Submitted 